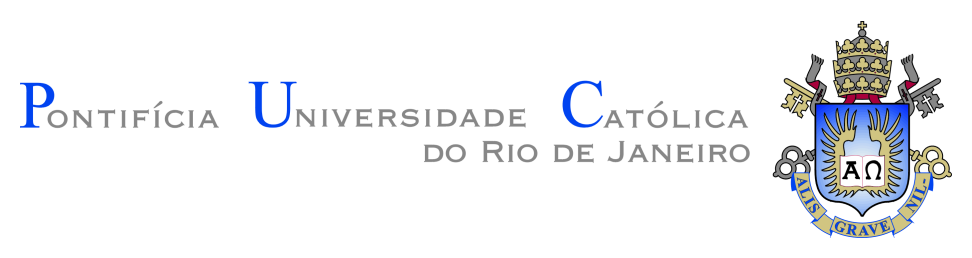

Bernardo Calvente

Política monetária ótima em uma armadilha da liquidez global

Dissertação apresentada como requisito parcial para obtenção do grau de Mestre pelo Programa de Pós-graduação em Economia do Departamento de Economia do Centro de Ciências Sociais da PUC-Rio.

Orientador: Prof. Tiago Couto Berriel 


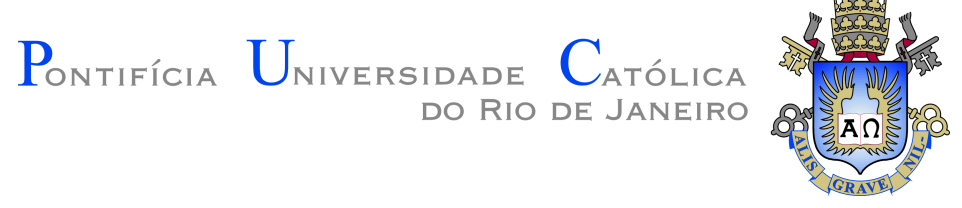

Bernardo Calvente

\section{Política monetária ótima em uma armadilha da liquidez global}

Dissertação apresentada como requisito parcial para obtenção do grau de Mestre pelo Programa de Pós-graduação em Economia do Departamento de Economia do Centro de Ciências Sociais da PUC-Rio. Aprovada pela Comissão Examinadora abaixo assinada.

Prof. Tiago Couto Berriel

Orientador

Departamento de Economia - PUC-Rio

Prof. Eduardo Zilberman

Departamento de economia - PUC-Rio

Prof. Marco Antonio Cesar Bonomo

Departamento de economia - Insper

Prof. Monica Herz

Coordenador Setorial do Centro de Ciências Sociais - PUC-Rio 
Todos os direitos reservados. É proibida a reprodução total ou parcial do trabalho sem autorização da universidade, do autor e do orientador.

\section{Bernardo Calvente}

Graduação em Economia, Insper (2010-2014). São Paulo, Brasil.

Ficha Catalográfica

Calvente, Bernardo

Política monetária ótima em uma armadilha da liquidez global / Bernardo Calvente; orientador: Tiago Couto Berriel. $-2017$.

v., 65 f: il. color. ; $30 \mathrm{~cm}$

Dissertação (mestrado) - Pontifícia Universidade Católica do Rio de Janeiro, Departamento de Economia.

Inclui bibliografia

1. Economia - Teses. 2. Política monetária ótima;. 3. Armadilha da liquidez global;. 4. Economia aberta;. 5. Limite inferior zero da taxa de juros nominal;. I. Berriel, Tiago Couto. II. Pontifícia Universidade Católica do Rio de Janeiro. Departamento de Economia. III. Título. 


\section{Agradecimentos}

Primeiramente eu gostaria de expressar meu agradecimento por todos aqueles que, de uma maneira ou de outra, me ajudaram nesses últimos dois anos.

Também agradeço ao meu orientador, Prof. Tiago Berriel, por todos os ensinamentos e assistência no decorrer do desenvolvimento deste trabalho.

Eu sou grato pela minha família, sem a qual nada disso seria possível, eles são e sempre serão os principais responsáveis por todas as minhas realizações.

Por último, mas não menos importante, eu gostaria de agradecer ao CNPq pela ajuda financeira. 


\section{Resumo}

Calvente, Bernardo; Berriel, Tiago Couto. Política monetária ótima em uma armadilha da liquidez global. Rio de Janeiro, 2017. 65p. Dissertação de Mestrado - Departamento de Economia, Pontifícia Universidade Católica do Rio de Janeiro.

Quais devem ser a características da política monetária ótima sob comprometimento em uma situação de armadilha da liquidez global quando os Bancos Centrais não coordenam suas ações? Fazendo o uso de um modelo de economia aberta com dois países, fizemos um exercício numérico para endereçar essa questão e estudar as diferenças entre este caso e uma situação cooperativa, na qual as autoridades monetárias não estão somente preocupadas com a utilidade da população nacional, mas em vez disso maximizam uma medida de bem-estar global. Nossas descobertas apontam para diferenças nas características de dependência histórica e internacional da prescrição monetária em cada um dos casos observados. Também é feita uma análise de bem-estar do nosso experimento que sugere que um Banco Central local prefere, não só permanecer restrito pelo limite inferior zero da taxa de juros nominal por um período maior, mas também que o país estrangeiro saia dessa situação o quanto antes. Por fim, fazemos uma análise de robustez dos nossos resultados variando o tamanho de cada nação e o grau de substituição dos produtos produzidos em cada localidade.

\section{Palavras-chave}

Política monetária ótima; Armadilha da liquidez global; Economia aberta; Limite inferior zero da taxa de juros nominal; 


\section{Abstract}

Calvente, Bernardo; Berriel, Tiago Couto (Advisor). Optimal monetary policy in a global liquidity trap. Rio de Janeiro, 2017. 65p. Dissertação de Mestrado - Departamento de Economia, Pontifícia Universidade Católica do Rio de Janeiro.

What should be the characteristics of the optimal monetary policy under commitment in the situation of a "global liquidity trap" when Central Banks do not coordinate their actions? Using a two-country open economy model, we perform a numerical exercise in order to address this question and study the differences between this setting and a cooperative situation, when monetary authorities are not only worried with the national household utility, but instead maximize a measure of world welfare. Our findings points towards differences of history and international dependence features of optimal monetary prescriptions in each of the observed cases. We also execute a welfare analysis of our experiment that suggests that a local Central Bank prefers, not only to stay restrained by zero lower bound (ZLB) on nominal interest rates for a longer period, but also that the foreign country exists this situation as early as possible. Lastly, we make a robustness analysis of our results varying the size of each nation and the degree of substitution of the composite goods produced in each locality.

\section{Keywords}

Optimal monetary policy; Global liquidity trap; Open economy; Zero lower bound on nominal interest rates; 


\section{Sumário}

1 Introdução 11

2 Modelo $\quad 16$

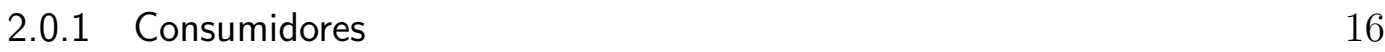

$\begin{array}{ll}\text { 2.0.2 Relação entre os índices de consumo } & 18\end{array}$

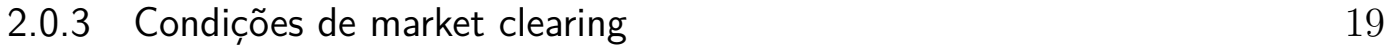

$\begin{array}{lll}2.0 .4 & \text { Firmas } & 19\end{array}$

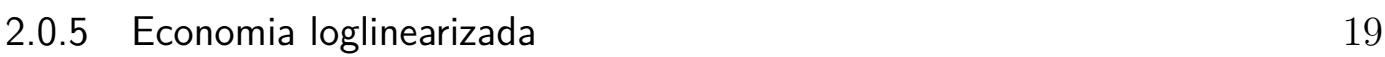

2.0.6 Escolhas dos Bancos Centrais 21

2.0.6.1 Política monetária ótima com cooperação 21

2.0.6.2 Política monetária ótima sem cooperação 22

3 Características do experimento numérico $\quad 24$

4 Políticas ótimas $\quad 25$

4.0.1 Armadilha da liquidez em um país com duração de um período 25

4.0.1.1 Economia fechada 26

4.0.1.2 Cooperação e não cooperação em economias abertas 27

4.0.1.3 Mudando $\sigma \quad 32$

4.0.2 Armadilha da liquidez global 34

4.0.3 Análise de bem-estar 36

$\begin{array}{ll}\text { 4.0.4 Análise de sensibilidade } & 40\end{array}$

5 Conclusão 44

6 Refências bibliográficas $\quad 45$

7 Apêndice $\quad 48$

$\begin{array}{ll}\text { 7.0.1 Modelo } & 48\end{array}$

7.0.1.1 Consumidor do país $F$ e condições de primeira ordem 48

7.0.1.2 Produto natural 49

$\begin{array}{lll}\text { 7.0.1.3 Curva IS } & 50\end{array}$

7.0.1.4 Curva AS 51

7.0.1.5 Aproximação da utilidade do consumidor $\quad 52$

7.0.1.6 Aproximação da utilidade do mundo 53

7.0.1.7 Problema não cooperativo 55

7.0.1.8 Problema cooperativo 56

7.0.2 Parâmetros da política monetária ótima 57

$\begin{array}{ll}\text { 7.0.3 Resolvendo o exercício numérico } & 59\end{array}$

7.0.3.1 Estado 9: $t \geq \tau_{j}+k_{j}\left(\tau_{H}, \tau_{F}\right) \quad 60$

7.0.3.2 Estado 6: $t \geq \tau_{F}+k_{F}\left(\tau_{H}, \tau_{F}\right)$ e $\tau_{H}+k_{H}\left(\tau_{H}, \tau_{F}\right)>t \geq \tau_{H}$

7.0.3.3 Estado 5: $\tau_{H}+k_{H}\left(\tau_{H}, \tau_{F}\right)>t \geq \tau_{H}$ e $\tau_{F}+k_{F}\left(\tau_{H}, \tau_{F}\right)>t \geq \tau_{F} \quad 61$

7.0.3.4 Estado 3: $t \geq \tau_{F}+k_{F}\left(\tau_{H}, \tau_{F}\right)$ e $t<\tau_{H}$

7.0.3.5 Estado 2: $\tau_{F}+k_{F}\left(\tau_{H}, \tau_{F}\right)>t \geq \tau_{F}$ e $t<\tau_{H}$

7.0.3.6 Estado 1: $\tau_{F}>t$ e $t<\tau_{H}$ 
7.0.4 Gráfico: política ótima cooperativa vs política ótima não cooperativa 64

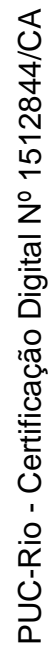




\section{Lista de figuras}

1.1 Taxas de juros de política monetária (linha azul: EUA; linha verde: Japão; linha laranja: Reino Unido; linha amarela: Canadá; linha roxa: Suécia).

4.1 Política monetrária ótima em uma economia fechada $\left(\tau_{H}=2\right)$.

4.2 País $H$ - política monetária ótima $\left(\tau_{H}=2\right.$; linha rosa com asteriscos: caso cooperativo; linha azul claro: caso não cooperativo). 28

4.3 País $F$ - política monetária ótima $\left(\tau_{H}=2\right.$; linha rosa com asteriscos: caso cooperativo; linha azul claro: caso não cooperativo). 29

4.4 Política monetária ótima não cooperativa do país $F$ para diferentes valores de $\sigma\left(\tau_{H}=2\right.$; linha rosa com asteriscos: $\sigma=2$; linha verde: $\sigma=1$; linha azul claro com bolas: $\sigma=0.1)$.

4.5 Política monetária ótima não cooperativa $(j=H, F ; \sigma=2$; $\tau_{F}=6 ; \tau_{H}=16$; linha vermelha: país $F$; linha azul: país $H$ ).

4.6 Soma descontada da perda do país $H$ para diferentes valores de $\tau_{F}$ and $\tau_{H}$.

4.7 Valor da função perda $\left(\tau_{F}=6 ; \tau_{H}=16\right)$.

4.8 Perda de $H$ em $t=\tau_{H}$ para diferentes valores de $\tau_{H}$ e $\tau_{F}$.

4.9 Perda de $H$ em $t=\tau_{F}$ para diferentes valores de $\tau_{H}$ e $\tau_{F}$.

4.10 Regra de metas de inflação $(\bar{\pi}=0)$ vs Política monetária ótima não cooperativa $\left(j=H, F ; \tau_{F}=6 ; \tau_{H}=16\right.$; linha azul: país $H$; linha vermelha: país $F$; linha sólida: política ótima não cooperativa; linha pontilhada: regra de metas de inflação).

4.11 Política monetária ótima não cooperativa para diferentes tamanhos de países $\left(j=H, F ; \tau_{F}=6 ; \tau_{H}=16\right.$; linha vermelha: país $F$; linha azul: país $H$; linha sólida: $n_{H}=n_{F}=0.5$; linha pontilhada: $n_{H}=0.1$ e $\left.n_{F}=0.9\right)$.

7.1 Política ótima cooperativa vs política ótima não cooperativa ( $j=$ $H, F, \tau_{H}=16, \tau_{H}=16$, linha vermelha: país $F$, linha azul: país $H$, linha sólida: não cooperação, linha pontilhada: cooperação). 


\section{Lista de tabelas}

4.1 Calibração base. 25

4.2 Soma descontada da perda de cada país e do mundo $\left(\tau_{H}=16 \mathrm{e}\right.$ $\left.\tau_{F}=6\right) . \quad 42$

7.1 Sinais dos coeficientes de acordo com $\sigma$. 58

7.2 Estados. 


\section{Introdução}

O tema "armadilha da liquidez" foi negligenciado por uma significante porção dos macroeconomistas durante a maior parte da segunda metade do século passado, uma vez que, como Krugman (1998) coloca, "sua visão era basicamente que uma armadilha de liquidez não pode acontecer, não aconteceu e não iria acontecer novamente" ${ }^{1}$. Certamente houve uma concepção equivocada em torno desta matéria e, inspirada especialmente pela recessão japonesa dos anos 90 e pela crise financeira do final dos anos 2000, uma literatura mais moderna acerca de tal temática começou a ser desenvolvida.

Devido aos efeitos recessivos dos episódios de 2007/2008 foram observadas medidas anticíclicas em uma vasta gama de países. Diversos Bancos Centrais engajaram em uma significativa redução das taxas de juros de política monetária a fim de estimular os níveis de atividade econômica. Todavia, tendo em vista os baixos patamares de juros a priori praticados em países desenvolvidos, houve uma frustração na acomodação dos efeitos recessivos da crise em uma série de localidades, uma vez que diferentes autoridades monetárias foram levadas a "estranha"situação na qual as taxas juros se aproximam do seu limite inferior (ver figura 1.1). Ainda assim podemos nos perguntar se esses países não estão de fato se dirigindo a uma situação semelhante à japonesa, na qual a efetividade da restrição do limite inferior zero para as taxas nominais não é uma fenômeno esporádico. Desta forma uma compreensão mais aprofundada de como um Banco Central deve se comportar em um mundo onde armadilhas da liquidez não são eventos únicos e isolados, ademais de um tema interessante, pode vir a se tornar cada vez mais uma questão prática relevante.

Assim sendo este artigo visa fazer contribuições para a literatura neoWilckselliana de abordagem de uma armadilha da liquidez global ${ }^{2}$ expandindo os trabalhos de Fujiwara et al. $(2013)^{3}$ sobre a temática da condução da política monetária ótima quando os Bancos Centrais se comportam de forma competitiva. À vista disso as principais questões em que nos concentramos são

\footnotetext{
${ }^{1}$ Tradução livre de Krugman (1998).

${ }^{2} \mathrm{Na}$ qual uma armadilha de liquidez global (ou seja, todos os países do mundo são levados a uma armadilha da liquidez) se origina por perturbações nas taxas de juros naturais.

${ }^{3}$ Fujiwara et al. (2013) se concentraram na análise do desenvolvimento de uma política monetária ótima em uma armadilha da liquidez global quando os Bancos Centrais cooperam.
} 


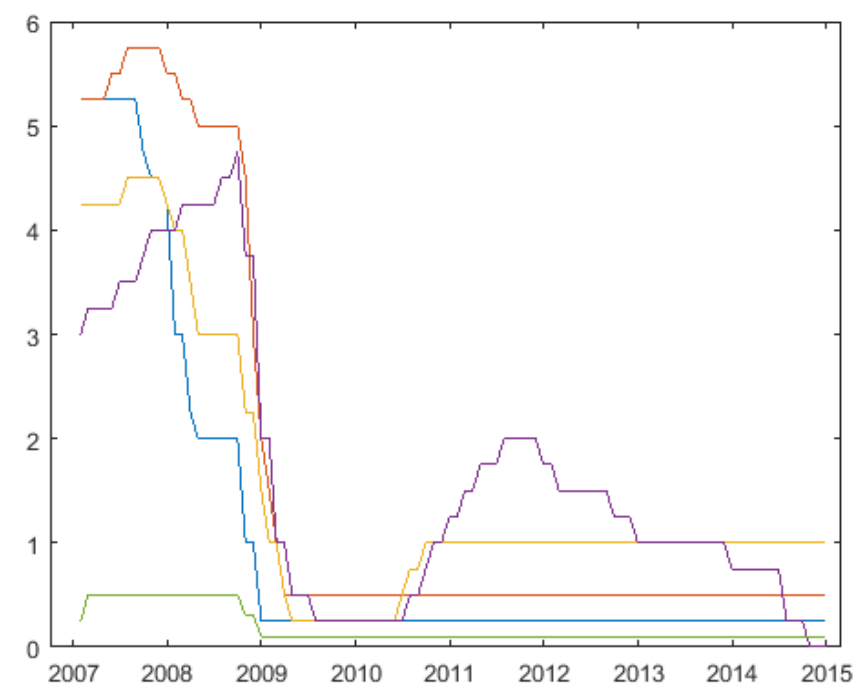

Figura 1.1: Taxas de juros de política monetária (linha azul: EUA; linha verde: Japão; linha laranja: Reino Unido; linha amarela: Canadá; linha roxa: Suécia).

as seguintes: "quais são as características da política monetária ótima sob commitment numa armadilha de liquidez global quando as autoridades monetárias não cooperam?"e "como as políticas sob cooperação e não cooperação se comparam uma com a outra?". Para endereçar esses pontos, após definir como será a condução das políticas ótimas em um modelo com dois países, será produzido um exercício numérico com o objetivo de examinar de que maneira se dará o comportamento de cada autoridade monetária na situação de uma armadilha da liquidez.

Um dos primeiros trabalhos de abordagem neo-Wilckselliana para a compreensão da armadilha de liquidez foi Krugman (1998), o autor coloca que sair desta situação, na qual as taxas de juros nominais encontram-se no seu limite inferior, se torna um desafio de credibilidade por parte do Banco Central local. A autoridade monetária tem de ser crível conforme prescreve estabilidade para o nível de preços, ainda que isso implique uma maior inflação futura. Como outros autores, tais como Eggertsson e Woodford (2003) e Eggertsson (2006), já discutiram amplamente esse problema, vamos nos abster aqui de qualquer investigação adicional assumindo que os Bancos Centrais possuem a habilidade operar sob commitment. Além disso, é relevante salientar que a situação de armadilha de liquidez com economias fechadas também foi tratada por outros artigos como Jung et al. (2005) e Adam e Billi (2006, 2007) entre outros.

Ademais de discussões acerca dos problemas de credibilidade quando da 
efetividade da restrição do zero lower bound (ZLB) ${ }^{4}$, Eggertsson e Woodford (2003) também fizeram outros avanços na análise iniciada por Krugman (1998), definindo a política monetária ótima sob commitment e fazendo uma investigação dinâmica da situação da armadilha de liquidez em uma economia fechada. Tal trabalho é a inspiração fundamental para o exercício numérico produzido neste artigo. Em nosso experimento, que se inicia em um ponto de estado estacionário, a taxa de juros natural ${ }^{5}$ sofre uma choque exógeno, caindo abaixo de zero e desta maneira levando as nações a uma armadilha de liquidez. Em seguida, um processo Markov seguido por cada taxa de juros natural estabelece estocasticamente a data em que cada localidade deixa essa circunstância.

Com o desenvolvimento de uma série de estudos voltados para o esboço de políticas ótimas em um cenário internacional, fomos capazes de construir as prescrições não-cooperativas e cooperativas. Quando não colaboram as autoridades monetárias buscam apenas maximizar a utilidade dos consumidores internos, tomando como dada a política monetária externa ${ }^{6}$. Por outro lado a colaboração implica que os Bancos Centrais resolvem um problema de Ramsey maximizando em conjunto uma medida de bem-estar mundial ${ }^{7}$. É essencial reconhecer aqui os esforços realizados por Clarida et al. (2002), que definiram como os ambientes cooperativos e não cooperativos do jogo de política monetária poderiam ser tratados com estruturas de economias abertas. Adicionalmente, de acordo com Clarida et al. (2001, 2002), Benigno e Benigno (2003) e como observado por Fujiwara et al. (2013), constatamos que, como no cenário cooperativo, ao não colaborar os Bancos Centrais também aspiram a estabilização dos níveis de inflação referentes ao producer price index em detrimento da inflação contabilizada pelo consumer price index. Outras realizações relevantes na literatura de política monetária ótima com economias abertas foram feitas em Corsetti e Persentti (2001, 2005), Devereux e Engle (2003), Faia e Monacelli (2008) entre outros.

Ao examinar as particularidades da cooperação e da não-cooperação produzidas pelo modelo utilizado, observam-se algumas diferenças significativas, principalmente no que se refere à forma como as características de dependência internacional ${ }^{8}$ das políticas ótimas se apresentam. Ademais disso, também

${ }^{4}$ Restrição do limite inferior zero para a taxa nominal de juros.

${ }^{5}$ Que é uma função da taxa de juros natural comum e da mudança nos termos de troca naturais (a taxa de juros e a mudança nos termos de troca no equilíbrio de preços flexíveis globais).

${ }^{6}$ Conforme Clarida et al. (2002) e Ida (2013).

${ }^{7}$ Como Clarida et. al (2002), Nakajima (2008) e Fujiwara et al. (2013).

${ }^{8}$ Características originadas pelo fato de uma política monetária responder à política monetária externa. 
pudemos notar a manutenção dos mesmos atributos de dependência historica ${ }^{9}$ da prescrição monetária ótima para ambos os casos, que se assemelham aos achados da situação de economia fechada em Eggertsson e Woodford (2003). Ainda, ao explicitar a formatação dessas políticas quando a restrição do ZLB sobre as taxas nominais de juros não é efetiva tem-se resultados semelhantes à Clarida et al. (2002), nos quais os Bancos Centrais em cooperação visam estabilizar internamente o hiato do produto e a inflação, enquanto a política não cooperativa ainda apresenta algum grau de dependência internacional.

Recentemente, alguns novos desenvolvimentos foram feitos na tentativa de abordar o cenário de armadilha de liquidez com economias abertas. Nkajima (2008) analisa a situação em um modelo semelhante ao nosso, definindo a política monetária ótima sob commitment e cooperação quando um único país entra em uma armadilha de liquidez, propondo um exercício numérico nos moldes de Eggertsson e Woodford (2003) para melhor compreender este cenário. Fujiwara et al. (2013) estende os resultados de Nakajima (2008) para uma condição de armadilha de liquidez global. Cook e Devereux (2011) investigam o caso de como a coordenação fiscal pode agir de maneira a combater os efeitos de uma armadilha de liquidez global. Haberis e Lipinska (2015) concentraram a sua análise na forma como a política monetária numa economia relativamente grande afeta um país pequeno quando um choque de demanda global é capaz de levar as taxas de juros para zero, analisando as discrepâncias entre políticas sob discretion e commitment. Bhattarai e Egorov (2016) diagnosticaram como a política monetária e fiscal podem atuar quando as taxas de juros nominais estão perto de zero em uma pequena economia. Jeanne (2009) dirige sua atenção para políticas monetárias e fiscais ótimas em uma armadilha global que dura apenas um período. Ida (2013) estuda as características analíticas da política monetária ótima sob cooperação e não cooperação em uma armadilha global da liquidez.

Assim sendo as principais contribuições do nosso trabalho, além da comparação dinâmica de políticas monetárias cooperativas e não-cooperativas em uma armadilha global da liquidez, são um exame das preferências de um Banco Central em relação à duração desta situação em cada país e uma análise de sensibilidade do nosso experimento numérico ${ }^{10}$. No que diz respeito à questão das preferências, pudemos encontrar alguns resultados contra intuitivos, que apontam na direção da predileção das autoridades monetárias, não apenas por

\footnotetext{
${ }^{9}$ Características originadas pelo fato de uma política monetária responder à efetividade da restrição do ZLB no seu próprio país.

${ }^{10}$ Observa-se o que acontece quando o caráter de substituição entre os bens produzidos em cada localidade muda (tornando-se assim complementares) e quando variamos o tamanho de cada país.
} 
permanecer períodos mais longos em uma armadilha de liquidez, mas também que a outra nação saia deste quadro o mais rapidamente possível. Quanto ao ponto da sensibilidade dos resultados, apesar do grau de substituição entre os bens produzidos em cada localidade e do tamanho dos países alterarem como será dada a política ótima, quando estas são comparadas ao caso no qual os bacos centrais seguem regras usuais de taxas de juros com metas de inflação, os casos com e sem cooperação apresentaram perdas de bem-estar mundial relativamente semelhantes um ao outro.

Destarte o artigo encontra-se organizado da seguinte forma: no capítulo 2 é apresentado o modelo; o capítulo 3 define as características do exercício numérico; no capítulo 4 encontram-se descritos os resultados do experimento; e no capítulo 5 estão as observações finais. 


\section{Modelo}

É adotado um modelo simples de economia aberta com dois países, preços relativamente rígidos e competição imperfeita, similar a Nakajima (2008) e Fujiwara et al. $(2013)^{1}$. Há uma economia sem moeda com $H$ e $F$ indexando o países home e foreign respectivamente, onde cada país $j=H, F$ produz um conjunto contínuo diferente de bens diferenciados denominado $N_{j}$. A população da nação $j$ é dada por $n_{j}$ e é normalizada para um (ou seja, $n_{H}+n_{F}=1$ ). Para fins de simplificação é válido o pressuposto padrão de que $N_{H}=\left[0, n_{H}\right]$ e $N_{F}=\left(n_{H}, 1\right]$.

Nesta configuração, depois que os consumidores escolhem seus níveis de consumo, mão-de-obra e títulos, e as empresas determinarem seus preços, os Bancos Centrais estabelecem a política monetária ótima sob uma tecnologia de commitment para maximizar o bem-estar dos consumidores. Uma derivação mais completa do modelo pode ser encontrada no apêndice.

\subsection{1}

\section{Consumidores}

Em cada localidade os consumidores representativos têm preferências simétricas. No caso do país home, a utilidade do consumidor é dada por:

$$
U_{H, 1}=E_{1} \sum_{t=1}^{\infty} \beta^{t-1}\left[\tilde{u}\left(C_{t}\right)-\frac{1}{n_{H}} \int_{N_{H}} \tilde{v}\left(l_{t}(i)\right) d i\right],
$$

onde $C_{t}$ é o índice de consumo de bens produzidos em ambos os países utilizados no país $H, l_{t}(i)$ é a oferta de mão-de-obra para a produção do bem $i \in N_{H}, \beta$ $\in(0,1)$ é o fator de desconto intertemporal e $\tilde{u}(\cdot)$ e $\tilde{v}(\cdot)$ são as funções que dão a utilidade de consumo e desutilidade de trabalhando respectivamente, com formato com elasticidade constante de substituição,

$$
\tilde{u}\left(C_{t}\right)=\frac{C_{t}^{1-\sigma}}{1-\sigma} \tilde{v}\left(l_{t}(i)\right)=\frac{l_{t}(i)^{1+\omega}}{1+\omega},
$$

onde $\sigma, \omega>0$. O índice de consumo como Benigno e Benigno (2003) é dado por:

$$
C_{t}=\left[n_{H}^{\frac{1}{\rho}} C_{H, t}^{\frac{\rho-1}{\rho}}+n_{F}^{\frac{1}{\rho}} C_{F, t}^{\frac{\rho-1}{\rho}}\right]^{\frac{\rho}{\rho-1}}
$$

${ }^{1}$ Tais modelos são em grande parte inspirados nos trabalhos de Woodford (2003). 
onde $\rho$ é a elasticidade de substituição entre os bens produzidos em cada país. Então

$$
u\left(C_{H, t}, C_{F, t}\right) \equiv \tilde{u}\left(\left[n_{H}^{\frac{1}{\rho}} C_{H, t}^{\frac{\rho-1}{\rho}}+n_{F}^{\frac{1}{\rho}} C_{F, t}^{\frac{\rho-1}{\rho}}\right]^{\frac{\rho}{\rho-1}}\right),
$$

onde $C_{j, t}, j=H, F$, são índices de bens domésticos e estrangeiros consumidos pelo consumidor representativo de $H$ com formato Dixit-Stigliz,

$$
C_{j, t}=\left[n_{j}^{-1 / \theta} \int_{N_{j}} c_{t}(i)^{(\theta-1) / \theta} d i\right]^{\theta /(\theta-1)}, j=H, F,
$$

onde $\theta$ é a elasticidade de substituição de bens produzidos dentro de um país. Aqui é importante notar, dada a especificação dos índices de consumo, a relevância do parâmetro $\sigma$, não apenas por representar o inverso da elasticidade intertemporal de substituição, mas também por ser um dos responsáveis por determinar a relação de substituição ou complementariedade entre as cestas de produtos produzida em cada localidade ${ }^{2}$.

O consumidor representativo do país $H$ enfrenta uma restrição orçamentária com mercados financeiros completos da forma:

$$
P_{t} C_{t}+E_{t} Q_{t, t+1} W_{t+1}=W_{t}+\int_{N_{H}}\left(w_{t}(i) l_{t}(i)+\Pi_{t}(i)\right) d i+T_{t},
$$

onde $T_{t}$ é uma taxação lump-sum, $\Pi_{t}(i)$ é o lucro nominal per capita pela venda do bem $i, w_{t}(i)$ é o salário nominal para a produção de $i, W_{t+1}$ é a quantidade de títulos com vencimento no próximo período em posse do consumidor representativo, $Q_{t, t+1}$ é o fator de desconto estocástico e $P_{t}$ é o índice de preços correspondente de bens produzidos em ambos os países vendidos em $H$, dado por:

$$
\begin{gathered}
P_{t}=\left(n_{H} P_{H, t}^{1-\rho}+n_{F} P_{F, t}^{1-\rho}\right)^{\frac{1}{1-\rho}} \\
P_{j, t}=\left[\frac{1}{n_{j}} \int_{N_{j}} p_{t}(i)^{1-\theta} d i\right]^{1 /(1-\theta)}, j=H, F,
\end{gathered}
$$

onde $p_{t}(i), i \in N_{j}, j=H, F$, é o preço do bem $i$, produzido no país $j$, vendido em $H$ e cotado na moeda do país home.

Também tomamos como válida a lei do preço único, que implica:

$$
p_{t}(i)=\epsilon_{t} p_{t}^{*}(i)
$$

onde $\epsilon_{t}$ é a taxa de câmbio nominal e $p_{t}^{*}(i), i \in N_{j}, j=H, F$, é o preço do bem $i$, produzido no país $j$, vendido em $F$ e cotado em moeda estrangeira.

Como em Woordford (2003), o "limite natural da dívida"exige que os consumidores não possam incorrer em dívidas maiores do que o valor presente da renda líquida não-financeira futura,

\footnotetext{
${ }^{2} u_{H F}$ maior ou menor que zero depende não só do valor de $\rho$, mas também de $\sigma$.
} 


$$
-W_{t+1} \leq \sum_{T=t+1}^{\infty} E_{t+1} Q_{t+1, T}\left[\int_{N_{H}}\left(w_{t+1}(i) l_{t+1}(i)+\Pi_{t+1}(i)\right) d i+T_{t}\right]
$$

onde

$$
Q_{t, T} \equiv \prod_{s=t+1}^{T} Q_{s-1, s}
$$

O consumidor representativo de $H$ então escolhe $\left(C_{H, t}, C_{F, t}, l_{t}(i), W_{t}\right)_{t=1}^{\infty}$ para maximizar a equação (2-1) sujeito às equações (2-6) e (2-10), dada a quantidade inicial de títulos $W_{0}$. O caso para o país $F$ é analogo, uma vez que preferências, índices e restrições tem a mesma formatação, a única diferença é que as variáveis encontram-se indexador por $*$, de maneira que temos $C_{t}^{*}$, $C_{H, t}^{*}, C_{H, t}^{*}, l_{t}^{*}(i), P_{t}^{*}, P_{H, t}^{*}, P_{H, t}^{*}, p_{t}^{*}(i), W_{t}^{*}, w_{t}^{*}(i), \Pi_{t}^{*}(i)$ e $Q_{t, t+1}^{*}$.

\subsection{2}

\section{Relação entre os índices de consumo}

Para nossa análise é interessante, como em Nakajima (2008), que a proporção dos índices de consumo de bens produzidos em um país consumidos cada um em uma localidade permaneça inalterada para diferentes políticas monetárias. Como provado pelo autor, precisamos fazer duas suposições para que isso seja verdadeiro: primeiro a elasticidade de substituição entre as cestas de bens produzidas em cada país é igual a unidade (ou seja, $\rho=1$ ); segundo no período inicial o montante total de dívida pública local (ou seja, $\mathcal{W}_{t}$ para $H$ e $\mathcal{W}_{t}^{*}$ para $F$ ) é mantida somente pelas pessoas de seu país, então

$$
\begin{aligned}
& \mathcal{W}_{0}=n_{H} W_{0}, \\
& \mathcal{W}_{0}^{*}=n_{F} W_{0}^{*},
\end{aligned}
$$

o que não é necessariamente verdade para $t>0$, uma vez que os habitantes de uma nação podem deter obrigações do governo externo, precisando apenas obedecer à condição de market clearing do mercado de títulos:

$$
\mathcal{W}_{t}+\epsilon_{t} \mathcal{W}_{t}^{*}=n_{H} W_{t}+n_{F} \epsilon_{t} W_{t}^{*}
$$

Essas duas hipóteses implicam que ${ }^{3}$ :

e

$$
\begin{gathered}
C_{t}=\left(\frac{C_{H, t}}{n_{H}}\right)^{n_{H}}\left(\frac{C_{F, t}}{n_{F}}\right)^{n_{F}}, C_{t}^{*}=\left(\frac{C_{H, t}^{*}}{n_{H}}\right)^{n_{H}}\left(\frac{C_{F, t}^{*}}{n_{F}}\right)^{n_{F}}, \\
P_{t}=P_{H, t}^{n_{H}} P_{F, t}^{n_{F}}=\epsilon_{t} P_{t}^{*}=\epsilon_{t} P_{H, t}^{* n_{H}} P_{F, t}^{* n_{F}} \\
\frac{C_{t}}{C_{t}^{*}}=\frac{C_{H, t}}{C_{H, t}^{*}}=\frac{C_{F, t}}{C_{F, t}^{*}}=\frac{c_{t}(i)}{c_{t}^{*}(i)}=1, \quad i \in[0,1] .
\end{gathered}
$$

${ }^{3}$ A prova pode ser obtida no apêndice de Nakajima (2008). 


\subsection{3}

\section{Condições de market clearing}

Tomando $y_{t}(i)$ como a oferta do bem $i \in N_{H}$ e $y_{t}^{*}(i)$ como a oferta do bem $i \in N_{F}$, as condições de market clearing implicam que

$$
\begin{aligned}
& y_{t}(i)=n_{H} c_{t}(i)+n_{F} c_{t}^{*}(i), \quad i \in N_{H}, \\
& y_{t}^{*}(i)=n_{H} c_{t}(i)+n_{F} c_{t}^{*}(i), \quad i \in N_{F} .
\end{aligned}
$$

Podemos definir índices de produção correspondentes com a seguinte forma:

$$
\begin{gathered}
Y_{j, t}=\left[n_{j}^{-1 / \theta} \int_{N_{j}} y_{t}(i)^{(\theta-1) / \theta} d i\right]^{\theta /(\theta-1)}=n_{H} C_{j, t}+n_{F} C_{j, t}^{*}, j=H, F, \\
Y_{t}=\left(\frac{Y_{H, t}}{n_{H}}\right)^{n_{H}}\left(\frac{Y_{F, t}}{n_{F}}\right)^{n_{F}}=n_{H} C_{t}+n_{F} C_{t}^{*},
\end{gathered}
$$

de maneira que as relações de equilíbrio podem ser descritas como

$$
C_{H, t}=C_{H, t}^{*}=Y_{H, t}, \quad C_{F, t}=C_{F, t}^{*}=Y_{F, t}, \quad C_{t}=C_{t}^{*}=Y_{t} .
$$

\subsection{4}

\section{Firmas}

As firmas são monopolistas na produção do bem $i$, e enfrentam no país $H$ uma função de produção linear no trabalho dada por:

$$
y_{t}(i)=A n_{H} l_{t}(i), \quad i \in N_{H},
$$

na qual $A$ é um parametro de produtividade. O país $F$ possui uma função similar com $y_{t}^{*}(i), n_{F}, l_{t}^{*}(i), A^{*}$ e $i \in N_{F}$. É admitido que a rigidez de preços pode ser representada como em Calvo (1983) de maneira que a firma no país $H$ na produção do bem $i$ objetiva maximizar os seus lucros esperados,

$$
E_{t} \sum_{T=t}^{\infty} \alpha^{T-t} Q_{t, T}\left[(1+\eta) p_{t}(i)-\frac{w_{T}(i)}{A}\right] \frac{Y_{H, t}}{n_{H}}\left[\frac{p_{t}(i)}{P_{H, t}}\right]^{-\theta}
$$

escolhendo $p_{t}(i)$, onde $\eta$ é um subsídio dado pelo governo com a função de eliminar as distorções geradas pela competição imperfeita (i.e. $\eta=1 /(1-\theta)$ ) e $\alpha$ é a probabilidade da firma não poder reajustar preços do bem $i$ em uma dada data $t$. As empresas em $F$ resolvem um problema análogo.

\subsection{5}

\section{Economia loglinearizada}

Loglinearizando as condições de otimalidade dos consumidores em torno do estado estacionário com inflação zero, pode-se escrever uma equação IS para 
cada país:

$$
\begin{array}{r}
i_{H, t}=E_{t}\left[\left(1+(\sigma-1) n_{H}\right)\left(x_{H, t+1}-x_{H, t}\right)+(\sigma-1) n_{F}\left(x_{F, t+1}-x_{F, t}\right)+\pi_{H, t+1}\right]+ \\
+r_{H, t}^{n}=r_{H, t}+E_{t} \pi_{H, t+1},
\end{array}
$$

$$
\begin{array}{r}
i_{F, t}=E_{t}\left[\left(1+(\sigma-1) n_{F}\right)\left(x_{F, t+1}-x_{F, t}\right)+(\sigma-1) n_{H}\left(x_{H, t+1}-x_{H, t}\right)+\pi_{F, t+1}^{*}\right]+ \\
+r_{F, t}^{n}=r_{F, t}+E_{t} \pi_{F, t+1}^{*},
\end{array}
$$

onde $i_{j, t}$ e $r_{j, t}$ são as taxas nominais e reais de juros, inflação e hiato do produto são definidos, respectivamente, como $\pi_{H, t}=\log P_{H, t}-\log P_{H, t-1}, \quad \pi_{F, t}^{*}=$ $\log P_{F, t}^{*}-\log P_{F, t-1}^{*}$ e $x_{j, t}=\log Y_{j, t}-\log Y_{j, t-1}^{n}$, onde $Y_{j, t}^{n}$ é o produto do país $j$ no equilíbrio global de preços flexíveis, e $r_{j, t}^{n}$ é a taxa natural de juros $(j=H, F)$, dada por:

$$
r_{H, t}^{n}=r_{t}^{n}-n_{F} E_{t} \delta_{t+1}^{n}
$$

$$
r_{F, t}^{n}=r_{t}^{n}+n_{H} E_{t} \delta_{t+1}^{n},
$$

onde

$$
\begin{gathered}
\delta_{t+1}^{n}=\log \left(\frac{Y_{F, t+1}^{n}}{Y_{F, t}^{n}}\right)-\log \left(\frac{Y_{H, t+1}^{n}}{Y_{H, t}^{n}}\right), \\
r_{t}^{n}=-\log \left(\beta E_{t} \frac{\tilde{u}_{C}\left(Y_{t+1}^{n}\right)}{\tilde{u}_{C}\left(Y_{t}^{n}\right)}\right),
\end{gathered}
$$

são a mudança natural nos termos de troca e a taxa natural de juros comum aos dois países respectivamente.

Loglinearizando as condições de primeira ordem do problema de maximização das firmas em torno do estado estacionário não inflacionário nós chegamos as curvas de oferta agregada (AS):

$$
\begin{aligned}
& \pi_{H, t}=\gamma_{H} x_{H, t}+\gamma_{H F} n_{F} x_{F, t}+\beta E_{t} \pi_{H, t+1}, \\
& \pi_{F, t}^{*}=\gamma_{H F} n_{H} x_{H, t}+\gamma_{F} x_{F, t}+\beta E_{t} \pi_{F, t+1}^{*},
\end{aligned}
$$

onde

$$
\begin{gathered}
\zeta=\frac{1-\alpha}{\alpha} \frac{1-\alpha \beta}{1+\omega \theta}>0, \\
\gamma_{H}=\zeta\left(1+\omega+(\sigma-1) n_{H}\right)>0, \\
\gamma_{F}=\zeta\left(1+\omega+(\sigma-1) n_{F}\right)>0, \\
\gamma_{H F}=\zeta(\sigma-1) .
\end{gathered}
$$

\subsection{6}




\section{Escolhas dos Bancos Centrais}

Aqui imagina-se os Bancos Centrais locais seguindo dois possíveis tipos de ações. Eles podem cooperar, maximizando conjuntamente uma medida de bemestar global, ou podem se comportar de maneira competitiva, individualmente só se preocupando com a utilidade das pessoas de seu país.

\subsubsection{1}

\section{Política monetária ótima com cooperação}

Fujiwara et al. (2013) definem a política ótima adotada pela autoridade monetária sob commitment no caso de cooperação como a política na qual uma utilidade mundial é maximizada, a qual é descrita como a soma ponderada do bem-estar dos consumidores representativos de cada localidade:

$$
U_{W, 1}=n_{H} U_{H, 1}+n_{F} U_{F, 1}
$$

Dadas as condições de maximização das firmas e dos indivíduos, representadas pelas relações ISs e ASs, equações (2-25), (2-26), (2-31) e (2-32), e a restrição do ZLB para cada taxa nominal de juros,

$$
i_{j, t} \geq 0, \quad j=H, F
$$

os Bancos Centrais resolvem um problema de Ramsey escolhendo as sequências ótimas de $\left(x_{H, t}, x_{F, t}, \pi_{H, t}, \pi_{F, t}^{*}\right)_{t=1}^{\infty}$. Aplicando uma aproximação de segunda ordem em torno do estado estacionário, conforme Woodford (2003), o problema de maximização pode ser analogamente descrito como a minimização de uma função perda, então

$$
\operatorname{Max} U_{W, 1} \equiv \operatorname{Min} \sum_{t=1}^{\infty} \beta^{t-1} \operatorname{Perd} a_{W, t}=\operatorname{Perda~}_{\text {total }}, t,
$$

onde

$$
\begin{aligned}
\operatorname{Perd}_{W, t}=\frac{\zeta}{\theta}\left[\frac{n_{H}}{2}(1+\omega+(\sigma\right. & \left.-1) n_{H}\right) x_{H, t}^{2}+\frac{n_{F}}{2}\left(1+\omega+(\sigma-1) n_{F}\right) x_{F, t}^{2}+ \\
& \left.+(\sigma-1) n_{H} n_{F} x_{H, t} x_{F, t}\right]+\frac{n_{H}}{2} \pi_{H, t}^{2}+\frac{n_{F}}{2} \pi_{F, t}^{* 2} .
\end{aligned}
$$

As condições de primeria ordem são:

$$
\begin{gathered}
\Lambda x_{t}-\theta \Lambda \psi_{t}+A\left(\phi_{t}-\beta^{-1} \phi_{t-1}\right)=0, \\
\pi_{t}+\psi_{t}-\psi_{t-1}-\beta^{-1} \phi_{t-1}=0,
\end{gathered}
$$




$$
i_{t} \geq 0, \quad \phi_{t} \geq 0, \quad \phi_{H, t} i_{H, t}=\phi_{F, t} i_{F, t}=0,
$$

onde $x_{t}=\left(x_{H, t}, x_{F, t}\right)^{\prime}, \pi_{t}=\left(\pi_{H, t}, \pi_{F, t}^{*}\right)^{\prime}, i_{t}=\left(i_{H, t}, i_{F, t}\right)^{\prime}, \phi_{t}=\left(\phi_{H, t}, \phi_{F, t}\right)^{\prime}$, $\psi_{t}=\left(\psi_{H, t}, \psi_{F, t}\right)^{\prime}, A=\left(\begin{array}{cc}n_{H}\left(1+(\sigma-1) n_{H}\right) & (\sigma-1) n_{H} n_{F} \\ (\sigma-1) n_{H} n_{F} & n_{F}\left(1+(\sigma-1) n_{F}\right)\end{array}\right)$ e $\Lambda=$ $\frac{1}{\theta}\left(\begin{array}{cc}\gamma_{H} n_{H} & \gamma_{H F} n_{H} n_{F} \\ \gamma_{H F} n_{H} n_{F} & \gamma_{F} n_{F}\end{array}\right)$.

\subsubsection{2}

\section{Política monetária ótima sem cooperação}

Quando não cooperando, analogamente a Clarida et al. (2002) e Ida (2013), o equilíbrio global será dado pelas escolhas separadas de cada autoridade monetária de $\left(x_{j, t}, \pi_{j, t}\right)_{t=1}^{\infty}$ que maximiza o bem-estar do país $j$ sujeito a sua IS, AS e a restrição do ZLB para a sua taxa nomianl de juros (i.e. $i_{j, t} \geq 0$ ), tomando como dadas as variáveis externas (indexadas por $q$ ) e os processos exógenos. Da mesma forma, como em Woodford (2003), podemos expressar o problema de maximização como uma tarefa de minimização, após uma aproximação de segunda ordem em torno do estado estacionário não inflacionário ${ }^{4}$,

$$
\operatorname{Max} U_{j, 1} \equiv \operatorname{Min} \sum_{t=1}^{\infty} \beta^{t-1} \operatorname{Perda} a_{j, t}=\operatorname{Perda}_{\text {total }_{j, t}}
$$

onde

$$
\begin{array}{r}
\operatorname{Perda}_{j, t}=\frac{\zeta}{\theta}\left[\left(1-n_{j}\right) x_{j, t}-n_{q} x_{q, t}+\frac{1}{2}\left((\sigma-1) n_{j}^{2}+1+\omega\right) x_{j, t}^{2}+\right. \\
\left.+\frac{1}{2} n_{q}^{2}(\sigma-1) x_{q, t}^{2}+(\sigma-1) n_{j} n_{q} x_{j, t} x_{q, t}\right]+\frac{1}{2} \pi_{j, t}^{2} .
\end{array}
$$

As condições de primeira ordem são:

$$
\begin{gathered}
\frac{\zeta}{\theta}\left(1-n_{j}\right)+\frac{\zeta}{\theta}\left((\sigma-1) n_{j}^{2}+1+\omega\right) x_{j, t}+\frac{\zeta}{\theta}(\sigma-1) n_{H} n_{F} x_{q, t}-\gamma_{j} \psi_{j, t}+ \\
+\left(1+(\sigma-1) n_{j}\right)\left(\phi_{j, t}-\beta^{-1} \phi_{j, t-1}\right)=0, \\
\pi_{j, t}+\psi_{j, t}-\psi_{j, t-1}-\beta^{-1} \phi_{j, t-1}=0, \\
i_{j, t} \geq 0, \quad \phi_{j, t} \geq 0, \quad \phi_{j, t} i_{j, t}=0,
\end{gathered}
$$

onde $q, j=H, F$ e $j \neq q$.

É importante salientar que, como já fora colocado, a política ótima visa estabilizar a inflação de preços do produtor nacional (ou seja, $\pi_{H, t}$ e $\pi_{F, t}^{*}$ ) em vez dos índices de preços ao consumidor. Isto ocorre, devido ao fato de que

${ }^{4}$ Para as equações (2-44) a (2-48), se $j=F, \pi_{j, t}=\pi_{F, t}^{*}$. 
somente a inflação do índice de preços dos produtores aparece nas equações $(2-40)$ e $(2-45)^{5}$.

${ }^{5}$ Esse fenômeno também é observado em diferentes contextos por Clarida et al. (2001, 2002), Benigno e Benigno (2003) e Fujiwara et al (2013). 


\section{3}

\section{Características do experimento numérico}

Para compreender as implicações para a política monetária de um ambiente em que as dificuldades de uma armadilha de liquidez estão presentes, vamos realizar um experimento numérico com as seguintes características:

- Primeiro supõe-se que no período inicial, $t=0$, ambas as economias se encontram em estado estacionário não inflacionário, portanto temos como equilíbrio de políticas ótimas nos casos cooperativo e não-cooperativo $x_{H, T}=x_{F, t}=\pi_{H, t}=\pi_{F, t}=0, i_{H, t}=r_{H, t}^{n}=r_{H i g h}^{n}$ e $i_{F, t}=r_{F, t}^{n}=r_{h i g h}^{n}{ }^{1}$.

- No primeiro período, $t=1$, cada economia sofre um choque estocástico persistente inesperado em sua taxa de juros natural, onde $r_{j, t}^{n}(j=H, F)$ cai de $r_{\text {high }}^{n}>0$ para $r_{\text {low }}^{n}<0$, ipedindo que os países coloquem sua taxa nominal de juros igual a taxa natural, dada a restrição do ZLB.

- A taxa natural em cada país segue um processo de Markov independente com as seguintes características para $j=H, F$ :

$-\operatorname{Prob}\left(r_{j, t+1}^{n}=r_{\text {high }}^{n} \mid r_{j, t}^{n}=r_{\text {low }}^{n}\right)=\gamma$

$-\operatorname{Prob}\left(r_{j, t+1}^{n}=r_{h i g h}^{n} \mid r_{j, t}^{n}=r_{h i g h}^{n}\right)=1$

- Existe um valor $\tau_{\max }$ de maneira que $\operatorname{Prob}\left(r_{j, \tau_{\max }}^{n}=r_{h i g h}^{n} \mid r_{j, \tau_{\max }-1}^{n}=\right.$ $\left.r_{\text {low }}^{n}\right)=1$

- Vamos definir a primeira data em que a taxa natural retorna para o seu valor de estado estacionário em cada local como $\tau_{j}(j=H, F)$, portanto $\tau_{j} \leq \tau_{\max }$

Assim o equilíbrio das políticas monetárias ótimas, dado um par $\left(\tau_{H}, \tau_{F}\right)$, é caracterizado por $\left(x_{H, t}, x_{F, t}, \pi_{H, t}, \pi_{F, t}, i_{H, t}, i_{F, t}\right)_{t=0}^{\infty}$. O algoritmo de solução para o modelo, dados estes choques, é uma expansão do que fora proposto por Eggertsson e Woodford (2003) e encontra-se descrito no apêndice.

\footnotetext{
${ }^{1}$ Onde os valores de estado estacionário de $r_{H, t}^{n}$ e $r_{F, t}^{n}$ são $r_{\text {high }}^{n}=(1-\beta) / \beta$.
} 


\section{Políticas ótimas}

A fim de organizar os resultados esta seção é dividida da seguinte forma: primeiro investiga-se como é caracterizada a política ideal em uma circunstância na qual somente um país se encontre em armadilha da liquidez, esta durando apenas um período; em seguida é examinada a situação de uma armadilha de liquidez global; depois voltamos nossa atenção para uma análise de bem-estar do experimento; e por fim é fornecido um exame de sensibilidade dos resultados.

\subsection{1}

\section{Armadilha da liquidez em um país com duração de um período}

Para observar separadamente a essência das características das políticas monetárias ótimas, consideremos um primeiro cenário simples, no qual apenas a nação $H$ sofre o choque estocástico descrito com a duração de um período (ou seja, $r_{H, 1}^{n}=r_{\text {low }}^{n}$ e $r_{H, t}^{n}=r_{h i g h}^{n} \forall t \neq 1$ ). Vale ressaltar que, apesar de apresentarmos aqui uma realização específica da política ótima para valores definidos de $\tau_{H}$ e $\tau_{F}$, os agentes ecoôomicos não possuem conhecimento prévio de qual serão tais valores até que essas datas de fato aconteçam. O exercício numérico é feito sob a seguinte calibração ${ }^{1}$ :

Tabla 4.1: Calibração base.

\begin{tabular}{lll}
\hline Parâmetros & Valores & \\
\hline$\beta$ & 0.99 & Fator de desconto intertemporal \\
$\gamma$ & 0.2 & $P\left(r_{j, t+1}^{n}=r_{h i g h}^{n} \mid r_{j, t}^{n}=r_{l o w}^{n}\right)$ para $j=H, F$ \\
$\sigma$ & 2 & Inverso da elasticidade de substituição intertemporal \\
$\theta$ & 7.88 & Elasticidade de substituição entre bens diferenciados produzidos em um país \\
$\omega$ & 0.47 & Elasticidade da desutilidade do trabalho \\
$n_{j}$ & 0.5 & População do país $j$ \\
$\alpha$ & 0.66 & Probabilidade de não haver reajuste de preços no período \\
$r_{l o w}^{n}$ & $-0.02 / 4$ & Choque negativo na taxa natural de juros \\
$\rho$ & 1 & Elasticidade de substituição entre as cestas de bens produzidas em cada localidade \\
$\tau_{\max }-1$ & 19 & Número máximo de períodos que o país j fica com $r_{j, t}^{n}=r_{l o w}^{n}$ \\
\hline
\end{tabular}

${ }^{1}$ A calibração é a mesma de Fujiwara et al. (2013), com exceção de $\tau_{\text {max }}$, que foi reduzido para 20 para fins de eficiência numérica do algorítimo utilizado, não afetando a direção dos movimentos observados nos resultados a seguir. 


\subsubsection{1}

\section{Economia fechada}

Antes de abordar a relação internacional de políticas ótimas, tomemos o caso de uma economia fechada (ou seja, $n_{H}=1$ e $n_{F}=0$ ), uma vez que as características desse arranjo sobreviverão na situação de economias abertas.
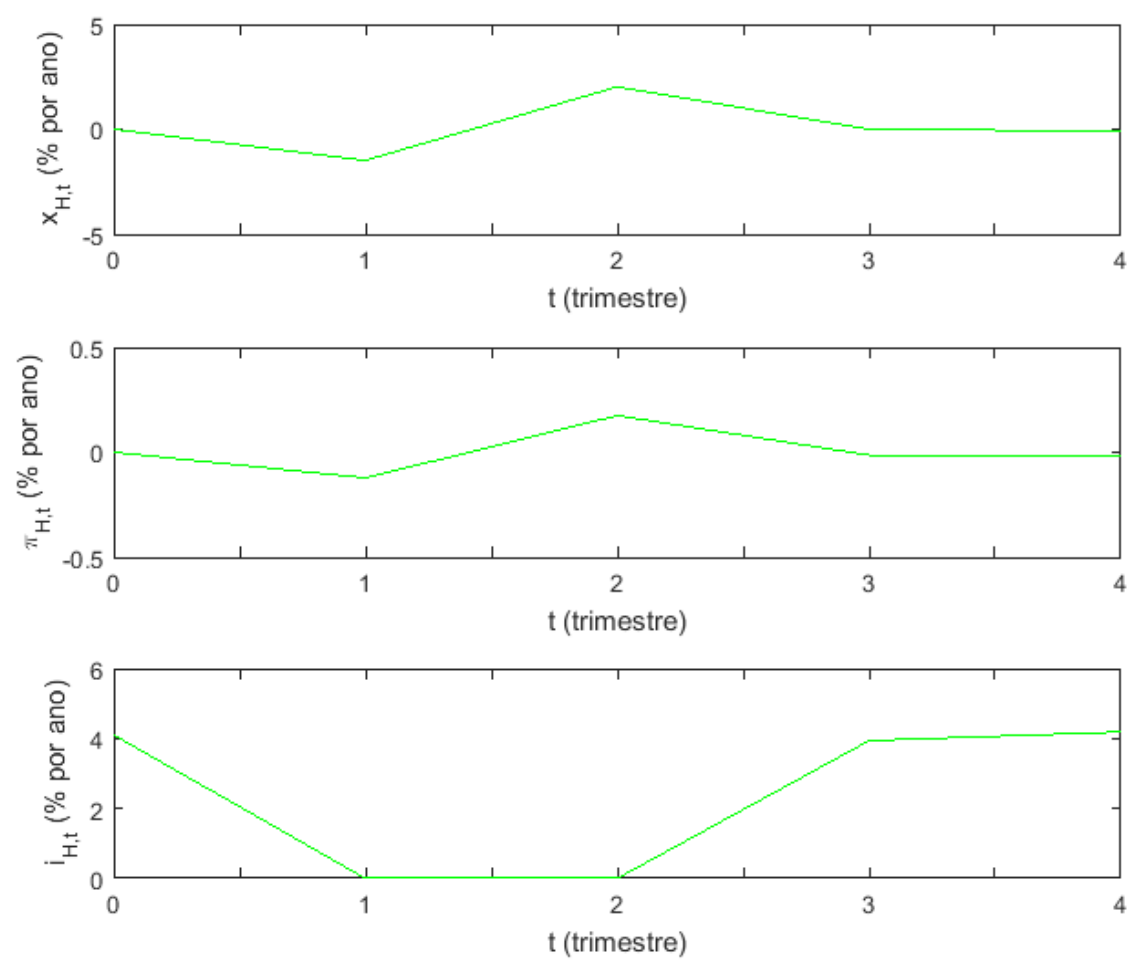

Figura 4.1: Política monetrária ótima em uma economia fechada $\left(\tau_{H}=2\right)$.

Em primeiro lugar cabe destacar que não precisamos lidar com cooperação e não cooperação neste cenário, já que somente o país $H$ existe (ou seja, Perd $\left.a_{H, 1}=\operatorname{Per} d a_{W, 1}\right)$. Na figura 4.1, como em Eggertsson e Woodford (2003), não é difícil perceber o lado da dependência histórica do programa monetário. O Banco Central responde ao impacto negativo em sua taxa de juros natural - que não pode ser totalmente acomodado com uma queda na taxa de juros nominal, dada a restrição do ZLB - em $t=1$, comprometendo-se com uma manutenção do juros nominal em zero em $t=2$, gerando assim um aumento no hiato do produto e inflação nesta data. Mantendo sua taxa de juros baixa quando o choque passa, além de provocar um hiato positivo da taxa de ju$\operatorname{ros}^{2}$ em $t=2$, a autoridade monetária aumenta a expectativa de inflação para $t=1$, ampliando deste modo a diferença entre as taxas natural e real em nesse

${ }^{2} \mathrm{O}$ hiato de juros aqui é definido como $r_{H, t}^{n}-\left(i_{H, t}-\pi_{H, t+1}\right)$. 
período. Este aumento na sequência de hiato dos juros estimula o consumo enquanto a política monetária se encontra restrita e assim suaviza os caminhos para o hiato do produto e o crescimento dos preços. Além disso, conforme apontado pelos autores, o aumento da receita futura produz um acréscimo do consumo atual de acordo com a hipótese da "renda permanente". Portanto esta mitigação dos efeitos recessivos, gerados pela armadilha da liquidez, também barra a queda dos preços quando a restrição do ZLB é efetiva.

Matematicamente, essas repercussões ocorrem em função da forma tomada pelas condições de primeira ordem das políticas ótimas, que podem ser reescritas como ${ }^{3}$

$$
\frac{1}{\theta}\left(x_{j, t}-x_{j, t-1}\right)+\pi_{j, t}=\Upsilon_{1} \phi_{j, t}+\Upsilon_{2} \phi_{j, t-1}+\Upsilon_{3} \phi_{j, t-2},
$$

para $j=H, F$, e possuem multiplicadores de Lagrange defasados associados às restrições do ZLB (i.e. $\phi_{j, t-1}, \phi_{j, t-2}$ ). Implicando que o valor para a inflação e o hiato do produto escolhidos depende de valores prévios das variáveis endógenas do modelo.

\subsubsection{2}

\section{Cooperação e não cooperação em economias abertas}

Quando temos um ambiente cooperativo com economias abertas, como em Nakajima (2008) e Fujiwara et al. (2013), a política ótima apresenta outra face, uma vez que os efeitos internacionais provocados pela condução da política monetária devem ser considerados. Nesse contexto o Banco Central, cujo país fora afetado pelo choque, deve prescrever em certa medida a continuidade do comportamento de economia fechada (visto na figura 4.2), dado que a mesma política reduzirá os efeitos recessivos da queda de sua taxa natural de juros.

Além disso, sob um ponto de vista colaborativo, a nação foreign também desempenhará um papel relevante, ajudando a localidade $H$ durante o período que esta se encontra em armadilha da liquidez. Se focarmos nossa atenção na figura 4.3, é possível perceber que isso é exatamente o que está acontecendo. $\mathrm{O}$ país $F$ cresce seu hiato de produção de $t=1$ para $t=2$, ajudando o país $H$ com um estímulo positivo, quando $i_{H, 1}$ está no seu limite inferior. Se pensarmos neste lado da política monetária cooperativa como tentando diminuir a intensidade com que vincula a restrição do ZLB para o país home, esse crescimento na produção de $F$ faz particularmente isso, uma vez que gera um impacto expansionista sobre o país $H$ em $t=1$.

\footnotetext{
${ }^{3}$ Os valores dos coeficiente podem ser vistos no apêndice definindo $n_{j}=1$ e $n_{q}=0$ na equação (7- 80) ou (7-87).
} 

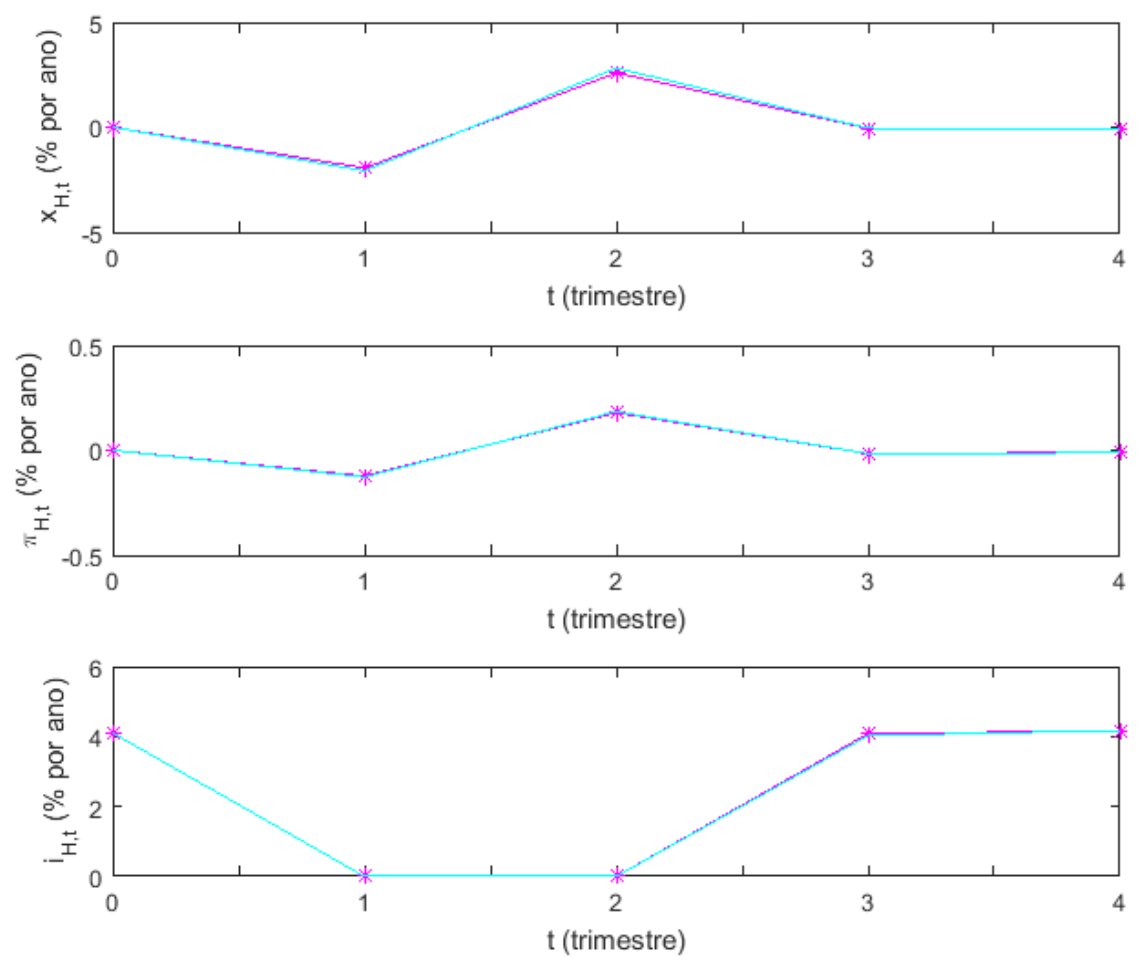

Figura 4.2: País $H$ - política monetária ótima $\left(\tau_{H}=2\right.$; linha rosa com asteriscos: caso cooperativo; linha azul claro: caso não cooperativo).

Ainda no caso colaborativo, focando na trajetória da taxa de juros nominal da nação foreign (figura 4.3), também é interessante compreendêla com base na curva IS de $F$, equação (2-26). Na data $t=2$ como $x_{F, 2}$ e $x_{H, 2}$ estão relativamente elevados e o choque terminou no país $H$, não há mais a necessidade da criação de distorções adicionais, portanto é esperado $x_{j, 3}-x_{j, 2}<0, j=H, F$. Tal queda ocasiona uma redução de $i_{F, 2}$, dado que a taxa de juros real do país $F$ diminui. Em $t=1$ temos o mesmo mecanismo, mas como existe a probabilidade de que se o choque terminar no país $H$ observemos $x_{j, 2}-x_{j, 1}>0$, para $j=H, F$, ocorre o inverso para o taxa nominal de juros da nação $F$. Essa queda no juros nominal gerada no país foreign da data $t=1$ para a data $t=2$ está de acordo com o crescimento do hiato do produto e da inflação de $F$ no mesmo intervalo de tempo.

Em contraste, na situação não-cooperativa, a dependência internacional de políticas ótimas acontece da maneira inversa. Como os Bancos Centrais só estão preocupados com o bem-estar dos consumidores internos, o país $F$, em vez de tentar ajudar $H$, vai tirar proveito de sua situação. Tal fato se dá, pois na figura 4.2 é possível notar a persistência de uma política monetária semelhante adotada pela nação home tanto no caso cooperativo como no não 

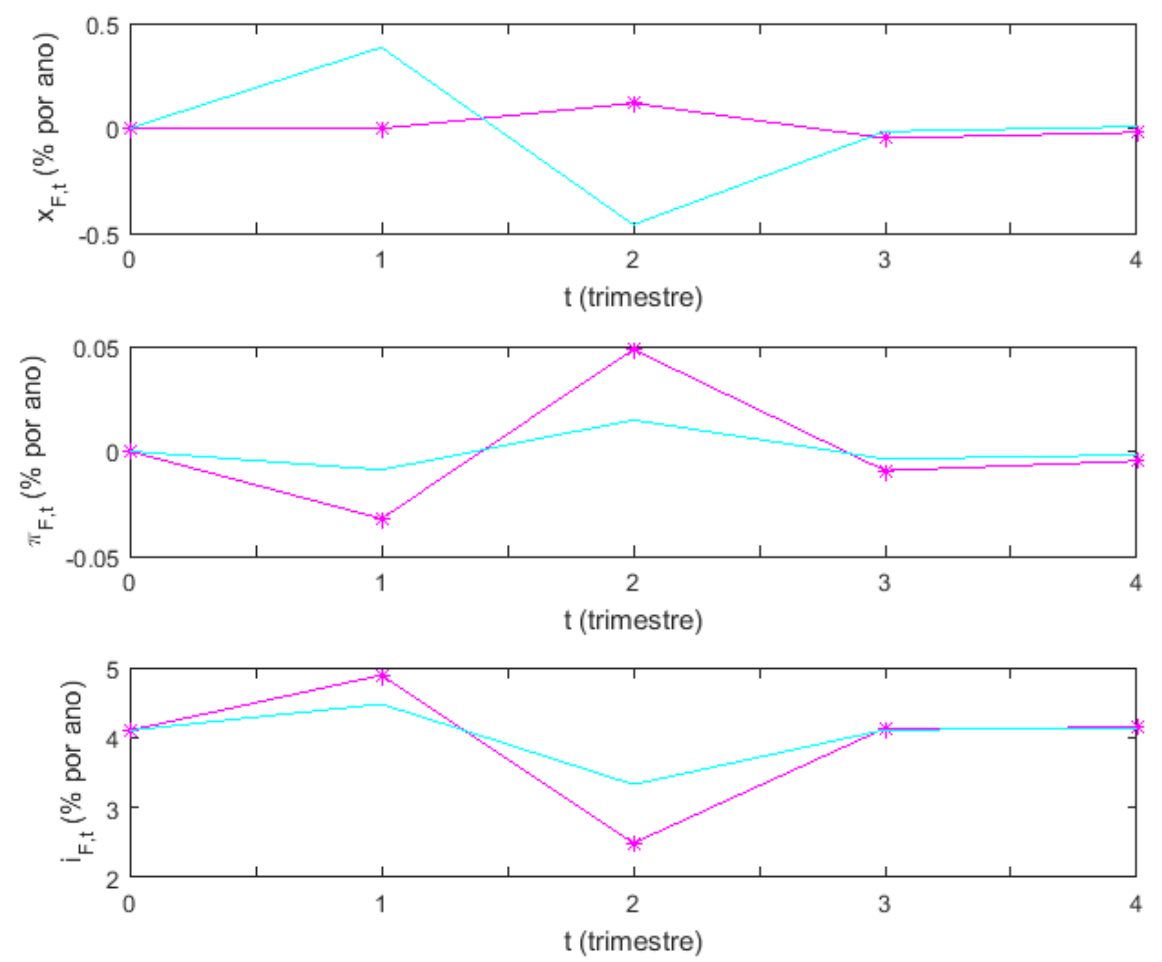

Figura 4.3: País $F$ - política monetária ótima $\left(\tau_{H}=2\right.$; linha rosa com asteriscos: caso cooperativo; linha azul claro: caso não cooperativo).

cooperativo, caracterizada principalmente pela mesma dependência histórica da circunstância de economia fechada. Assim, em $t=2$, quando o país $H$ aumenta sua produção - dado o fim do choque e como prescrito pela dependência histórica-, uma vez que as cestas de bens produzidas em cada local são substitutas ${ }^{4}$ e a proporção dos índices de consumo doméstico e externo são iguais à unidade - conforme provado por Nakajima (2008) -, a utilidade marginal de consumir bens produzidos em $F$ diminui. Desta maneira o Banco Central de $F$ pode produzir ganhos para o consumidor de seu país permitindo um menor hiato do produto, uma vez que as perdas geradas pelo menor consumo de bens produzidos internamente serão relativamente baixas e haverá um ganho de utilidade com a redução do total de horas trabalhadas. Em $t=1$, à medida que o hiato do produto do país $H$ cai - dado o choque negativo em sua taxa de juros natural -, a utilidade marginal do consumo da cesta bens produzidos no país $F$ aumenta. Deste modo passa a ser interessante para a autoridade monetária de $F$ expandir sua produção, uma vez que os ganhos de utilidade de consumir bens produzidos internamente estão relativamente altos para o seu consumidor representativo, ainda que isso implique em mais

\footnotetext{
${ }^{4}$ If $\sigma>1$, então $u_{H F}<0$ e os bens são substitutos, e se $\sigma<1$, então $u_{H F}>0$ e os bens são complementares.
} 
horas trabalhadas nessa localidade. Como esta é exatamente a movimentação contrária para o hiato do produto em relação a situação cooperativa, o país foreign dificulta os esforços feitos pela nação $H$ na estabilização de sua produção e inflação.

Embora as flutuações no hiato do produto sejam diferentes nos casos com e sem cooperação, pode-se notar que em ambas as situações a inflação e a taxa de juros nominal seguem processos relativamente semelhantes - com menor volatilidade para o cenário não-cooperativo -. Isso ocorre, pois a variabilidade na produção de bens no país $H$ é maior comparativamente a do país $F$ (ver figuras 4.2 e 4.3). Tomemos em consideração aqui a taxa de inflação em $t=2$ para o país foreign. Quando o país home expande sua produção, considerando que os bens são substitutos (i.e. $u_{F H}<0$ ), a utilidade marginal do consumo no país $F$ de bens produzidos em $F$ diminui, o que, consequentemente, leva a uma redução da oferta de mão-de-obra para a produção desses valores. Esta contração da oferta de trabalho aumenta os custos marginais reais das empresas, que em contrapartida aumentam os seus preços. É importante notar que esse efeito ofusca a repercussão da diminuição da produção de $F$ no caso não cooperativo, o que ceteris paribus levaria a um aumento na utilidade marginal do consumo dos bens produzidos em $F^{5}$. Portanto, uma vez que $x_{H, 2}$ e $x_{F, 2}$ se movem em direções opostas, na política não colaborativa observamos uma inflação menor em comparação com o caso cooperativo em $t=2$. Um raciocínio análogo pode ser feito para a inflação de $F$ em $t=1$, mas agora os movimentos de hiato do produto ocorrem em diferentes orientações, com $x_{H, 1}$ caindo e $x_{F, 1}$ aumentando.

A explicação para as flutuações observadas na da taxa de juros de $F$ também tem origem nas oscilações da produção dos dois países. Em $t=2$, como houve uma distorção relativamente alta do hiato do produto de $H$ é esperado $x_{H, 3}-x_{H, 2}<0$, o que ocasionaria em um impacto recessivo para o país foreign. A princípio, como já foi argumentado, esse efeito contracionista corrobora com os desejos do consumidor de $F$ que gosta de uma pequena queda em sua produção quando há um aumento no produto de $H$. Entretanto há um limite para o quanto os consumidores do país foreign se aproveitam desta contração, dado que conforme a produção de $F$ cai a utilidade marginal de consumir bens produzidos em $F$ aumenta. Deste modo, a fim de adequar a quantidade ideal de produção, o Banco Central de $F$ não cooperando reduz ligeiramente sua taxa de juros nominal, bloqueando parcialmente os efeitos recessivos provenientes da política monetária do país $H$, ainda deixando que ocorra uma queda em seu hiato do produto, mas não de maneira tão severa.

${ }^{5}$ Dado $u_{F F}<0$. 
Em $t=1 \mathrm{um}$ argumento semelhante pode ser feito, agora que $H$ está restrito, há uma probabilidade de um crescimento na produção de $H$ de $t=1$ para $t=2$ que estimularia a atividade econômica em $F$ acima do que deveria ser ótimo. Portanto esta também é em algum grau contida pela autoridade monetária de $F$ com um aumento da taxa de juros.

Fazendo uma digressão para os atributos analíticos das instruções monetárias ideais, é possível perceber que essas características, como no cenário de economia fechada, ocorrem devido à presença de multiplicadores de Lagrange associados às restrições de ZLB nas políticas cooperativas e não cooperativas, equações (4-2) e (4-3) respectivamente ${ }^{6}$ :

$$
\begin{aligned}
\frac{1}{\theta}\left(x_{j, t}-x_{j, t-1}\right)+\pi_{j, t}=\tilde{\Upsilon}_{1, j} \phi_{j, t}+\tilde{\Upsilon}_{2, j} \phi_{j, t-1}+\tilde{\Upsilon}_{3, j} \phi_{j, t-2}+ & \tilde{\Gamma}_{1, q} \phi_{q, t}+ \\
& \tilde{\Gamma}_{2, q} \phi_{q, t-1}+ \\
& +\tilde{\Gamma}_{3, q} \phi_{q, t-2},
\end{aligned}
$$

$$
\begin{aligned}
\Xi_{j}\left(x_{j, t}-x_{j, t-1}\right)+\gamma_{j} \pi_{j, t}=\hat{\Upsilon}_{1, j} \phi_{j, t}+ & \hat{\Upsilon}_{2, j} \phi_{j, t-1}+\hat{\Upsilon}_{3, j} \phi_{j, t-2}+\hat{\Gamma}_{1, q} \phi_{q, t}+ \\
& +\hat{\Gamma}_{2, q} \phi_{q, t-1}+\hat{\Gamma}_{3, q} \phi_{q, t-2}+\Omega_{q} \pi_{q, t}
\end{aligned}
$$

onde $q, j=H, F$ e $j \neq q$. Entretando agora não estão presentes somente multiplicadores locais, mas externos também (i.e. $\phi_{q, t}, \phi_{q, t-1}, \phi_{q, t-2}$ ), que serão responsáveis pela existência da já descritas características de dependência internacional das políticas monetárias ${ }^{7}$.

Por fim também é relevante mencionar que, quando a restrição do ZLB não é efetiva (i.e. $\phi_{H, t}=\phi_{F, t}=0, \forall t$ ), a política monetária ótima com e sem cooperação ainda apresentam resultados diferentes. No caso não cooperativo há a permanencia de algum grau de dependência internacional entre os Bancos Centrais, tendo em vista que a inflação exógena persiste nas regras ótimas:

$$
\Xi_{j}\left(x_{j, t}-x_{j, t-1}\right)+\gamma_{j} \pi_{j, t}=\Omega_{q} \pi_{q, t},
$$

onde $q, j=H, F$ e $j \neq q$. Por outro lado o caso cooperativo é intimamente relacionado com a situação de economia fechada ${ }^{8}$,

$$
\frac{1}{\theta}\left(x_{j, t}-x_{j, t-1}\right)+\pi_{j, t}=0,
$$

onde $j=H, F$, com as políticas ótimas sendo caracterizadas por autoridades

${ }^{6}$ Estas equações são obtidas manipulando as condições de primeira ordem dos problemas cooperativos e não-cooperativos dos Bancos Centrais.

${ }^{7}$ Uma análise dos parâmetros associados aos multiplicadores de Lagrange pode ser encontrada no apêndice.

${ }^{8}$ Basta colocar os multiplicadores de Lagrange igual a zero na equação (4-1) para que tal relação fique clara. 
monetárias focando sua atenção somente nos níveis de produto e inflação internos ${ }^{9}$.

\subsubsection{3}

\section{Mudando $\sigma$}
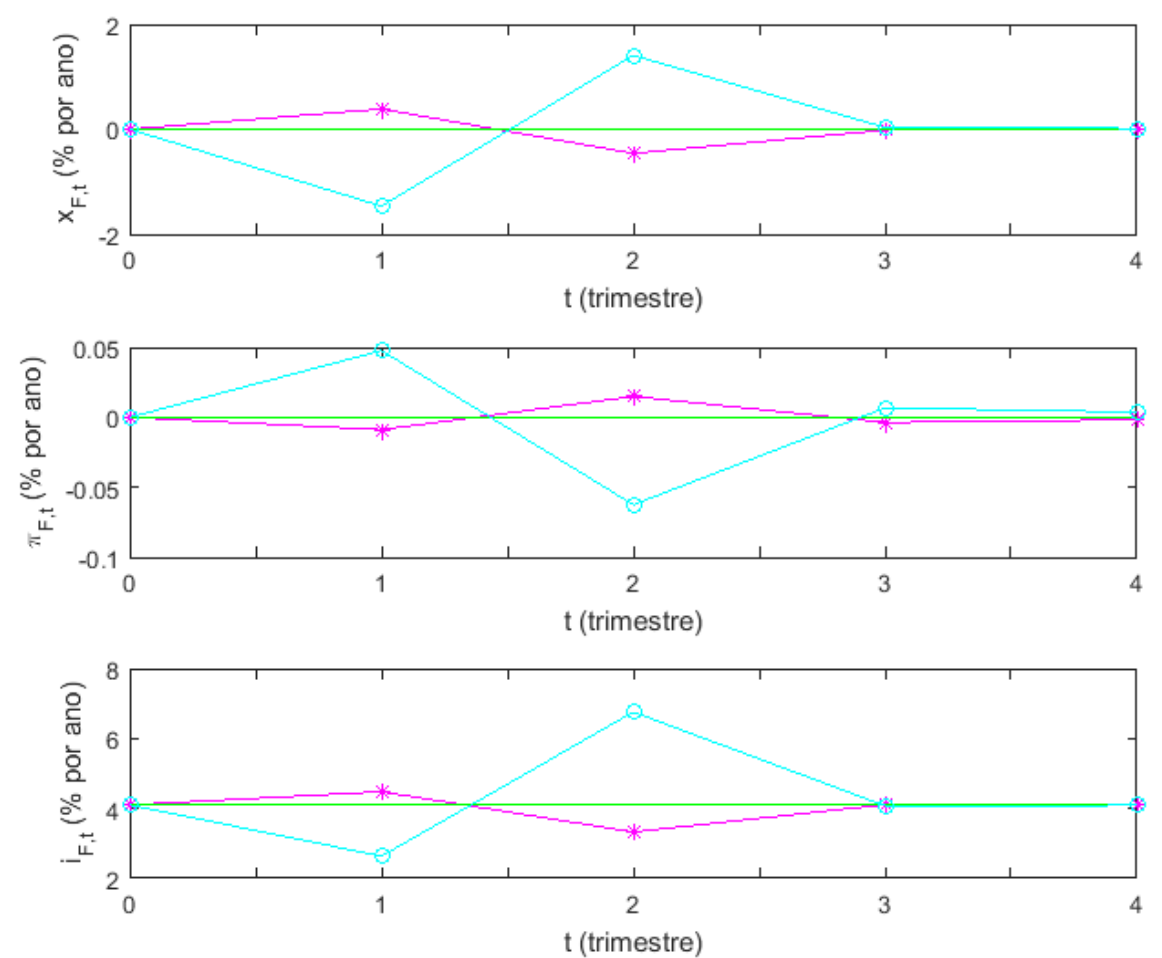

Figura 4.4: Política monetária ótima não cooperativa do país $F$ para diferentes valores de $\sigma\left(\tau_{H}=2\right.$; linha rosa com asteriscos: $\sigma=2$; linha verde: $\sigma=1$; linha azul claro com bolas: $\sigma=0.1$ ).

O parâmetro $\sigma$ desempenha um papel importante no modelo, já que é responsável pela determinação do grau de substituição dos bens produzidos em cada país. Para os resultados anteriores assumimos que os bens são substitutos, porém as características da relação internacional entre políticas ótimas estão completamente condicionadas a essa suposição. Como todos os canais de dependência internacional passam por como as flutuações no consumo do bem produzido externamente afetam a utilidade marginal do consumo do bem manufaturado internamente, alterações no caráter de substituição entre

${ }^{9}$ Para que esta conlusão esteja de acordo com o colocado por Clarida et. al (2002) é necessário que a definição da política ótima no caso dos autores esteja feita em termos do hiato do produto em relação ao equilíbrio de preços flexíveis globais, como é o caso deste artigo. 
tais produtos modificarão drasticamente as respostas produzidas pela política monetária ótima de um Banco Central a outro.

Uma vez que $\sigma$ tem pouco efeito sobre as características de dependência histórica, vamos voltar nossa atenção para as respostas do país $F$ relativamente à política implementada pelo país $H$ em uma situação não cooperativa (teremos aqui ainda o caso no qual somente o país $H$ sofre o choque com a duração de um período). Na figura 4.4 podemos observar que a política externa se altera completamente quando $\sigma$ passa de um valor maior para menor que um fazendo com que os bens produzidos em cada país mudem de substitutos para complementares -, com os movimentos nas taxas de juros, inflação e hiato do produto mudando de direção. Isso acontece, pois as alterações em $\sigma$ não só modificam o que a autoridade monetária do país foreign quer quando a produção de $H$ varia, mas também como os movimentos da produção em uma localidade afetam as taxas de juros reais e os custos marginais das firmas na outra.

Se $\sigma<1$ e os Bancos Centrais não cooperaram, quando $x_{H, t}$ for aumentado, uma vez que as cestas de bens são complementares uma a outra $\left(u_{F H}>0\right)$, a utilidade marginal de consumir bens do país foreign se expande. Como resultado os consumidores de $F$ preferem níveis mais altos de $x_{F, t}$ mesmo que eles tenham que trabalhar mais para isso. Além disso, dado que a utilidade marginal de consumir bens internos é afetada de maneira diferente pelas mudanças da produção externa, os custos marginais das firmas também serão afetados distintamente. Portanto a inflação nacional fica agora influenciada negativamente por um aumento no hiato do produto do país estrangeiro. Por fim as taxas de juros reais também acabam por ser perturbadas de forma diversa pelo crescimento do hiato de produção exterior, se os bens são complementares um crescimento esperado no outro país tem um efeito recessivo sobre a atividade econômica interna.

Podemos ainda notar que se $\sigma=1$ o país $F$ não responde a flutuações na política de $H$, possuindo a prescrição monetária ótima apenas qualidades advindas dos traços de dependência histórica. No entanto, as relações são de fato mais profundas que isso, se computarmos a política ótima nos ambientes cooperativos e não-cooperativos com $\sigma=1$ é possível constatar que estas tomam o mesmo formato da equação (4-1), implicando que em todas as configurações discutidas previamente (economia fechada, cooperação e não cooperação) apresentarão as mesmas características ${ }^{10}$. Isso, entretanto, não quer dizer que todos os casos produzirão os mesmos caminhos para a inflação

\footnotetext{
${ }^{10}$ Para isso ser observado basta colocar $\sigma=1$ nas equações (4-2) e (4-3) ((7-80) e (7-87) no apêndice).
} 
e o hiato do produto, já que $n_{H}=1$ e $\sigma=1$ produzem repercuções diferentes sobre a economia loglinearizada (isto é, as equações ISs e ASs) ${ }^{11}$.

\subsection{2}

\section{Armadilha da liquidez global}

Agora apresentamos o ambiente mais complexo de uma armadilha de liquidez global, no qual não apenas um, mas ambos os países se encontram restringidos pelo $Z_{L B}{ }^{12}$. Na figura 4.5 temos $H$ e $F$ sofrendo o choque descrito em suas taxas de juros naturais, com essa perturbação permanecendo durante uma quatidade de períodos diferente para cada localidade ${ }^{13}$.
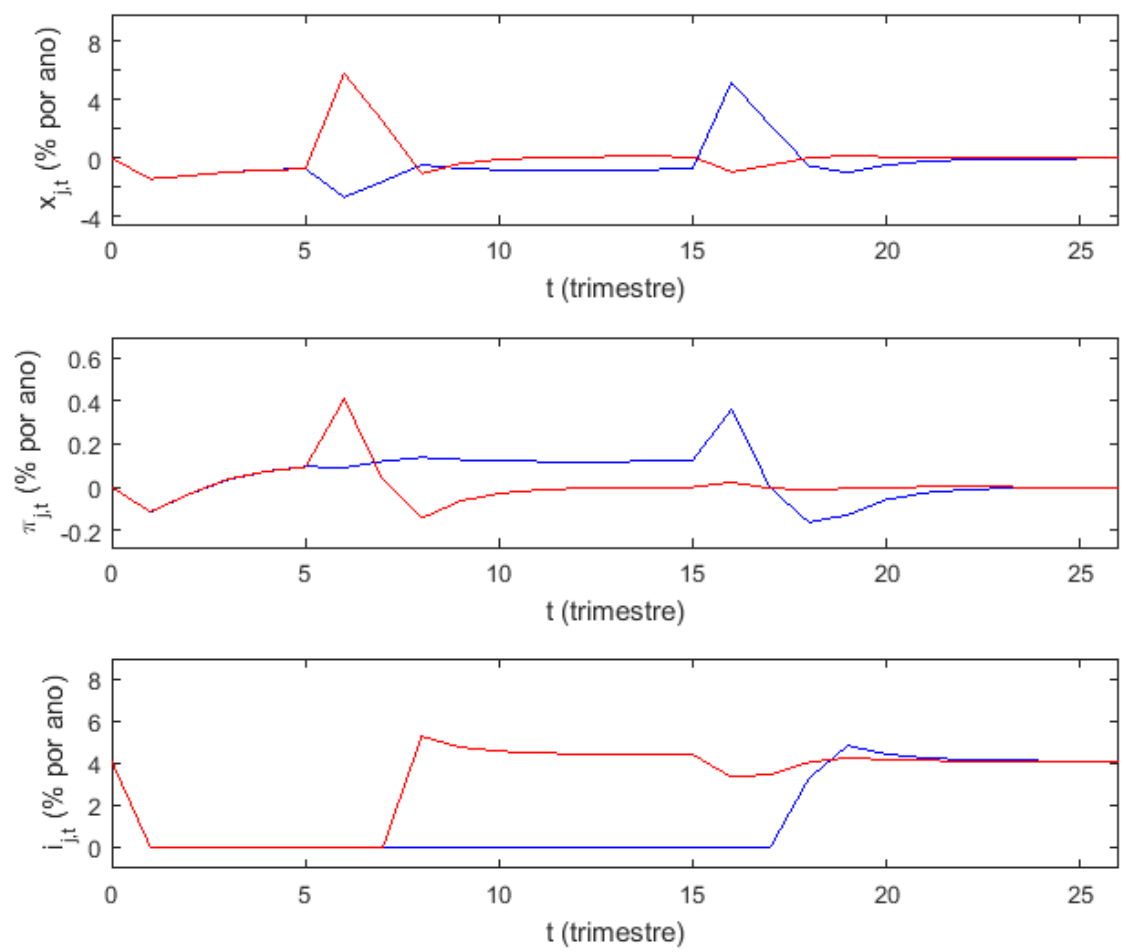

Figura 4.5: Política monetária ótima não cooperativa $\left(j=H, F ; \sigma=2 ; \tau_{F}=6\right.$; $\tau_{H}=16$; linha vermelha: país $F$; linha azul: país $\left.H\right)$.

Neste cenário é possível verificar a permanência das características de dependência histórica da política monetária, com ambos os Bancos Centrais elevando seu hiato de produção e inflação uma vez que o choque é revertido em seu país. Isto é feito, assim como na seção anterior, mantendo-se as taxas de

${ }^{11}$ Porém as políticas ótimas cooperativas e não cooperativas produzirão os mesmos resultados.

${ }^{12}$ Para esta seção também estamos assumindo os valores dos parâmetros do caso base expostos na tabela 4.1 .

${ }^{13}$ Vale ressaltar novamente que os agentes economicos não possuem conhecimento prévio dos valores de $\tau_{H}$ e $\tau_{F}$. 
juros de política monetária em zero mais alguns períodos após a taxa natural ter retornado a seu valor de estado estacionário, evidente em $t=6,16$ na figura 4.5. É relevante observar que isso ocorre mesmo se o impacto inicial atingiu as economias em $t=1$ e se reverteu apenas muitos períodos à frente, o raciocínio por trás desse fato pode ser melhor entendido considerando a equação IS iterada para $H^{14}$ :

$$
\begin{gathered}
x_{H, t}=E_{t} \sum_{j=0}^{\tau_{H}-1}\left[\Theta_{1} E_{t+j}\left(x_{F, t+1+j}-x_{F, t+j}\right)+\Theta_{2}\left(r_{H, t+j}^{n}+E_{t+j} \pi_{H, t+1+j}\right)\right]+ \\
\sum_{i=\tau_{H}}^{\infty}\left[\Theta_{1} E_{t+j}\left(x_{F, t+1+j}-x_{F, t+j}\right)+\Theta_{2}\left(r_{H, t+j}^{n}-\left(i_{H, t+j}-E_{t+j} \pi_{H, t+1+j}\right)\right)\right] \\
\Theta_{1}=\frac{(\sigma-1) n_{F}}{1+(\sigma-1) n_{H}} \\
\Theta_{2}=\frac{1}{1+(\sigma-1) n_{H}} .
\end{gathered}
$$

Aqui o hiato do produto de $H$ é dado pelo crescimento do hiato da produção de $F$ mais o hiato dos juros. Imaginando que os valores de $\tau_{H}$ e $\tau_{F}$ sejam sabidos, para os primeiros $\tau_{H}-1$ períodos, quando $H$ tem sua política monetária restringida, tudo o que o Banco Central pode fazer para mitigar a perturbação em $r_{H, t}^{n}$ é trazer sua taxa nominal para zero. No entanto, em $t>\tau_{H}-1$, uma vez que estamos assumindo commitment, se a autoridade monetária se compromete, em vez de retornar sua taxa de juros para o valor natural - neste momento maior do que zero -, mantê-la no ZLB isso ocasionaria em uma contra resposta à perturbação recessiva ocorrida em $t=1$. Tal fato se dá, não somente pelos efeitos da manutenção de um baixo nível de juros nominal futuro - o que propicia uma maior sequência de hiato de juros -, mas também pela geração de maiores inflações esperadas.

Ademais disso, observando a equação AS iterada para o país $H$,

$$
\pi_{H, t}=E_{t} \sum_{i=0}^{\infty} \beta^{i}\left(\gamma_{H} x_{h, t+i}+\gamma_{H F} n_{F} x_{F, t+i}\right),
$$

é possível notar que um aumento na sequência de hiatos de produção gera expectativas de inflação que novamente revertem como um incrementos adicionais positivos sob a produção de $H$ em sua curva IS. A probabilidade de inflação, na equação (4-6), ajuda a reduzir os juros reais aumentando o hiato da taxa de juros mesmo em períodos em que a política monetária se encontra restrita.

Aqui é essencial ressaltar a importância do fato de que esta sinalização

${ }^{14} \mathrm{O}$ racional para o país $F$ será análogo. 
pela autoridade monetária tem de ser crível pelos agentes econômicos, visto que, quando o Banco Central não se encontra mais restringido pelo limite inferior zero para sua taxa nominal de juros, esse é tentado a não produzir as distorções com as quais se comprometera. Isso pode ser observado na equação (2-45), onde para um determinado período e um nível adequado de atividade externa, a perda de um país específico tende a aumentar para maiores valores de inflação e de hiato do produto. De maneira que há um teto para o que a parte de dependência histórica da política monetária pode atingir para mitigar as implicações recessivas da efetividade da restrição ZLB.

Ademais, quando analisamos a situação de uma armadilha de liquidez global com economias abertas em um cenário não cooperativo, obtemos duas reações principaís de um país para a política ótima implementada pela autoridade monetária externa. Em primeiro lugar a dependência internacional entre as escolhas dos dois Bancos Centrais pode ser vista na figura $4.5 \mathrm{em} t=6$, quando há uma queda no hiato do produto do país $H$ durante o término do choque na nação $F$. Estas flutuações podem ser explicadas por um estímulo negativo na taxa real de $H$ - dado que é esperado $x_{F, \tau_{F}+1}-x_{F, \tau_{F}}<0$ - que não pode ser acomodado pelo Banco Central do país home, uma vez que a taxa nominal de juros está em seu limite inferior, gerando assim uma queda no hiato do produto de $H$. Esse fator de dependência entre as políticas é dado pelo fato de que a nação home está restrita quando $F$ sai da armadilha de liquidez, de maneira que é intuitivo afirmar que esse movimento é comum em ambos os casos cooperativos e não cooperativos, uma vez que as duas políticas ótimas apresentam características similares de dependência histórica (figura 4.2) ${ }^{15}$.

Outro atributo importante da relação internacional entre os dois Bancos Centrais acontece quando a perturbação na taxa natural de juros termina no país $H$, em $t=16$, e verificamos uma queda no hiato do produto de $F$. A queda esperada da atividade de $H$ é moderadamente contida pela autoridade monetária de $F$ com uma queda em $i_{F, t}$, mas não completamente dado o fato de que o consumidor do país foreign se beneficiaria com um produto ligeiramente menor enquanto é observado um hiato da produção alto no país home, conforme o que fora discutido na seção anterior.

\subsection{3}

\section{Análise de bem-estar}

Analisando a disposição da perda totdal do país $H^{16}$ com a situação da armadilha global da liquidez para diferentes valores de $\tau_{H}$ e $\tau_{F}$ (figura 4.6),

${ }^{15}$ Tal fato pode ser visto em $t=6$ na figura 7.1 no apêndice.

${ }^{16}$ A perda total aqui esta sendo computada de acordo com a equação (2-44). 


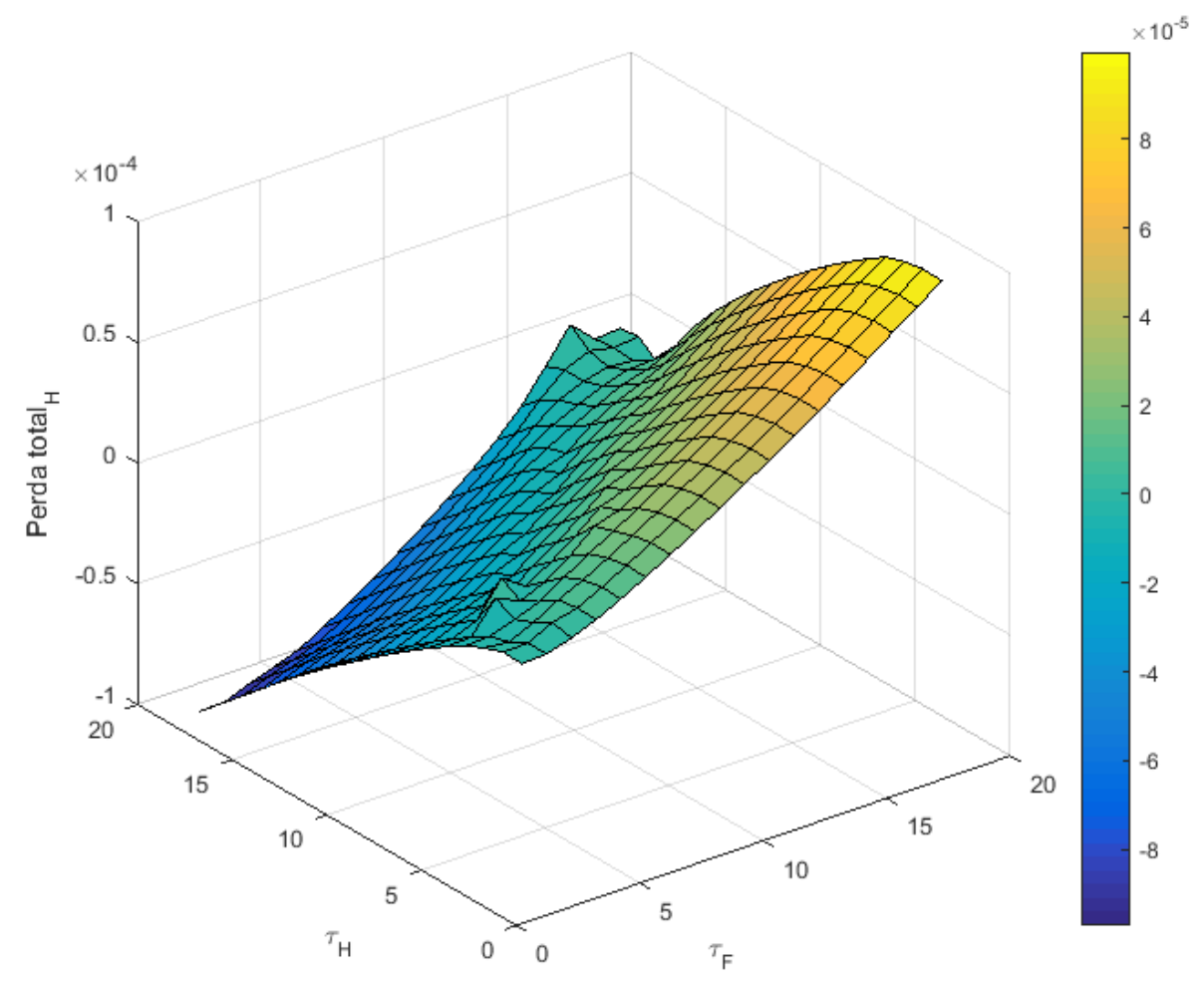

Figura 4.6: Soma descontada da perda do país $H$ para diferentes valores de $\tau_{F}$ and $\tau_{H}$.

encontramos à primeira vista alguns resultados contra intuitivos. Nota-se que um Banco Central prefere, uma vez em uma armadilha global da liquidez, ficar restrito pelo ZLB o maior número de períodos possível e que a autoridade monetária externa saia dessa situação o quanto antes. Resultado este contrário ao que a priori se esperaria, tendo em vista que intuitivamente Bancos Centrais não gostariam de ter sua política bloqueada e possivelmente teriam alguma vantagem competitiva sobre a outra nação o quanto mais tempo esta ficasse com suas ações limitadas.

A favor de rastrear as razões por trás destes resultados pode ser útil observar como é a colocação das perdas de bem-estar para os dois países em cada ponto no tempo ${ }^{17}$ para valores específicos de $\tau_{H}$ e $\tau_{F}$, apresentado pela figura 4.7. Em primeiro lugar é válido mencionar que durante os períodos iniciais, quando ambas as economias se encontram numa situação de armadilha de liquidez (ou seja, $t<6$ ), estas não parecem sentir grande desconforto com a vinculação da restrição do ZLB para as suas taxas de juros nominais. Além disso, a maior parte da perda de um país é gerada durante o período em que o choque termina neste local, quando, como colocado anteriormente, o Banco

\footnotetext{
${ }^{17}$ A perda de bem-estar aqui esta sendo computado de acordo com a equação (2-45).
} 

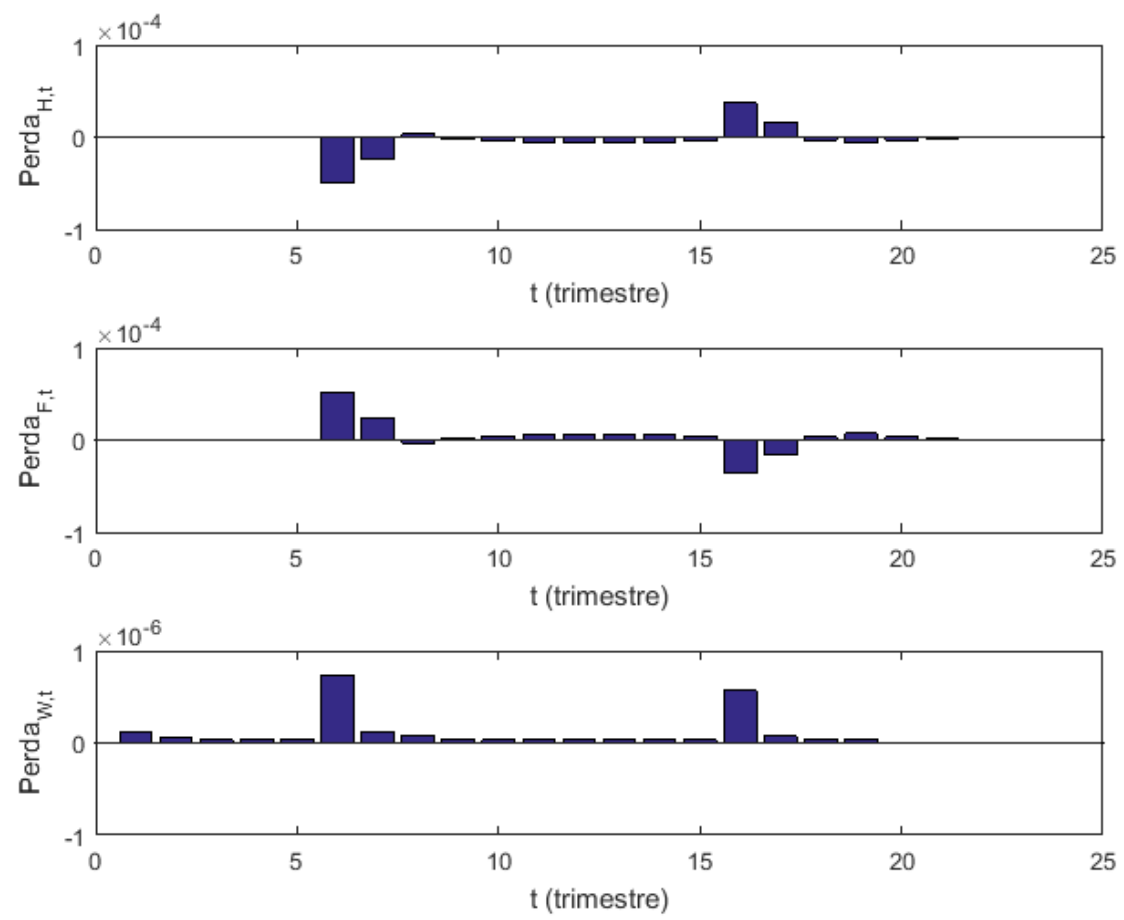

Figura 4.7: Valor da função perda $\left(\tau_{F}=6 ; \tau_{H}=16\right)$.

Central nacional gera altos níveis de inflação e hiato de produção, os quais usalmente não são apreciados pelos consumidores internos. Por outro lado a maior parte dos ganhos de bem-estar ocorre exatamente quando o impacto sobre a taxa de juros natural se dissipa na outra nação e a autoridade monetária nacional diminui o hiato do produto, seja por escolha própria ou porque o Banco Central local se encontra restrito. Assim sendo uma justificativa inicial do porquê um governo anseia por uma perturbação duradoura domesticamente e também prefere o fim precoce das limitações da política monetária externa, baseia-se no fato de que este cenário faz com que o dano de bem-estar maior aconteça somente em um futuro mais distante, tendo, portanto, um valor presente menor. Enquanto os benefícios de diminuir o hiato do produto quando o outro país aumenta o seu próprio ocorrem mais cedo no tempo, levando a um ganho de utilidade mais considerável, posto que estes terão um valore presente maior.

No entanto este não é o único argumento que legitima esses resultados. Considerando que a figura 4.7 mostra que a maioria das variações de bemestar acontece nas datas $\tau_{H}$ e $\tau_{F}$, se inspecionarmos a imagem $4.8^{18}$ é possível reconhecer que a perda para o país $H$ em $t=\tau_{H}$ é maior quando a taxa de juros

\footnotetext{
${ }^{18} \mathrm{~A}$ função apresenta esse formato em $\tau_{H}=\tau_{F}$, porque um país não pode tirar proveito da outra nação quando o choque acaba ao mesmo tempo em ambos os lugares, visto que os Bancos Centrais estão comprometidos a produzir uma política expansionista nesta data.
} 


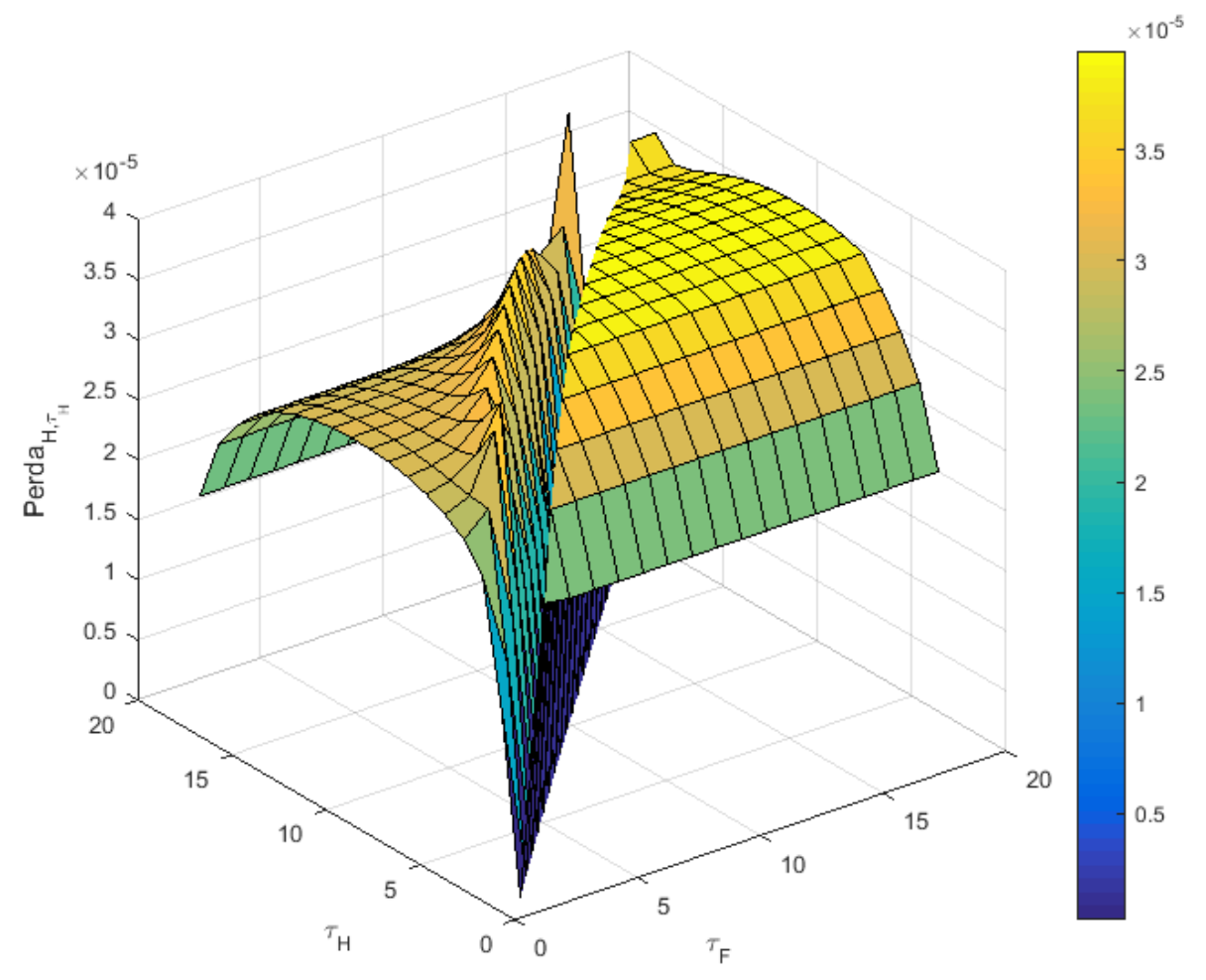

Figura 4.8: Perda de $H$ em $t=\tau_{H}$ para diferentes valores de $\tau_{H}$ e $\tau_{F}$.

natural demora mais para retornar ao seu valor de estado estacionário na nação foreign do que o país home (ou seja, $\tau_{H}<\tau_{F}$ ). Além disso, na figura $4.9^{19}$, é evidente que o ganho de $H$ em $t=\tau_{F}$ é maior se $\tau_{H}>\tau_{F}$. Assim, sem levar em conta o desconto intertemporal de eventos futuros, essas observações também apontam para a predileção de um Banco Central por uma maior longevidade para a perturbação em seu país do que no outro. Isto porque o ganho, na data do maior ganho, será maior e a perda, na data da maior perda, será menor.

Essa dinâmica pode ser sustentada pela natureza da dependência histórica da política ótima de $F$, que ajuda o país $H$ enquanto este ainda está em uma armadilha de liquidez. Tomando o caso de $\tau_{H}=16$ e $\tau_{F}=6$ em consideração (figura 4.5), após o pico em $x_{F, t}$ e $\pi_{F, t}^{*}$ em $t=\tau_{F}$ o Banco Central do país foreign aumenta a taxa de juros nominal acima de $r_{\text {high }}^{n}$ antes de faze-la progressivamente convergir para seu valor de estado estacionário. Esta queda contínua da taxa de juros gera um crescimento no hiato de produção do país $F$ em grande parte do período de $t \in\left(\tau_{F}, \tau_{F}\right)$, que ajuda a localidade home com incrementos positivos em sua IS, diminuindo assim a necessidade desta fazer distorções tão grandes na data $\tau_{H}$. É importante salientar que essa reação das taxas de juros nominais por parte da nação $F$ é vista tanto no exercício

${ }^{19}$ Idem. 


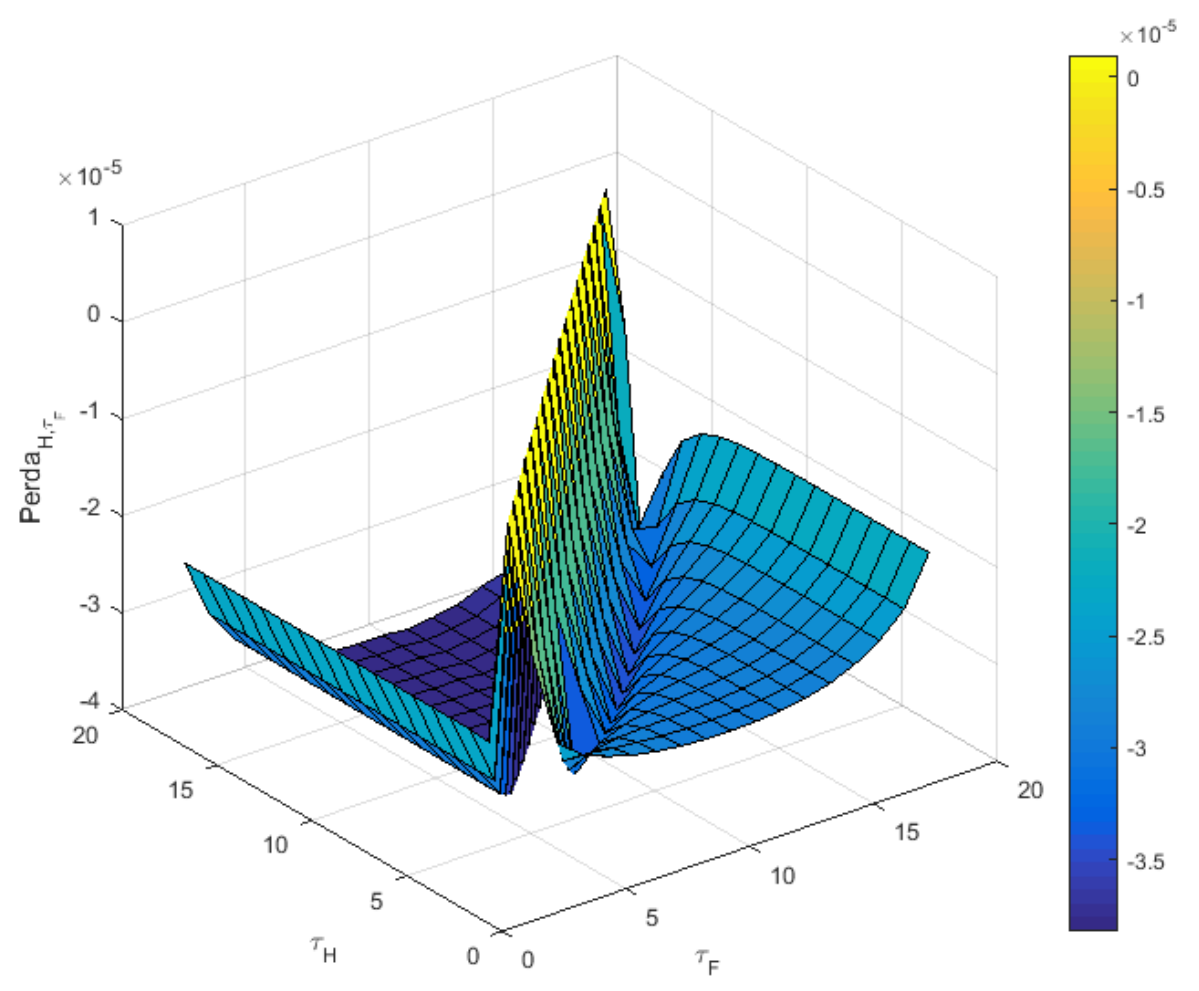

Figura 4.9: Perda de $H$ em $t=\tau_{F}$ para diferentes valores de $\tau_{H}$ e $\tau_{F}$.

de Eggertsson e Woodford (2003) quanto no de Fujiwara (2013). Portanto a perda de $H$ em $\tau_{H}$ é reduzida em comparação com a de $F$ em $\tau_{F}$ e os ganhos possíveis de $F$ em $\tau_{H}$ são reduzidos relativamente aos de $H$ em $\tau_{F}$. Além disso, durante $t \in\left(\tau_{H}, \tau_{F}\right)$ o hiato do produto do país $F$ permanece durante grande parte do tempo acima do de $H$, que está se recuperando lentamente dos efeitos recessivos da situação da armadilha de liquidez, prporcionando assim ganhos adicionais para a nação home $e^{20}$.

\subsection{4}

\section{Análise de sensibilidade}

Nosso objetivo agora é examinar a robustez dos achados anteriores, realizando uma análise de sensibilidade destes. Assim é ncessaria uma base de comparação para estabelecer a dimensão da distância entre o resultados apresentados pelas políticas ótimas com e sem cooperação. Para tanto vamos adotar o caso em que ambos os países fazem o uso de uma regra de metas de inflação como o pior cenário possível. Nesta situação os Bancos Centrais agem então de acordo com:

${ }^{20} \mathrm{O}$ mesmo argumento já feito, que uma localidade prefere um produto ligeiramente inferior, uma vez que a nação externa apresenta uma maior produção, se aplica neste caso. 

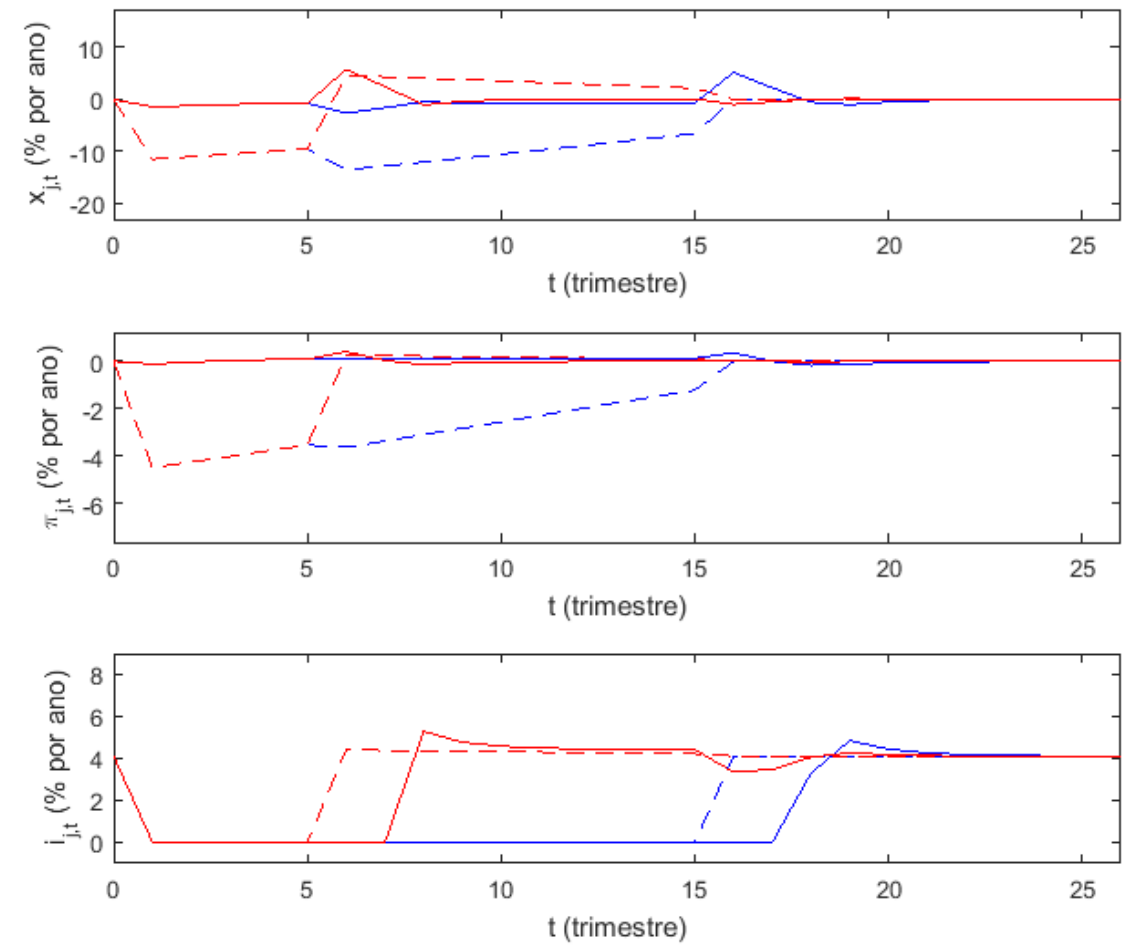

Figura 4.10: Regra de metas de inflação $(\bar{\pi}=0)$ vs Política monetária ótima não cooperativa $\left(j=H, F ; \tau_{F}=6 ; \tau_{H}=16\right.$; linha azul: país $H$; linha vermelha: país $F$; linha sólida: política ótima não cooperativa; linha pontilhada: regra de metas de inflação).

$$
\begin{gathered}
i_{H, t}=\phi_{\pi}\left(\pi_{H, t}-\bar{\pi}_{H}\right)+r_{H, t}^{n}, \\
i_{F, t}=\phi_{\pi}\left(\pi_{F, t}-\bar{\pi}_{F}\right)+r_{F, t}^{n},
\end{gathered}
$$

onde a meta de inflação $\left(\bar{\pi}_{j}, j=H, F\right)$ em cada local é definida como zero $^{21}$, de maneira que tenhamos no estado estacionário não inflacionário $i_{j, t}=r_{j, t}^{n}=r_{h i g h}^{n}$, com $j=H, F$. Observa-se na figura 4.10 que esse tipo de política gera respostas muito diferentes das configurações ótimas. Assim que a taxa natural cai para valores negativos, a autoridade monetária enfrenta um problema de desejar uma taxa de juros nominal menor que zero e deste modo é levada em uma armadilha de liquidez. Além disso, tendo em vista que um Banco Central não tem capacidade de se comprometer com ações futuras, parte significativa dos efeitos recessivos e deflacionários da queda de $r_{j, t}^{n}(\operatorname{com} j=H, F)$ não podem ser diminuídos. Dessa forma não há sentido na produção das distorções anteriormente discutidas, geradas pelas políticas monetárias ótimas. Destarte logo que $r_{j, \text { low }}^{n}$ retorna para $r_{j, h i g h}^{n}, i_{j, t}$ também

\footnotetext{
${ }^{21} \phi_{\pi}$ é calibrado para 1.1.
} 
retorna para $r_{j, h i g h}^{n}(j=H, F)$.

Tabla 4.2: Soma descontada da perda de cada país e do mundo $\left(\tau_{H}=16 \mathrm{e}\right.$ $\left.\tau_{F}=6\right)$.

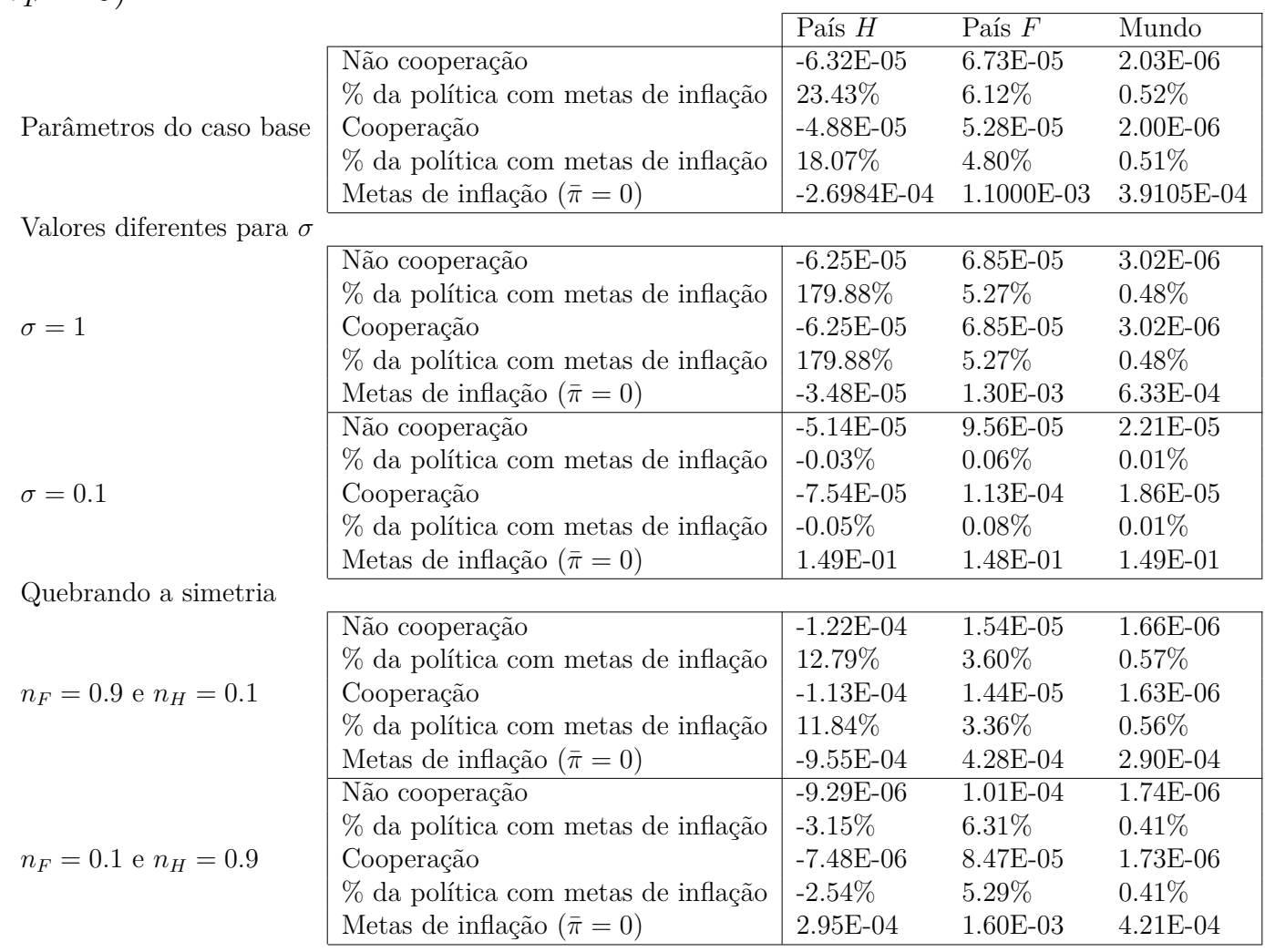

Na tabela 4.2 é calculada a soma da perda descontada de cada país, equação (2-44), e do mundo, equação (2-39), para valores específicos de $\tau_{H}$ e $\tau_{F}$. Em primeiro lugar é possível notar que nos casos da política ótima não cooperativa o país home apresentou uma perda menor em comparação com $F$, porquanto o choque persistiu lá por um númeor maior de períodos (ou seja, $\left.\tau_{H}>\tau_{F}\right)$, havndo ai um indício de robustez da questão tratada na seção anterior. Também se voltarmos nossa atenção para o cenário onde $\sigma=1$ pode-se notar que não há diferenças de bem-estar entre as perdas geradas pela política ótima cooperativa e não cooperativa, em razão de que todos os canais de dependência internacional são cancelados permanecendo somente o lado de dependência histórica da prescrição monetária, sendo este o mesmo em ambos os casos. Outra conclusão significativa que resulta destas comparações é que, embora existam diferenças entre as políticas ótimas, a colaboração ou não-colaboração por parte das autoridades monetárias não geram perdas de bem-estar significativamente diferentes uma a outra quando comparadas a um regra de metas de inflação, apontando para o fato de que talvez os ganhos de cooperar não sejam tão substanciais.

Não obstante as observações feitas serem válidas quando a simetria dos 

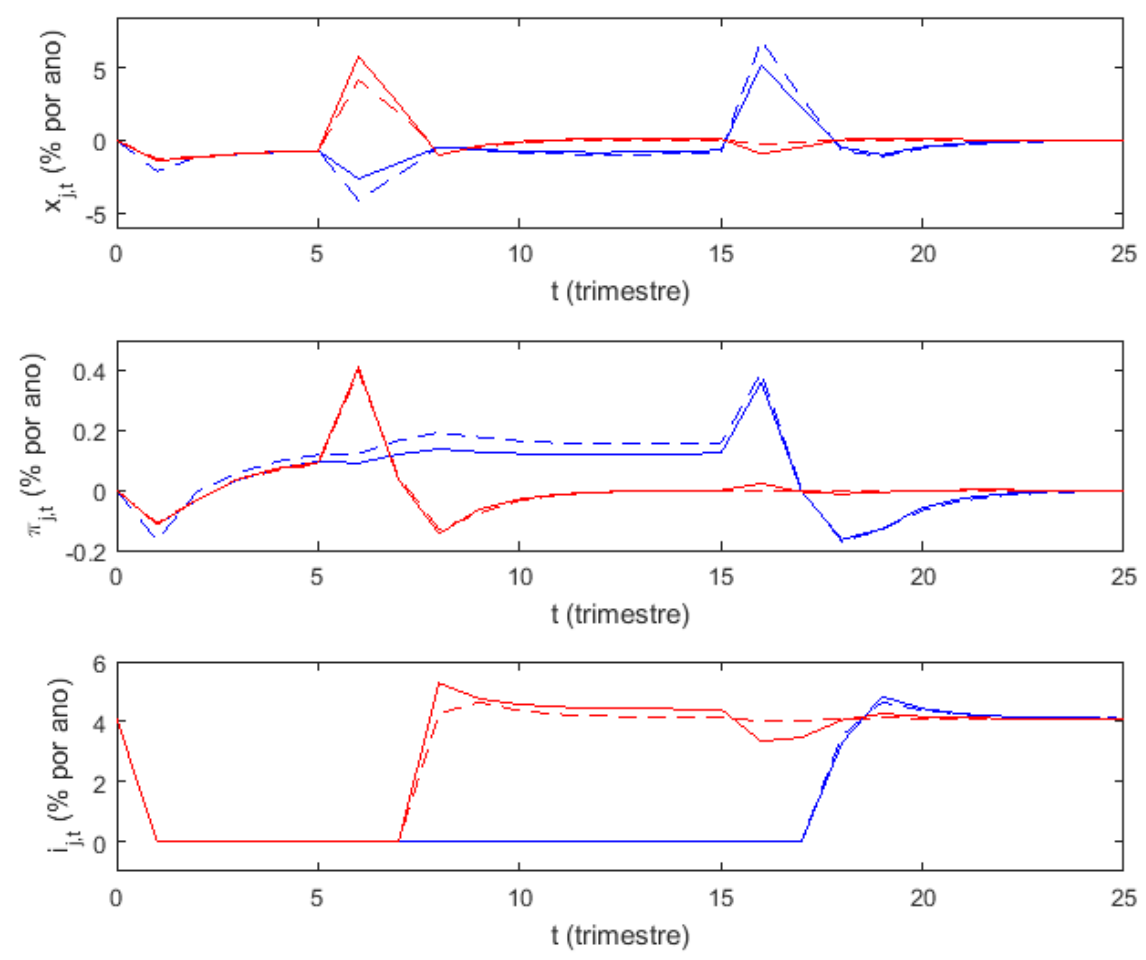

Figura 4.11: Política monetária ótima não cooperativa para diferentes tamanhos de países $\left(j=H, F ; \tau_{F}=6 ; \tau_{H}=16\right.$; linha vermelha: país $F$; linha azul: país $H$; linha sólida: $n_{H}=n_{F}=0.5$; linha pontilhada: $n_{H}=0.1$ e $\left.n_{F}=0.9\right)$.

países é quebrada (isto é $n_{H} \neq n_{F}$ ), é atraente investigar mais detalhadamente como é o desenvolvimento das políticas não-cooperativas nesse ambiente. É possível notar algumas diferenças na maneira como a dependência histórica e a dependência internacional ocorrem se os países tiverem tamanhos desiguais. Focando a atenção à figura 4.11, é evidente que a extensão das nações influencia a intensidade com que as escolhas de política em um local se propagam para o outro. Notamos que a magnitude da resposta da dependência internacional de um Banco Central é inversamente proporcional ao tamanho de seu país. Além disso, a imagem 4.11 mostra que o vigor das características de dependência histórica é condicionada às dimensões de $n_{H}$ e $n_{F}$, de tal forma que quanto maior o país menor a necessidade de gerar enormes distorções quando o choque passa internamente, posto que as perturbações intencionais negativas produzem um impacto recessivo menor em uma nação maior em $t=1$. 


\section{5 \\ Conclusão}

Assim sendo a política monetária ótima quando os Bancos Centrais não coordenam suas ações é caracterizada, como no cenário colaborativo, por dois tipos de atributos: dependência histórica e dependência internacional. A primeira apresentou os mesmos traços que os casos do ambiente cooperativo e o cenário de economia fechada. A segunda, particular para situações de economia aberta, envolveu um formato diferente para cada uma das condições não cooperativas e cooperativas. Além disso, observamos que, quando em uma armadilha de liquidez global, as autoridades monetárias preferem permanecer nesta situação por longos períodos enquanto o outro país saia desse estado rapidamente. Por fim tem-se ainda que estas conclusões parecem ser robustas à mudanças no grau de substituição entre os bens produzidos em cada local e modificações no tamanho dos países.

Concluindo, entende-se que a análise do tema deste artigo não está esgotada nesta investigação inicial. Nossos resultados são tão bons quanto os pressupostos realizados, de maneira que pesquisas adicionais precisam ser conduzidas para fortalecer as observações aqui feitas. Novos estudos podem abordar algumas simplificações impostas, tais como: a elasticidade de substituição entre bens domésticos e estrangeiros é assumida como sendo igual a um, choques tecnológicos ou de preferências podem ser incluídos em vez de perturbações exógenas nas taxas de juros naturais, choques que apresentam diferentes processos poderiam ser admitidos e uma situação em que os países não sejam igualmente ricos pode ser endereçada entre outras. 


\section{6}

\section{Refências bibliográficas}

ADAM, K., BILLI.. Optimal Monetary Policy under Commitment with a Zero Bound on Nominal Interest Rates. Journal of Money, Credit and Banking, v. 38, p. $1877-1905,2006$.

ADAM, K., BILLI.. Optimal Monetary Policy under Commitment with a Zero Bound on Nominal Interest Rates. Journal of Monetary Economics, v. 54, p. 728752, 2007.

BAHATTARAI, S., EGOROV, K.. Optimal Monetary and Fiscal Policy at the Zero Lower Bound in a Small Open Economy. Mimeo, 2016.

BENIGNO, G., BENIGNO, P.. Price Stability in Open Economies. The Review of Economic Studies, v. 70, p. 743-764, 2003.

CLARIDA, R.. Monetary policy in open economies: Practical perspectives for pragmatic central bankers. Journal of Economic Dynamics and Control, v. 49, p. 21-30, 2014.

CLARIDA, R., GALI, J., GERTLER, M.. Optimal monetary policy in open versus closed economies: an integrated approach. American Economic Review, v. 91, p. 248-252, 2001.

CLARIDA, R., GALI, J., GERTLER, M.. A simple framework for international monetary policy analysis. Journal of Monetary Economics, v. 49 , p. 879-904, 2002.

COENEN, G., WIELAND, V.. The zero-interest-rate bound and the role of the exchange rate for monetary policy in Japan. Journal of Monetary Economics, v. 50, p. 1071-1101, 2003.

COOK, D., DEVEREUX, M.. Optimal Fiscal Policy in a World Liquidity Trap. European Economic Review. v. 55, p. 443-462, 2011

CORSETTI, G., PESENTI , P.. Welfare and macroeconomic interdependence. The Quarterly Journal of Economics, v. 116, p. 421-445, 2001. 
CORSETTI, G., PESENTI , P.. International dimensions of optimal monetary policy. Journal of Monetary Economics, v. 52, p. 281-305, 2005.

DEVEREUX, M., ENGEL, C.. Monetary policy in the open economy revisited: price setting and exchange-rate flexibility. The Review of Economic Studies, v. 70 , p. 765-783, 2003.

EGGERTSSON, G.. The Deflation Bias and Committing to Being Irresponsible. Journal of Money, Credit and Banking, v.38, p. 283-321, 2006.

EGGERTSSON, G., WOODFORD, M.. The zero bound on interest rates and optimal monetary policy. Brookings Papers on Economic Activity, p. 139-211, 2003.

FAIA, E., MONACELLI, T.. Optimal Monetary Policy in a Small Open Economy with Home Bias. Journal of Money, Credit, and Banking, v. 40, p. 721-50, 2008.

FUJIWARA, I., NAKAJIMA, T., SUDO,N., TERANISHI, Y.. Global Liquidity Trap. NBER Working Papers, 2011.

FUJIWARA, I., NAKAJIMA, T., SUDO,N., TERANISHI, Y.. Global Liquidity Trap. Journal of Monetary Economics, v. 60, p. 936-949, 2013.

GALI, J., MONACELLI, T.. Monetary Policy and Exchange Rate Volatility in a Small Open Economy. The Review of Economic Studies, v. 72, p. 707-734, 2005.

HABERIS, A., LIPINSKA, A.. International Policy Spillovers at the Zero Lower Bound. Mimeo, 2015

IDA, D.,. Optimal monetary policy rules in a two-country economy with a zero bound on nominal interest rates. North American Journal of Economics and Finance, v. 24, p. 223-242, 2013.

JEANNE, O.. The Global Liquidity Trap. Mimeo, 2009.

JUNG, T., TERANISHI, Y., WATANABE, T.. Optimal monetary policy at the zero-interest-rate bound. Journal of Money, Credit and Banking, v. 37, p. 813-835, 2005.

KATO, R., NISHIYAMA, S.. Optimal monetary policy when interest rates are bounded at zero. Journal of Economic Dynamics and Control, v. I29, p. 97-133, 2005.

KRUGMAN, P.. It's Baaack! Japan's Slump and the Return of the Liquidity Trap. Brookings Papers on Economic Activity, p. 137-87, 1998. 
NAKAJIMA, T.. Liquidity trap and optimal monetary policy in open economies. Journal of the Japanese and International Economies, v. 22, p.1-33, 2008.

NAKATA, T.. Optimal fiscal and monetary policy with occasionally binding zero bound constraints. Journal of Economic Dynamics and Control, v. 73, p. 220-240, 2016.

NAKOV, A.. Optimal and simple monetary policy rules with zero floor on the nominal interest rate. International Journal of Central Banking, v. 4, p. 73-127, 2008.

NGO, P.. Optimal discretionary monetary policy in a micro-founded model with a zero lower bound on nominal interest rate. Journal of Economic Dynamics and Control, v.45, p. 44-65, 2014.

REIFSCHNEIDER, D., WILLIAMS, J.. Three lessons for monetary policy in a lowinflation era. Journal of Money, Credit and Banking, v. 32, p. 936-966, 2000.

WOODFORD, M.. Interest and Prices: Foundations of a Theory of Monetary Policy. Princeton University Press, 2003. 


\section{7}

\section{Apêndice}

\subsection{1}

\section{Modelo}

\subsubsection{1}

\section{Consumidor do país $F$ e condições de primeira ordem}

O consumidor representativo de $F$ maximiza:

$$
U_{F, 1}=E_{1} \sum_{t=1}^{\infty} \beta^{t-1}\left[u\left(C_{t}^{*}\right)-\frac{1}{n_{F}} \int_{N_{F}} v\left(l_{t}^{*}(i)\right) d i\right],
$$

onde $C_{t}^{*}$ é o índice de consumo de bens produzicos em cada um dos países e consumidos em $F, l_{t}^{*}(i)$ é a oferta de trabalho para a produção do bem $i \in N_{F}$.

$$
C_{t}^{*}=\left(\frac{C_{H, t}^{*}}{n_{H}}\right)^{n_{H}}\left(\frac{C_{F, t}^{*}}{n_{F}}\right)^{n_{F}}
$$

onde $C_{j, t}^{*} j=H, F$ são índices de bens produzidos em $F$ e $H$ consumidos em $F$ com formato Dixit-Stigliz,

$$
C_{j, t}^{*}=\left[n_{j}^{-1 / \theta} \int_{N_{j}} c_{t}^{*}(i)^{(\theta-1) / \theta} d i\right]^{\theta /(\theta-1)}, j=H, F .
$$

e essa maximixação é feita sujeito à seguinte restrição orçamentária,

$$
\begin{gathered}
\epsilon_{t} P_{t}^{*} C_{t}^{*}+E_{t} Q_{t, t+1} \epsilon_{t+1} W_{t+1}^{*}=\epsilon_{t} W_{t}^{*}+\int_{N_{F}} \epsilon_{t}\left(w_{t}^{*}(i) l_{t}^{*}(i)+\Pi_{t}^{*}(i)\right) d i+T_{t} \\
E_{t} Q_{t, t+1}^{*}=E_{t} Q_{t, t+1} \frac{\epsilon_{t+1}}{\epsilon_{t}}
\end{gathered}
$$

e ao limite "natural da dívida"

$$
-W_{t+1}^{*} \leq \sum_{T=t+1}^{\infty} E_{t+1} Q_{t+1, T}^{*}\left[\int_{N_{H}}\left(w_{t+1}^{*}(i) l_{t+1}^{*}(i)+\Pi_{t+1}^{*}(i)\right) d i+T_{t}^{*}\right]
$$

onde

$$
Q_{t, T}^{*} \equiv \prod_{s=t+1}^{T} Q_{s-1, s}^{*}
$$

As condições de primeira ordem (CPOs) do consumidor de $F$ em relação à $\left\{C_{t}^{*}, l_{t}^{*}(i), W_{t}^{*}(i)\right\}$ são:

$$
\beta \frac{\tilde{u}_{C}\left(C_{t+1}^{*}\right)}{\tilde{u}_{C}\left(C_{t}^{*}\right)}=Q_{t, t+1} \frac{P_{t+1}}{P_{t}},
$$




$$
\frac{1}{n_{F}} \frac{\tilde{v}_{l}\left(l_{t}^{*}(i)\right)}{\tilde{u}_{C}\left(C_{t}^{*}\right)}=\frac{w^{*}(i)}{P_{t}^{*}}, \quad i \in N_{F} .
$$

Analogamente as CPOs do consumidor de $H$ em relação à $\left\{C_{t}, l_{t}(i), W_{t}(i)\right\}$ são:

$$
\begin{gathered}
\beta \frac{\tilde{u}_{C}\left(C_{t+1}\right)}{\tilde{u}_{C}\left(C_{t}\right)}=Q_{t, t+1} \frac{P_{t+1}}{P_{t}}, \\
\frac{1}{n_{H}} \frac{\tilde{v}_{l}\left(l_{t}(i)\right)}{\tilde{u}_{C}\left(C_{t}\right)}=\frac{w(i)}{P_{t}}, i \in N_{H} .
\end{gathered}
$$

Se reescrevermos as CPOs em relação à $C_{j, t}$ e $C_{j, t}^{*}(j=H, F)$ para ambos os consumidores representativos obtemos:

$$
\begin{gathered}
\beta \frac{u_{H}\left(C_{H, t+1}, C_{F, t+1}\right)}{u_{H}\left(C_{H, t}, C_{F, t}\right)}=\beta \frac{u_{H}\left(C_{H, t+1}^{*}, C_{F, t+1}^{*}\right)}{u_{H}\left(C_{H, t}^{*}, C_{F, t}^{*}\right)}=Q_{t, t+1} \frac{P_{H, t+1}}{P_{H, t}}, \\
\beta \frac{u_{F}\left(C_{H, t+1}, C_{F, t+1}\right)}{u_{F}\left(C_{H, t}, C_{F, t}\right)}=\beta \frac{u_{F}\left(C_{H, t+1}^{*}, C_{F, t+1}^{*}\right)}{u_{F}\left(C_{H, t}^{*}, C_{F, t}^{*}\right)}=Q_{t, t+1} \frac{P_{F, t+1}}{P_{F, t}} \\
\frac{1}{n_{H}} \frac{\tilde{v}_{l}\left(l_{t}(i)\right)}{u_{H}\left(C_{H, t}, C_{F, t}\right)}=\frac{w(i)}{P_{H, t}} \\
\frac{1}{n_{F}} \frac{\tilde{v}_{l}\left(l_{t}^{*}(i)\right)}{u_{F}\left(C_{H, t}^{*}, C_{F, t}^{*}\right)}=\frac{w(i)}{P_{F, t}^{*}}, \\
\frac{u_{F}\left(C_{H, t}, C_{F, t}\right)}{u_{H}\left(C_{H, t}, C_{F, t}\right)}=\frac{u_{F}\left(C_{H, t}^{*}, C_{F, t}^{*}\right)}{u_{H}\left(C_{H, t}^{*}, C_{F, t}^{*}\right)}=\frac{\epsilon_{t} P_{F, t}^{*}}{P_{H, t}}
\end{gathered}
$$

\subsubsection{2}

\section{Produto natural}

A minimização de custos implica nas seguintes relações de demanda para o consumidor representativo em $H$ :

$$
\begin{gathered}
c_{t}(i)=n_{j}^{-1} C_{j, t}\left(\frac{p_{t}(i)}{P_{j, t}}\right)^{-\theta}, j=H, F, \\
C_{j, t}=n_{H} C_{t}\left(\frac{P_{j, t}}{p_{t}}\right)^{-1}, j=H, F .
\end{gathered}
$$

Isto posto, podemos explicitar como são dados os lucros de uma firma monopolista na produção do bem $i$. Com as condições de market clearing e as escolhas ótimas dos consumidores obtemos

$$
\begin{array}{r}
n_{H} \Pi_{t}(i)=(1+\eta) p_{t}(i) y_{t}(i)-w_{t}(i) n_{H} l_{t}(i)=\left[(1+\eta) p_{t}(i)-\frac{w_{t}(i)}{A}\right] y_{t}(i)= \\
=\left[(1+\eta) p_{t}(i)-\frac{w_{t}(i)}{A}\right] n_{H}^{-1} Y_{H, t}\left(\frac{p_{t}(i)}{P_{H, t}}\right)^{-\theta}
\end{array}
$$

Para explicitarmos o produto natural (ou seja, o produto em equilíbrio global de preços flexíveis) é necessário computar as escolhas ótimas das firmas quando estas podem escolher seus preços em cada período de maneira a manximizar 
seu lucro. As CPOs da resolução de tal problema implicam que:

$$
\frac{w_{t}(i)}{A P_{H, t}}=\frac{p_{t}(i)}{P_{H, t}}(1+\eta) \frac{\theta-1}{\theta}=\frac{p_{t}(i)}{P_{H, t}}(1-\Phi),
$$

onde $\Phi$ são as distorções criadas por competição imperfeita. Manipulando as CPOs dos consumidores não é difícil ver que

$$
\frac{w_{t}(i)}{A P_{H, t}}=\frac{v_{y}\left(y_{t}(i)\right)}{u_{H}\left(Y_{H, t}, Y_{F, t}\right)},
$$

onde $\tilde{v}\left(l_{t}(i)\right)=v\left(\frac{y_{t}(i)}{A n_{H}}\right) \equiv v\left(y_{t}(i)\right)$. De maneira que no equilíbrio de preços flexíveis temos

$$
\frac{v_{y}\left(Y_{H, t}^{n} / n_{H}\right)}{u_{H}\left(Y_{H, t}^{n}, Y_{F, t}^{n}\right)}=(1-\Phi) \text {. }
$$

O caso para o país $F$ é análogo, então loglinearizando essas equações em torno do estado estacionário com inflação zero obtemos:

$$
\begin{aligned}
& \left(\omega+1+n_{H}\right) x_{H}^{e}+n_{F}(\sigma-1) x_{F}^{e} \approx \Phi \\
& \left(\omega+1+n_{F}\right) x_{F}^{e}+n_{H}(\sigma-1) x_{H}^{e} \approx \Phi^{*}
\end{aligned}
$$

onde $x_{j}^{e}=\log Y_{j}^{e}-\log \bar{Y}_{j}, Y_{j}^{e}$ é o produto eficiente do país $j$ (i.e. $\left.v_{y}\left(Y_{j, t}^{e}\right) / u_{j}\left(Y_{j, t}^{e}, Y_{q, t}^{e}\right)=1\right), q, j=H, F, q \neq j$. Assim sendo assumindo que o governo subsidia as empresas com o fim de eliminar as distorções de competição imperfeita (i.e. $\eta=1 /(\theta-1)$ ), o nível de produção no estado estacionário eficiente será igual ao produto natural.

\subsubsection{3}

\section{Curva IS}

Loglinearizando as CPOs do consumidor,

$$
\begin{aligned}
& E_{t} \beta \frac{\tilde{u}_{C}\left(C_{t+1}\right)}{\tilde{u}_{C}\left(C_{t}\right)}=E_{t} Q_{t, t+1} \frac{P_{t+1}}{P_{t}}, \\
& E_{t} \beta \frac{\tilde{u}_{C}\left(C_{t+1}^{*}\right)}{\tilde{u}_{C}\left(C_{t}^{*}\right)}=E_{t} Q_{t, t+1}^{*} \frac{P_{t+1}^{*}}{P_{t}^{*}},
\end{aligned}
$$

temos

$$
\begin{aligned}
& -r_{t}=-i_{H, t}+E_{t} \pi_{t+1}, \\
& -r_{t}=-i_{F, t}+E_{t} \pi_{t+1}^{*},
\end{aligned}
$$

onde $r_{t}=-\log E_{t}\left[\beta \frac{\tilde{u}_{C}\left(C_{t+1}^{*}\right)}{\tilde{u}_{C}\left(C_{t}^{*}\right)}\right]=-\log E_{t}\left[\beta \frac{\tilde{u}_{C}\left(C_{t+1}\right)}{\tilde{u}_{C}\left(C_{t}\right)}\right], i_{H, t}=-\log E_{t} Q_{t, t+1}$, $i_{F, t}=-\log E_{t} Q_{t, t+1}^{*}, E_{t} \pi_{t+1}=\log E_{t} \frac{P_{t+1}}{P_{t}}$ e $E_{t} \pi_{t+1}^{*}=\log E_{t} \frac{P_{t+1}^{*}}{P_{t}^{*}} . \delta_{t+1}$ é a variação nos termos de troca definida como

$$
\delta_{t+1}=\log \frac{P_{H, t+1}}{P_{F, t+1}}-\log \frac{P_{H, t}}{P_{F, t}}=\pi_{H, t+1}-\pi_{F, t+1}=\log \frac{Y_{F, t+1}}{Y_{F, t}}-\log \frac{Y_{H, t+1}}{Y_{H, t}}
$$


onde a terceira igualdade vem das CPOs dos consumidores. Fazendo o uso das definiçôes de $P_{t}$ e $P_{t}^{*}$ podemos reescrever

$$
\begin{aligned}
& \pi_{t+1}=n_{H} \pi_{H, t+1}+n_{F} \pi_{F, t+1}, \\
& \pi_{t+1}^{*}=n_{H} \pi_{H, t+1}^{*}+n_{F} \pi_{F, t+1}^{*},
\end{aligned}
$$

então, combinando as equações acima, a taxa nominal de juros pode ser expressa como

$$
\begin{aligned}
& i_{H, t}=r_{t}-n_{F} E_{t} \delta_{t+1}+E_{t} \pi_{H, t+1}, \\
& i_{H, t}=r_{t}+n_{H} E_{t} \delta_{t+1}+E_{t} \pi_{F, t+1}^{*} .
\end{aligned}
$$

Podemos definir então a taxa de juros natural e a mudança natural nos termos de troca como

$$
\begin{gathered}
r_{t}^{n}=-\log E_{t} \beta \frac{\tilde{u}_{C}\left(Y_{t+1}^{n}\right)}{\tilde{u}_{C}\left(Y_{t}^{n}\right)}, \\
\delta_{t+1}^{n}=\log \frac{Y_{F, t+1}^{n}}{Y_{F, t}^{n}}-\log \frac{Y_{H, t+1}^{n}}{Y_{H, t}^{n}} .
\end{gathered}
$$

Com as equações (7-34) e (7-35) podemos manipular as expressões (7-32) e (7-33) chegando nas relações IS para cada país

$$
\begin{array}{r}
i_{H, t}=E_{t}\left[\left(1+(\sigma-1) n_{H}\right)\left(x_{H, t+1}-x_{H, t}\right)+(\sigma-1) n_{F}\left(x_{F, t+1}-x_{F, t}\right)+\pi_{H, t+1}\right]+ \\
+r_{H, t}^{n}
\end{array}
$$

$$
\begin{array}{r}
i_{F, t}=E_{t}\left[\left(1+(\sigma-1) n_{F}\right)\left(x_{F, t+1}-x_{F, t}\right)+(\sigma-1) n_{H}\left(x_{H, t+1}-x_{H, t}\right)+\pi_{F, t+1}^{*}\right]+ \\
+r_{F, t}^{n}
\end{array}
$$

\subsubsection{4}

\section{Curva AS}

Com preços rígidos à Calvo (1983) as firmas escolhem $p_{t}(i)$ que maximiza

$$
E_{t} \sum_{T=t}^{\infty} \alpha^{T-t} Q_{t, T}\left[(1+\eta) p_{t}(i)-\frac{w_{T}(i)}{A}\right] \frac{Y_{H, T}}{n_{H}}\left[\frac{p_{t}(i)}{P_{H, T}}\right]^{-\theta}
$$

Então a condição de primeira ordem desse problema conjuntamente com a equalção (7-22) implica em

$$
E_{t} \sum_{T=t}^{\infty} \alpha^{T-t} Q_{t, T} \frac{Y_{H, T}}{n_{H}}\left[\frac{p_{t}^{o}(i)}{P_{H, T}}\right]^{-\theta-1}\left[\frac{v_{y}\left(y_{T}(i)\right)}{u_{H}\left(Y_{H, T}, Y_{F, T}\right)}-(1-\Phi) \frac{p_{t}^{o}(i)}{P_{H, T}}\right]=0
$$

onde $p_{t}^{o}(i)$ é o preço escolhido pela firma na produção do bem $i$. Se chamarmos $s_{t}=\frac{v_{y}\left(y_{t}(i)\right)}{u_{H}\left(Y_{H, t}, Y_{F, t}\right)}$ "o custo marginal real"na produção de $i$ e loglinearzando essa 
expressão em torno do estado estcionário obtemos

$$
E_{t} \sum_{T=t}^{\infty}(\alpha \beta)^{T-t}\left[\hat{s}_{t, T}-\left(\hat{p}_{t}^{o}(i)+\sum_{\tau=t+1}^{T} \pi_{H, \tau}\right)\right]=0
$$

onde, como em Woodford (2003),

$$
\hat{s}_{t, T}=\hat{s}_{t}-\omega \theta\left(\hat{p}_{t}^{o}(i)-\sum_{\tau=t+1}^{T} \pi_{H, \tau}\right)
$$

onde $\hat{s}_{t}=\log \frac{s_{t}}{1-\Phi}$ e $\hat{p}_{t}^{o}(i)=\log \frac{p_{t}^{o}(i)}{P_{H, t}}$. Aproximando $\hat{s}_{t}$ em torno do estado estacionário

$$
\hat{s}_{t}=\left((\sigma-1) n_{H}+1+\omega\right) x_{H, t}+n_{F}(\sigma-1) x_{F, t} .
$$

Ademais disso, é possível observar, como em Woodoford (2003),

$$
P_{H, t}^{1-\theta}=(1-\alpha) p_{t}^{o}(i)^{1-\theta}+\alpha P_{H, t-1}^{1-\theta},
$$

entao pode-se escrever

$$
\pi_{H, t}=\frac{1-\alpha}{\alpha} \hat{p}_{t}^{o}(i)
$$

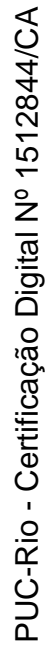

Combinado as equações (7-40), (7-41), (7-42) e (7-44) chegamos na relação AS para $H$,

$$
\pi_{H, t}=\gamma_{H} x_{H, t}+\gamma_{H F} n_{F} x_{F, t}+\beta E_{t} \pi_{H, t+1} .
$$

O processo para a AS de $F$ é similar.

\subsubsection{5}

\section{Aproximação da utilidade do consumidor}

A utilidade do consumidor pode ser escrita como:

$$
\begin{array}{r}
U_{H, 1}=E_{1} \sum_{t=1}^{\infty} \beta^{t-1} \tilde{U}_{H, t}=E_{1} \sum_{t=1}^{\infty} \beta^{t-1}\left[\tilde{u}\left(C_{t}\right)-\frac{1}{n_{H}} \int_{N_{H}} \tilde{v}\left(l_{t}(i)\right) d i\right]= \\
=E_{1} \sum_{t=1}^{\infty} \beta^{t-1}\left[u\left(C_{H, t}, C_{F, t}\right)-\frac{1}{n_{H}} \int_{N_{H}} v\left(y_{t}(i)\right) d i\right] .
\end{array}
$$

Se definirmos

$$
\int_{N_{H}} v\left(y_{t}(i)\right) d i=n_{H} v\left(\frac{Y_{H, t}}{n_{H}}\right) \Delta_{H, t}, \quad \Delta_{H, t}=\frac{1}{n_{H}} \int_{N_{H}}\left(\frac{p_{t}(i)}{P_{H, t}}\right)^{-\sigma(1+\omega)},
$$

é possível escrever

$$
U_{H, 1}=E_{1} \sum_{t=1}^{\infty} \beta^{t-1}\left[u\left(C_{H, t}, C_{F, t}\right)-v\left(\frac{Y_{H, t}}{n_{H}}\right) \Delta_{H, t}\right] .
$$

Aproximando a utilidade do consumo e a desutilidade do trabalho em torno do estado estacionário temos 


$$
\begin{array}{r}
u\left(C_{H, t}, C_{F, t}\right) \approx \frac{\bar{u}_{H} \bar{Y}_{H}}{n_{H}}\left[n_{H} \hat{Y}_{H, t}+\frac{1}{2} n_{H}^{2}(1-\sigma) \hat{Y}_{H, t}^{2}+n_{F} \hat{Y}_{F, t}+\frac{1}{2} n_{F}^{2}(1-\sigma) \hat{Y}_{F, t}^{2}+\right. \\
\left.+n_{H} n_{F}(1-\sigma) \hat{Y}_{H, t} \hat{Y}_{F, t}\right]+ \text { t.i.p. },
\end{array}
$$

$$
\begin{aligned}
v\left(\frac{Y_{H, t}}{n_{H}}\right) \Delta_{H, t} \approx \frac{\bar{u}_{H} \bar{Y}_{H}}{n_{H}}\left[(1-\Phi) \hat{Y}_{H, t}+\right. & \frac{1}{2}(1+\omega)(1-\Phi) \hat{Y}_{H, t}^{2}+ \\
& \left.+\frac{1-\Phi}{1+\omega} \hat{\Delta}_{H, t}\right]+ \text { t.i.p. },
\end{aligned}
$$

onde $\bar{Y}_{j, t}$ é o valor de estado estacionário para o produto do país $j$ e $\hat{Y}_{j, t}=$ $\log \frac{Y_{j, t}}{\bar{Y}_{j, t}}$. Assim obtemos

$$
\begin{array}{r}
\tilde{U}_{H, t} \approx \frac{\bar{u}_{H} \bar{Y}_{H}}{n_{H}}\left[\left(n_{H}-1+\Phi\right) \hat{Y}_{H, t}+\frac{1}{2}\left(n_{H}^{2}(1-\sigma)-(1+\omega)(1-\Phi)\right) \hat{Y}_{H, t}^{2}+n_{F} \hat{Y}_{F, t}+\right. \\
\left.+\frac{1}{2} n_{F}^{2}(1-\sigma) \hat{Y}_{F, t}^{2}+n_{H} n_{F}(1-\sigma) \hat{Y}_{H, t} \hat{Y}_{F, t}-\frac{1-\Phi}{1+\omega} \hat{\Delta}_{H, t}\right]+ \text { t.i.p.. }
\end{array}
$$

Como em Woodford (2003) é possível escrever a seguinte relação

$$
\sum_{t=1}^{\infty} \beta^{t-1} \frac{\hat{\Delta}_{H, t}}{1+\omega} \approx \theta \frac{\alpha(1+\omega \theta)}{(1-\alpha)(1-\alpha \beta)} \sum_{t=1}^{\infty} \beta^{t-1} \frac{\pi_{H, t}^{2}}{2}+\text { t.i.p. . }
$$

Entâo combinando as duas expressões acima e o fato que o produto de estado estacionário é o mesmo que o produto natural chegamos em:

$$
\begin{array}{r}
U_{H, 1}=E_{1} \sum_{t=1}^{\infty} \tilde{U}_{H, t} \approx-\frac{\bar{u}_{H} \bar{Y}_{H}}{n_{H}} \frac{\theta}{\zeta} E_{1} \sum_{t=1}^{\infty} \beta^{t-1}\left\{\frac { \zeta } { \theta } \left[\left(1-n_{H}\right) x_{H, t}-n_{F} x_{F, t}+\right.\right. \\
\left.+\frac{1}{2}\left((\sigma-1) n_{H}+1+\omega\right) x_{H, t}^{2}+\frac{1}{2} n_{F}^{2}(\sigma-1) x_{F, t}^{2}+(\sigma-1) n_{H} n_{F} x_{H, t} x_{F, t}\right]+ \\
\left.+\frac{1}{2} \pi_{H, t}^{2}\right\}+t . i . p . .
\end{array}
$$

O caso para a utilidade do consumidor de $F$ é análogo.

\subsubsection{6}

\section{Aproximação da utilidade do mundo}

A utilidade do mundo pode ser expressa por: 


$$
\begin{array}{r}
U_{W, 1}=n_{H} U_{H, 1}+n_{F} U_{F, 1}=E_{1} \sum_{t=1}^{\infty} \beta^{t-1} \tilde{U}_{W, t}=E_{1} \sum_{t=1}^{\infty} \beta^{t-1}\left[u\left(C_{H, t}, C_{F, t}\right)-\right. \\
\left.\quad-\frac{1}{n_{H}} \int_{N_{H}} v\left(y_{t}(i)\right) d i-\frac{1}{n_{F}} \int_{N_{F}} v^{*}\left(y_{t}^{*}(i)\right) d i\right] .
\end{array}
$$

Definindo

$$
\begin{aligned}
& \int_{N_{H}} v\left(y_{t}(i)\right) d i=n_{H} v\left(\frac{Y_{H, t}}{n_{H}}\right) \Delta_{H, t}, \quad \Delta_{H, t}=\frac{1}{n_{H}} \int_{N_{H}}\left(\frac{p_{t}(i)}{P_{H, t}}\right)^{-\sigma(1+\omega)}, \\
& \int_{N_{F}} v^{*}\left(y_{t}^{*}(i)\right) d i=n_{F} v\left(\frac{Y_{F, t}}{n_{F}}\right) \Delta_{F, t}, \quad \Delta_{F, t}=\frac{1}{n_{F}} \int_{N_{F}}\left(\frac{p_{t}^{*}(i)}{P_{F, t}^{*}}\right)^{-\sigma(1+\omega)},
\end{aligned}
$$

é possível escrever que

$$
U_{W, 1}=E_{1} \sum_{t=1}^{\infty} \beta^{t-1}\left[u\left(C_{H, t}, C_{F, t}\right)-n_{H} v\left(\frac{Y_{H, t}}{n_{H}}\right) \Delta_{H, t}-n_{F} v\left(\frac{Y_{F, t}}{n_{F}}\right) \Delta_{F, t}\right] .
$$

Aproximando a utilidade de consumir e a desutilidade de trabalhar em torno do estado estacionário nós temos

$$
\begin{aligned}
& u\left(C_{H, t}, C_{F, t}\right) \approx \frac{\bar{u}_{H} \bar{Y}_{H}}{n_{H}}\left[n_{H} \hat{Y}_{H, t}+\frac{1}{2} n_{H}^{2}(1-\sigma) \hat{Y}_{H, t}^{2}+n_{F} \hat{Y}_{F, t}+\frac{1}{2} n_{F}^{2}(1-\sigma) \hat{Y}_{F, t}^{2}+\right. \\
& \left.+n_{H} n_{F}(1-\sigma) \hat{Y}_{H, t} \hat{Y}_{F, t}\right]+ \text { t.i.p. } \\
& n_{H} v\left(\frac{Y_{H, t}}{n_{H}}\right) \Delta_{H, t} \approx \frac{\bar{u}_{H} \bar{Y}_{H}}{n_{H}}\left[n_{H}(1-\Phi) \hat{Y}_{H, t}+n_{H} \frac{1}{2}(1+\omega)(1-\Phi) \hat{Y}_{H, t}^{2}+\right. \\
& \left.+n_{H} \frac{1-\Phi}{1+\omega} \hat{\Delta}_{H, t}\right]+ \text { t.i.p. } \\
& n_{F} v\left(\frac{Y_{F, t}}{n_{F}}\right) \Delta_{F, t} \approx \frac{\bar{u}_{H} \bar{Y}_{H}}{n_{H}}\left[n_{F}\left(1-\Phi^{*}\right) \hat{Y}_{F, t}+n_{F} \frac{1}{2}(1+\omega)\left(1-\Phi^{*}\right) \hat{Y}_{F, t}^{2}+\right. \\
& \left.+n_{F} \frac{1-\Phi^{*}}{1+\omega} \hat{\Delta}_{F, t}\right]+t . i . p .
\end{aligned}
$$

Assim sendo obtemos 


$$
\begin{gathered}
\tilde{U}_{W, t} \approx \frac{\bar{u}_{H} \bar{Y}_{H}}{n_{H}}\left[n_{H} \Phi \hat{Y}_{H, t}+n_{F} \Phi^{*} \hat{Y}_{F, t}+\frac{n_{H}}{2}\left(n_{H}(\sigma-1)-(1+\omega)(1-\Phi)\right) \hat{Y}_{H, t}^{2}+\right. \\
\left.+\frac{n_{F}}{2}\left(n_{F}(\sigma-1)-(1+\omega)\left(1-\Phi^{*}\right)\right) \hat{Y}_{F, t}^{2}-\frac{n_{H}(1-\Phi)}{1+\omega} \hat{\Delta}_{H, t}-\frac{n_{F}\left(1-\Phi^{*}\right)}{1+\omega} \hat{\Delta}_{F, t}\right]+
\end{gathered}
$$

Como em Woodford (2003) é possível escrever as seguintes relações

$$
\begin{aligned}
& \sum_{t=1}^{\infty} \beta^{t-1} \frac{\hat{\Delta}_{H, t}}{1+\omega} \approx \theta \frac{\alpha(1+\omega \theta)}{(1-\alpha)(1-\alpha \beta)} \sum_{t=1}^{\infty} \beta^{t-1} \frac{\pi_{H, t}^{2}}{2}+t . i . p . \\
& \sum_{t=1}^{\infty} \beta^{t-1} \frac{\hat{\Delta}_{F, t}}{1+\omega} \approx \theta \frac{\alpha(1+\omega \theta)}{(1-\alpha)(1-\alpha \beta)} \sum_{t=1}^{\infty} \beta^{t-1} \frac{\pi_{F, t}^{* 2}}{2}+t . i . p . .
\end{aligned}
$$

Entâo combinando as três expressões acima e o fato que o produto de estado estacionário é o mesmo que o produto natural chegamos em:

$$
U_{W, 1} \approx E_{1} \sum_{t=1}^{\infty} \beta^{t-1}\left\{\frac{1}{2} x_{t}^{\prime} \Lambda x_{t}+\frac{n_{H}^{2}}{2} \pi_{H, t}^{2}+\frac{n_{F}^{2}}{2} \pi_{F, t}^{* 2}\right\}+\text { t.i.p. }
$$

\subsubsection{7}

\section{Problema não cooperativo}

O problema do Banco Central do país $j=H, F$ no cenário não cooperativo pode ser expresso pelo seguinte Lagrangeano ${ }^{1}$ :

$$
\begin{array}{r}
\mathcal{L}=E_{1} \sum_{t=1}^{\infty} \beta^{t-1}\left\{\frac { \zeta } { \theta } \left[\left(1-n_{j}\right) x_{j, t}-n_{q} x_{q, t}+\right.\right. \\
\left.+\frac{1}{2}\left((\sigma-1) n_{j}+1+\omega\right) x_{j, t}^{2}+\frac{1}{2} n_{q}^{2}(\sigma-1) x_{q, t}^{2}+(\sigma-1) n_{j} n_{q} x_{j, t} x_{q, t}\right]+\frac{1}{2} \pi_{j, t}^{2}+ \\
+\psi_{j, t}\left[\pi_{j, t}-\gamma_{j} x_{j, t}-\gamma_{H F} n_{q} x_{q, t}-\beta \pi_{j, t+1}\right]+ \\
\left.+\phi_{j, t}\left[\left(1+(\sigma-1) n_{j}\right)\left(x_{j, t}-x_{j, t+1}\right)+(\sigma-1) n_{q}\left(x_{q, t}-x_{q, t+1}\right)-\pi_{j, t+1}-r_{j, t}^{n}\right]\right\} .
\end{array}
$$

Entao temos como equilíbrio de políticas ótimas

$$
\begin{gathered}
\frac{\zeta}{\theta}\left(1-n_{j}\right)+\frac{\zeta}{\theta}\left((\sigma-1) n_{j}^{2}+1+\omega\right) x_{j, t}+\frac{\zeta}{\theta}(\sigma-1) n_{H} n_{F} x_{q, t}-\gamma_{j} \psi_{j, t}+ \\
+\left(1+(\sigma-1) n_{j}\right)\left(\phi_{j, t}-\beta^{-1} \phi_{j, t-1}\right)=0, \\
\pi_{j, t}+\psi_{j, t}-\psi_{j, t-1}-\beta^{-1} \phi_{j, t-1}=0,
\end{gathered}
$$

${ }^{1}$ Se $j=H, F$, então $\pi_{j, t}=\pi_{F, t}^{*}$. 


$$
\begin{gathered}
\pi_{j, t}=\gamma_{j} x_{j, t}+\gamma_{H F} n_{q} x_{q, t}+\beta E_{t} \pi_{j, t+1} \\
i_{t}=E_{t}\left[\left(1+(\sigma-1) n_{j}\right)\left(x_{j, t+1}-x_{j, t}\right)+(\sigma-1) n_{q}\left(x_{q, t+1}-x_{q, t}\right)+\pi_{j, t+1}\right]+r_{j, t}^{n}, \\
i_{j, t} \geq 0, \quad \phi_{j, t} \geq 0, \quad \phi_{j, t} i_{j, t}=0
\end{gathered}
$$

onde $q, j=H, F$ e $j \neq q$.

\subsubsection{8}

\section{Problema cooperativo}

O problema cooperativo pode ser expresso pelo seguinte Lagrangeano:

$$
\begin{array}{r}
\mathcal{L}=E_{1} \sum_{t=1}^{\infty} \beta^{t-1}\left\{\frac{1}{2} x_{t}^{\prime} \Lambda x_{t}+\frac{n_{H}^{2}}{2} \pi_{H, t}^{2}+\frac{n_{F}^{2}}{2} \pi_{F, t}^{* 2}+\right. \\
+\psi_{H, t}\left[n_{H} \pi_{H, t}-\gamma_{H} n_{H} x_{H, t}-\gamma_{H F} n_{H} n_{F} x_{F, t}-\beta n_{H} \pi_{H, t+1}\right]+ \\
+\psi_{F, t}\left[n_{F} \pi_{F, t}^{*}-\gamma_{F} n_{F} x_{F, t}-\gamma_{H F} n_{H} n_{F} x_{H, t}-\beta n_{F} \pi_{F, t+1}^{*}\right]+ \\
+\phi_{H, t}\left[n_{H}\left(1+(\sigma-1) n_{H}\right)\left(x_{H, t}-x_{H, t+1}\right)+\right. \\
\left.+(\sigma-1) n_{H} n_{F}\left(x_{F, t}-x_{F, t+1}\right)-n_{H} \pi_{H, t+1}-n_{H} r_{H, t}^{n}\right]+ \\
+\phi_{F, t}\left[n_{F}\left(1+(\sigma-1) n_{F}\right)\left(x_{F, t}-x_{F, t+1}\right)+\right. \\
\left.\left.+(\sigma-1) n_{H} n_{F}\left(x_{H, t}-x_{H, t+1}\right)-n_{F} \pi_{F, t+1}^{*}-n_{F} r_{F, t}^{n}\right]\right\}
\end{array}
$$

Então as equações do modelo neste caso são

$$
\begin{gathered}
\Lambda x_{t}-\theta \Lambda \psi_{t}+A\left(\phi_{t}-\beta^{-1} \phi_{t-1}\right)=0, \\
\pi_{t}+\psi_{t}-\psi_{t-1}-\beta^{-1} \phi_{t-1}=0, \\
\pi_{t}=\theta N^{-1} \Lambda x_{t}+\beta E_{t} \pi_{t+1}, \\
i_{t}=E_{t}\left[N^{-1} A\left(x_{t+1}-x_{t}\right)+\pi_{t+1}+r_{t}^{n}\right], \\
i_{t} \geq 0, \quad \phi_{t} \geq 0, \quad \phi_{H, t} i_{H, t}=\phi_{F, t} i_{F, t}=0,
\end{gathered}
$$

onde $x_{t}=\left(x_{H, t}, x_{F, t}\right), \pi_{t}=\left(\pi_{H, t}, \pi_{F, t}\right), i_{t}=\left(i_{H, t}, i_{F, t}\right), \phi_{t}=\left(\phi_{H, t}, \phi_{F, t}\right), \psi_{t}=$ $\left(\psi_{H, t}, \psi_{F, t}\right), A=\left(\begin{array}{cc}n_{H}\left(1+(\sigma-1) n_{H}\right) & (\sigma-1) n_{H} n_{F} \\ (\sigma-1) n_{H} n_{F} & n_{F}\left(1+(\sigma-1) n_{F}\right)\end{array}\right), N=\left(\begin{array}{cc}n_{H} & 0 \\ 0 & n_{F}\end{array}\right)$ 
$\mathrm{e} \Lambda=\frac{1}{\theta}\left(\begin{array}{cc}\gamma_{H} n_{H} & \gamma_{H F} n_{H} n_{F} \\ \gamma_{H F} n_{H} n_{F} & \gamma_{F} n_{F}\end{array}\right)$

\subsection{2}

\section{Parâmetros da política monetária ótima}

As instruções monetárias ideais são descritas pelas condições de primeira ordem do problema de Ramsey, no caso da colaboração, e pela melhor resposta de um Banco Central específico, no caso não cooperativo. Com uma pouco de álgebra é possível reescrevê-las como Clarida et al. (2001, 2002), obtendo para o ambiente cooperativo

$$
\begin{gathered}
\frac{1}{\theta}\left(x_{j, t}-x_{j, t-1}\right)+\pi_{j, t}=\tilde{\Upsilon}_{1, j} \phi_{j, t}+\tilde{\Upsilon}_{2, j} \phi_{j, t-1}+\tilde{\Upsilon}_{3, j} \phi_{j, t-2}+\tilde{\Gamma}_{1, q} \phi_{q, t}+ \\
+\tilde{\Gamma}_{2, q} \phi_{q, t-1}+\tilde{\Gamma}_{3, q} \phi_{q, t-2} \\
\tilde{\Upsilon}_{1, j}=-\frac{\sigma+\omega+\omega(\sigma-1) n_{j}}{\zeta(1+\omega)(\omega+\sigma)} \\
\tilde{\Upsilon}_{2, j}=\beta^{-1}+\frac{\sigma+\omega+\omega(\sigma-1) n_{j}}{\zeta(1+\omega)(\omega+\sigma)}+\beta^{-1} \frac{\sigma+\omega+\omega(\sigma-1) n_{j}}{\zeta(1+\omega)(\omega+\sigma)} \\
\tilde{\Upsilon}_{3, j}=-\beta^{-1} \frac{\sigma+\omega+\omega(\sigma-1) n_{j}}{\zeta(1+\omega)(\omega+\sigma)} \\
\tilde{\Gamma}_{1, q}=-\frac{\omega(\sigma-1) n_{q}}{\zeta(1+\omega)(\omega+\sigma)} \\
\tilde{\Gamma}_{2, q}=\frac{\omega(\sigma-1) n_{q}}{\zeta(1+\omega)(\omega+\sigma)}\left(1+\beta^{-1}\right) \\
\tilde{\Gamma}_{3, q}=-\frac{\omega(\sigma-1) n_{q}}{\zeta(1+\omega)(\omega+\sigma)} \beta^{-1}
\end{gathered}
$$

e para o não cooperativo

$$
\begin{gathered}
\Xi_{j}\left(x_{j, t}-x_{j, t-1}\right)+\gamma_{j} \pi_{j, t}=\begin{array}{r}
\hat{\Upsilon}_{1, j} \phi_{j, t}+\hat{\Upsilon}_{2, j} \phi_{j, t-1}+\hat{\Upsilon}_{3, j} \phi_{j, t-2}+\hat{\Gamma}_{1, q} \phi_{q, t}+ \\
+\hat{\Gamma}_{2, q} \phi_{q, t-1}+\hat{\Gamma}_{3, q} \phi_{q, t-2}+\Omega_{q} \pi_{q, t}
\end{array} \\
\Xi_{j}=\frac{\zeta}{\theta}\left[\begin{array}{r}
\left.(\sigma-1) n_{j}^{2}+1+\omega-\frac{(\sigma-1)^{2} n_{H}^{2} n_{F}^{2}}{(\sigma-1) n_{q}^{2}+1+\omega}\right] \\
\hat{\Upsilon}_{1, j}=-\left(1+(\sigma-1) n_{j}\right)
\end{array}\right. \\
\hat{\Upsilon}_{2, j}=\gamma_{j} \beta^{-1}+\left(1+(\sigma-1) n_{j}\right)+\left(1+(\sigma-1) n_{j}\right) \beta^{-1} \\
\hat{\Upsilon}_{3, j}=-\left(1+(\sigma-1) n_{j}\right) \beta^{-1} \\
\hat{\Gamma}_{1, q}=\frac{(\sigma-1) n_{H} n_{F}}{(\sigma-1) n_{q}^{2}+1+\omega}\left(1+(\sigma-1) n_{q}\right)
\end{gathered}
$$




$$
\begin{gathered}
\hat{\Gamma}_{2, q}=-\frac{(\sigma-1) n_{H} n_{F}}{(\sigma-1) n_{q}^{2}+1+\omega}\left(\gamma_{q} \beta^{-1}+\left(1+(\sigma-1) n_{q}\right)+\left(1+(\sigma-1) n_{q}\right) \beta^{-1}\right) \\
\hat{\Gamma}_{3, q}=\frac{(\sigma-1) n_{H} n_{F}}{(\sigma-1) n_{q}^{2}+1+\omega}\left(1+(\sigma-1) n_{q}\right) \beta^{-1} \\
\Omega_{q}=\frac{(\sigma-1) n_{H} n_{F}}{(\sigma-1) n_{q}^{2}+1+\omega} \gamma_{q}
\end{gathered}
$$

onde $q, j=H, F$ e $j \neq q$.

Tabla 7.1: Sinais dos coeficientes de acordo com $\sigma$.

\begin{tabular}{|c|c|c|c|}
\hline \multicolumn{4}{|c|}{ Cooperation } \\
\hline$\tilde{\Upsilon}_{1, j}$ & $<0$ & $<0$ & $<0$ \\
\hline$\tilde{\Upsilon}_{2, j}$ & $>0$ & $>0$ & $>0$ \\
\hline$\tilde{\Upsilon}_{3, j}$ & $<0$ & $<0$ & $<0$ \\
\hline$\tilde{\Gamma}_{1, q}$ & $<0$ & $=0$ & $>0$ \\
\hline$\tilde{\Gamma}_{2, q}$ & $>0$ & $=0$ & $<0$ \\
\hline$\tilde{\Gamma}_{3, q}$ & $<0$ & $=0$ & $>0$ \\
\hline \multicolumn{4}{|c|}{ No cooperation } \\
\hline$\Xi$ & $>0$ & $>0$ & $>0$ \\
\hline$\hat{\Upsilon}_{1, j}$ & $<0$ & $<0$ & $<0$ \\
\hline$\hat{\Upsilon}_{2, j}$ & $>0$ & $>0$ & $>0$ \\
\hline$\hat{\Upsilon}_{3, j}$ & $<0$ & $<0$ & $<0$ \\
\hline$\hat{\Gamma}_{1, q}$ & $>0$ & $=0$ & $<0$ \\
\hline$\hat{\Gamma}_{2, q}$ & $<0$ & $=0$ & $>0$ \\
\hline$\hat{\Gamma}_{3, q}$ & $>0$ & $=0$ & $<0$ \\
\hline$\Omega$ & $>0$ & $=0$ & $<0$ \\
\hline
\end{tabular}
\begin{tabular}{|c|c|c|}
\hline$\sigma \in(1,2]$ & $\sigma=1$ & $\sigma \in(0,1)$ \\
\hline
\end{tabular}

Conforme especificado anteriormente a dependência histórica é produto da presença de valores defasados dos multiplicadores de Lagrange associados à restrição do ZLB para taxa de juros interna $\left(\phi_{j, t}, \phi_{j, t-1}\right.$ e $\left.\phi_{j, t-2}, j=H, F\right)$ em ambas as regras ótimas. De maneira que mesmo quando essas condições não são mais vinculativas, elas ainda têm influência sobre a política monetária corrente.

Na tabela 7.1 é possível confirmar os resultados obtidos pelo o exercício numérico na seção 4.0.1. É perceptível que, uma vez que os parâmetros associados a dependência histórica têm o mesmo sinal em ambientes cooperativos e não cooperativos $\left(\operatorname{sgn}\left(\tilde{\Upsilon}_{i, j}\right)=\operatorname{sgn}\left(\hat{\Upsilon}_{i, j}\right), i=1,2,3\right.$, para $\left.\sigma \in(0,2]\right)$, a direção das flutuações dessas políticas é a mesma nesses casos, como mostrado na figura 4.2. É imperativo comentar que o sinal dos parâmetros em teoria não é o completo responsável pelos movimentos observados, mas, conforme o choque passa, $\phi_{H, t}$ cai drasticamente, implicando em um $\phi_{H, \tau_{j}}$ muito maior que $\phi_{H, \tau_{j}+1}$ e $\phi_{H, \tau_{j}+2}(j=H, F)$. Tal fato causa com que na prática o coeficiente ser maior ou menor que zero determine a direção das políticas ótimas nesse exercício. 
Outra observação é que ambas as políticas apresentam a característica de responder à vinculação da restrição do ZLB da outra nação, uma vez que nas expressões acima (7-80) e (7-87) é possível encontrar o multiplicador externo de Lagrange associado à restrição da taxa de juros estrangeira ser maior que zero $\left(\phi_{q, t}, \phi_{q, t-1}\right.$ e $\left.\phi_{q, t-2}, q=H, F q \neq f\right)$. Podemos também notar que no caso cooperativo, se $\sigma>1$, o coeficiente indentificado com $\phi_{j, t}$ e $\phi_{q, t}$ tem o mesmo sinal (i.e. $\left.\operatorname{sgn}\left(\tilde{\Upsilon}_{i, j}\right)=\operatorname{sgn}\left(\tilde{\Gamma}_{i, q}\right), i=1,2,3\right)$, então implicando que ambos os países respodem na mesma direção quando uma nação cai em armadilha de liquidez. Ademais, se os bens produzidos em cada localidade são complementares, a reação colaborativa ocorre em direções diferentes em cada país, tendo em vista que os mesmos coeficiente apresentam sinais opostos (i.e. $\left.\operatorname{sgn}\left(\tilde{\Upsilon}_{i, j}\right) \neq \operatorname{sgn}\left(\tilde{\Gamma}_{i, q}\right), i=1,2,3\right)$. No caso não cooperativo, deixando de lado o possível impacto da condução política sobre a inflação exógena, observamos o contrário. Quando os bens são substitutos, os parâmetros seguem o mesmo sentido do cenário cooperativo com $\sigma<1$ (i.e. $\operatorname{sgn}\left(\hat{\Upsilon}_{i, j}\right) \neq \operatorname{sgn}\left(\hat{\Gamma}_{i, q}\right)$, $i=1,2,3)$, e quando temos os bens complementares obtemos coeficientes com a mesma direção do cenário cooperativo $\operatorname{com} \sigma>1$ (i.e. $\operatorname{sgn}\left(\hat{\Upsilon}_{i, j}\right)=\operatorname{sgn}\left(\hat{\Gamma}_{i, q}\right)$, $i=1,2,3)$. Isso nos leva à conclusão de que a localidade que não esta restrita pelo ZLB se comporta de maneira oposta nas circunstâncias colaborativas e não colaborativas.

\subsection{3}

\section{Resolvendo o exercício numérico}

\begin{tabular}{|c|l|l|l|}
\multicolumn{1}{c|}{ Tabla 7.2: Estados. } \\
\cline { 2 - 4 } \multicolumn{1}{c|}{} & $r_{F, t}^{n}<0$ & $r_{F, t}^{n}>0$ & $r_{F, t}^{n}>0$ \\
$i_{F, t}=0$ & $i_{F, t}=0$ & $i_{F, t}>0$ \\
\hline $\begin{array}{c}r_{H, t}^{n}<0 \\
i_{H, t}=0\end{array}$ & estado 1 & estado 2 & estado 3 \\
\hline $\begin{array}{l}r_{H, t}^{n}>0 \\
i_{H, t}=0\end{array}$ & estado 4 & estado 5 & estado 6 \\
\hline $\begin{array}{c}r_{H, t}^{n}>0 \\
i_{H, t}>0\end{array}$ & estado 7 & estado 8 & estado 9 \\
\hline
\end{tabular}

Ao resolver o experimento numérico, no contexto do modelo apresentado, temos dois problemas principais. Primeiro, há uma não-linearidade nas equações de modelo geradas pelas condições de Karush-Kuhn-Tucker associadas à restrição ZLB na condução de políticas monetárias ótimas, equações (7-73) e (7-79). Segundo, a taxa natuiral de juros em cada localidade segue um processo de Markov podendo ter dois possíveis valores. Estes problemas podem ser resolvidos dividindo nosso exercício em estados, representados na tabela 
7.2. ${ }^{2}$, onde em cada situação esta complicação não está mais presente. Quando fazemos tal divisão surge um problema adicional dado que não sabemos os valores para a variável $k_{j}\left(\tau_{H}, \tau_{F}\right)$, definida como o número de períodos que o país $j=H, F$ mantém sua taxas de juros iguais a zero após $r_{j, t}^{n}$ ter retornado para $r_{h i g h}^{n}$. Neste caso, vamos realizar o seguinte processo para descobrir $k_{j}\left(\tau_{H}, \tau_{F}\right)$ : assuma que para valores específicos de $\tau_{H}$ e $\tau_{F} k_{j}\left(\tau_{H}, \tau_{F}\right)=0$, compute então a solução do modelo, compute o valor para todas as variáveis em todas os períodos $t$, se $i_{j, \tau_{j}+k_{j}\left(\tau_{H}, \tau_{F}\right)}=0$ aumente o valor de $k_{j}\left(\tau_{H}, \tau_{F}\right)$ para o país $j$ e repita esse processo até que isso não mais ocorra, também faça isso para todos os possíveis valores de $\left(\tau_{H}, \tau_{F}\right)$. Cada estado pode entao ser resolvido da seguinte maneira (lembre-se que estamos assumindo em um primeiro momento que $k_{j}\left(\tau_{H}, \tau_{F}\right), j=H, F$, é conhecido):

\subsubsection{1}

Estado 9: $t \geq \tau_{j}+k_{j}\left(\tau_{H}, \tau_{F}\right)$

Uma vez que $\tau_{j}, j=H, F$, já ocorreu não temos nenhuma incerteza nas equações do modelo, portanto as equações (7-69)-(7-73) ou (7-75)-(7-79) podem ser reescritas sem o operador $E_{t}$ e também temos que

$$
i_{H, t} \geq 0, i_{F, t} \geq 0, \phi_{H, t}=\phi_{F, t}=0, r_{H, t}^{n}=r_{F, t}^{n}=r_{h i g h}^{n}
$$

Podemos então escrever as equações do modelo como:

$$
A\left(\begin{array}{c}
E_{t} Z_{t+1} \\
P_{t}
\end{array}\right)=B\left(\begin{array}{c}
Z_{t} \\
P_{t-1}
\end{array}\right)
$$

onde: $Z_{t}=\left(\begin{array}{c}\pi_{t} \\ x_{t} \\ i_{t}(\text { estado }=9)\end{array}\right)$ e $P_{t}=\left(\begin{array}{c}i_{t} \text { (outros estados) } \\ \phi_{t} \\ \psi_{t} \\ 1\end{array}\right)$. Usamos o algorítimo "Reduction of Dynamic Systems" e "Solution to Dynamic Systems" de Woodford para obtermos uma solução da forma ${ }^{3}$ :

$$
\begin{aligned}
& P_{t}=G_{9} P_{t-1} \\
& Z_{t}=D_{9} P_{t-1}
\end{aligned}
$$

\subsubsection{2}

\footnotetext{
${ }^{2} \mathrm{Na}$ teoria, é possível ter outros estados, mas com nossa configuração de parâmetros confirmamos numericamente que eles não ocorrem.

${ }^{3}$ Os sobescritos nas matrizes são parte de sua identificação e não operações de potenciação.
} 
Estado 6: $t \geq \tau_{F}+k_{F}\left(\tau_{H}, \tau_{F}\right)$ e $\tau_{H}+k_{H}\left(\tau_{H}, \tau_{F}\right)>t \geq \tau_{H}$

Como $t \geq \tau_{j}, j=H, F$, não temos incerteza e o modelo pode ser escrito sem o operador $E_{t}$ e

$$
i_{H, t}=0, \phi_{H, t} \geq 0, i_{F, t} \geq 0, \phi_{F, t}=0, r_{H, t}^{n}=r_{F, t}^{n}=r_{h i g h}^{n}
$$

como no estado 9 podemos escrever o sistemas como:

$$
\left(\begin{array}{cc}
A_{1} & A_{2} \\
A_{3} & A_{4}
\end{array}\right)\left(\begin{array}{c}
Z_{t+1} \\
P_{t}
\end{array}\right)=\left(\begin{array}{cc}
B_{1} & B_{2} \\
B_{3} & B_{4}
\end{array}\right)\left(\begin{array}{c}
Z_{t} \\
P_{t-1}
\end{array}\right)
$$

Fazendo um decomposição de Gauss-Jordan o sistema pode ser reescrito como

$$
\left(\begin{array}{c}
Z_{t+1} \\
P_{t}
\end{array}\right)=\left(\begin{array}{ll}
C_{1} & C_{2} \\
C_{3} & C_{4}
\end{array}\right)\left(\begin{array}{c}
Z_{t} \\
P_{t-1}
\end{array}\right)
$$

Como um pouco de álgebra é possível obter uma solução da forma

$$
P_{t}=G_{6}^{\tau_{F}+k_{F}\left(\tau_{H}, \tau_{F}\right)-t} P_{t-1}
$$

$$
Z_{t}=D_{6}^{\tau_{F}+k_{F}\left(\tau_{H}, \tau_{F}\right)-t} P_{t-1}
$$

onde $G_{6}^{j}=\left(I-C_{2} D_{6}^{j-1}\right)^{-1} C_{1}$ e $D_{6}^{j}=C_{3}+C_{4} D_{6}^{j-1} G_{6}^{j}$ para $j \neq 0$, onde $j=\tau_{F}+k_{F}\left(\tau_{H}, \tau_{F}\right)-t, D_{6}^{0}=D_{9}$ e $G_{6}^{0}=G_{9}$. O caso para o estado 8 é análogo.

\subsubsection{3}

Estado 5: $\tau_{H}+k_{H}\left(\tau_{H}, \tau_{F}\right)>t \geq \tau_{H}$ e $\tau_{F}+k_{F}\left(\tau_{H}, \tau_{F}\right)>t \geq \tau_{F}$

Como a duração do estado 5 depende dos valores de $\left(\tau_{H}, \tau_{F}\right)$ e como ambos já são conhecidos quando o estado 5 ocorre, precisamos computar as matrizes de resultado para cada possível par $\left(\tau_{H}, \tau_{F}\right)$. Aqui também não temos incerteza dado que $\tau_{H}, \tau_{F}$ e, consequentemente, $k_{j}(j=H, F)$ são sbidos. Portanto não temos aqui $E_{t}$ no modelo e

$$
i_{H, t}=i_{F, t}=0, \phi_{H, t} \geq 0, \phi_{F, t} \geq 0, r_{H, t}^{n}=r_{F, t}^{n}=r_{h i g h}^{n}
$$

Fazendo o mesmo processo que para o estado 6 temos uma solução da forma:

$$
\begin{aligned}
& P_{t}=G_{5, \tau_{H}, \tau_{F}}^{\tau_{F}+k_{F}\left(\tau_{H}, \tau_{F}\right)-t} P_{t-1} \\
& Z_{t}=D_{5, \tau_{H}, \tau_{F}}^{\tau_{F}+k_{F}\left(\tau_{H}, \tau_{F}\right)-t} P_{t-1}
\end{aligned}
$$

onde $G_{5, \tau_{H}, \tau_{F}}^{j}=\left(I-C_{2} D_{5, \tau_{H}, \tau_{F}}^{j-1}\right)^{-1} C_{1}$ e $D_{5, \tau_{H}, \tau_{F}}^{j}=C_{3}+C_{4} D_{5, \tau_{H}, \tau_{F}}^{j-1} G_{5, \tau_{H}, \tau_{F}}^{j}$, mas agora o valor de $D_{5, \tau_{H}, \tau_{F}}^{0}$ e $D_{5, \tau_{H}, \tau_{F}}^{0}$ depende do valor do vetor $\left(\tau_{H}, \tau_{F}\right)$. Por exemplo se $\tau_{F}+k_{F}>\tau_{H}+k_{H}$ e $\tau_{H}+k_{H}>\tau_{F}$, então $D_{5, \tau_{H}, \tau_{F}}^{0}=D_{8}^{\tau_{F}+k_{F}-\tau_{H}-k_{H}}$ e $G_{5, \tau_{H}, \tau_{F}}^{0}=G_{8}^{\tau_{F}+k_{F}-\tau_{H}-k_{H}}$. 


\subsubsection{4}

Estado 3: $t \geq \tau_{F}+k_{F}\left(\tau_{H}, \tau_{F}\right)$ e $t<\tau_{H}$

Observe que a duração do estado 3 depende do valor de $\tau_{F}$ através de $k_{H}\left(\tau_{H}, \tau_{F}\right)$, e uma vez $\tau_{F}$ é conhecido no estado 3 precisamos computar os resultados para cada possível valor de $\tau_{F}$. Nesse estado temos um novo problema, agora existe incerteza sobre o que pode acontecer no próximo período (por exmplo: se $t<\tau_{\max }-1$ não sabemos se em $t+1$ estaremos no estado 6 ou 3 , se $\left.k_{H}\left(t+1, \tau_{F}\right)>0\right)$. Isto posto também observamos

$$
i_{H, t}=0, \phi_{H, t} \geq 0, i_{F, t} \geq 0, \phi_{F, t}=0, r_{H, t}^{n}=r_{l o w}^{n} r_{F, t}^{n}=r_{\text {high }}^{n}
$$

Podemos escrever o modelo como:

$$
\left(\begin{array}{cc}
A_{1} & A_{2} \\
A_{3} & A_{4}
\end{array}\right)\left(\begin{array}{c}
E_{t} Z_{t+1} \\
E_{t} P_{t}
\end{array}\right)=\left(\begin{array}{cc}
B_{1} & B_{2} \\
B_{3} & B_{4}
\end{array}\right)\left(\begin{array}{c}
Z_{t} \\
P_{t-1}
\end{array}\right)
$$

onde: $E_{t} Z_{t+1}=(1-\gamma) \tilde{Z}_{t+1}+\gamma D_{6}^{k_{H}} \tilde{P}_{t}$, onde o til significa que temos o valor da variável contingente ao fato da continuação no mesmo estado naquele período, uma vez que existe a probabilidade que em $t+1$ o choque acabe no país $H$ e nós mudemos para o estado 6. De maneira que o modelo pode ser expresso como:

$$
\left(\begin{array}{cc}
A_{1, t} & A_{2, t} \\
A_{3, t} & A_{4, t}
\end{array}\right)\left(\begin{array}{c}
\tilde{Z}_{t+1} \\
\tilde{P}_{t}
\end{array}\right)=\left(\begin{array}{cc}
B_{1, t} & B_{2, t} \\
B_{3, t} & B_{4, t}
\end{array}\right)\left(\begin{array}{c}
\tilde{Z}_{t} \\
\tilde{P}_{t-1}
\end{array}\right)
$$

Da mesma maneira que antes podemos escrever:

$$
\left(\begin{array}{c}
\tilde{Z}_{t+1} \\
\tilde{P}_{t}
\end{array}\right)=\left(\begin{array}{cc}
C_{1, t} & C_{2, t} \\
C_{3, t} & C_{4, t}
\end{array}\right)\left(\begin{array}{c}
\tilde{Z}_{t} \\
\tilde{P}_{t-1}
\end{array}\right)
$$

Sendo a solução dada por :

$$
\begin{aligned}
& \tilde{P}_{t}=G_{3, k_{F}}^{t} \tilde{P}_{t-1} \\
& \tilde{Z}_{t}=D_{3, k_{F}}^{t} \tilde{P}_{t-1}
\end{aligned}
$$

onde temos a solução recursiva, como antes, para $t<\tau_{\max }-1: G_{3, k_{F}}=$ $\left[I-C_{2, t} D_{3, k_{F}}^{t+1}\right]^{-1} C_{1, t}$ e $D_{3, k_{F}}^{t}=C_{3, t}+C_{4, t} D_{3, k_{F}}^{t+1} G_{3, k f}^{t}$; e na data $t=\tau_{\max }-1$, $G_{3, k_{F}}^{\tau_{\max }}=G_{6}^{k_{H}}$ e $D_{3, k_{F}}^{\tau_{\max }}=D_{6}^{k_{H}}$ (se $k_{H}=0$, esses valores viriam do estado $9 \mathrm{em}$ vez de 6 ), o que implica que $G_{3, k_{F}}^{\tau_{\max }-1}=C_{1, \tau_{\max }-1}$ e $D_{3, k_{F}}^{\tau_{\max }-1}=C_{3, \tau_{\max }-1}$. O caso para o estado 7 é análogo.

\subsubsection{5}

Estado 2: $\tau_{F}+k_{F}\left(\tau_{H}, \tau_{F}\right)>t \geq \tau_{F}$ e $t<\tau_{H}$

Pela mesma razão da seção anterior a solução aqui depende do valor de $k_{F}$. Também temos incerteza, mas um pouco mais complicada do que antes. 
As mudanças no modelo são

$$
i_{H, t}=0, \phi_{H, t} \geq 0, i_{F, t}>0, \phi_{F, t}=0, r_{H, t}^{n}=r_{l o w}^{n}, r_{F, t}^{n}=r_{\text {high }}^{n}
$$

Para especificar a incerteza vamos primeiro definir:

$$
\begin{array}{r}
P 1=\operatorname{Prob}\left(t+1 \neq \tau_{F}+k_{F} \cap \tau_{H} \neq t+1\right)= \\
=\operatorname{Prob}\left(\tau_{H} \neq t+1\right) \operatorname{Prob}\left(t+1 \neq \tau_{F}+k_{F} \mid \tau_{H} \neq t+1\right)= \\
=(1-\gamma) \operatorname{Prob}\left(t+1 \neq \tau_{F}+k_{F} \mid \tau_{H} \neq t+1\right) \\
P 2=\operatorname{Prob}\left(t+1=\tau_{F}+k_{F} \cap \tau_{H} \neq t+1\right)= \\
=\operatorname{Prob}\left(\tau_{H} \neq t+1\right) \operatorname{Prob}\left(t+1=\tau_{F}+k_{F} \mid \tau_{H} \neq t+1\right)= \\
=(1-\gamma) \operatorname{Prob}\left(t+1=\tau_{F}+k_{F} \mid \tau_{H} \neq t+1\right) \\
P 3=\operatorname{Prob}\left(t+1=\tau_{F}+k_{F} \cap \tau_{H}=t+1\right)= \\
=\operatorname{Prob}\left(\tau_{H}=t+1\right) \operatorname{Prob}\left(t+1=\tau_{F}+k_{F} \mid \tau_{H}=t+1\right)= \\
=\gamma \operatorname{Prob}\left(t+1=\tau_{F}+k_{F} \mid \tau_{H}=t+1\right) \\
P 4=\operatorname{Prob}\left(t+1 \neq \tau_{F}+k_{F} \cap \tau_{H}=t+1\right)= \\
=\operatorname{Prob}\left(\tau_{H}=t+1\right) \operatorname{Prob}\left(t+1 \neq \tau_{F}+k_{F} \mid \tau_{H}=t+1\right)= \\
=\gamma \operatorname{Prob}\left(t+1 \neq \tau_{F}+k_{F} \mid \tau_{H}=t+1\right)
\end{array}
$$

Uma vez que não sabem nesse estado o valor de $k_{F}\left(\tau_{H}, \tau_{F}\right)$, considerando que $\tau_{H}$ ainda não ocorreu, temos de computar $\operatorname{Prob}\left(t+1 \neq \tau_{F}+k_{F} \mid \tau_{H} \neq t+1\right)$ como:

$$
\begin{array}{r}
\operatorname{Prob}\left(t+1 \neq \tau_{F}+k_{F} \mid \tau_{H} \neq t+1\right)= \\
=P\left(\tau_{H}=t+1 \mid \tau_{H} \neq t+1\right) 1\left(t+1 \neq \tau_{F}+k_{F}\left(t+1, \tau_{F}\right)\right)+ \\
+P\left(\tau_{H}=t+2 \mid \tau_{H} \neq t+1\right) 1\left(t+1 \neq \tau_{F}+k_{F}\left(t+2, \tau_{F}\right)\right)+\ldots \\
+P\left(\tau_{H}=\tau_{\text {max }} \mid \tau_{H} \neq t+1\right) 1\left(t+1 \neq \tau_{F}+k_{F}\left(\tau_{\text {max }}, \tau_{F}\right)\right)= \\
=0+\gamma 1\left(t+1 \neq \tau_{F}+k_{F}\left(t+2, \tau_{F}\right)\right)+ \\
+(1-\gamma) \gamma 1\left(t+1 \neq \tau_{F}+k_{F}\left(t+3, \tau_{F}\right)\right)+\ldots
\end{array}
$$

Então P1, P2, P3 e P4 são imediatas. Podemos então produzir $E_{t} Z_{t+1}=$ $P 1 \tilde{Z}_{t+1}+P 2 D_{3, \tau_{F}}^{t+1} \tilde{P}_{t}+P 3 D_{6}^{k_{H}\left(t+1, \tau_{F}\right)} \tilde{P}_{t}+P 4 D_{5, t+1, \tau_{F}}^{j} \tilde{P}_{t}$ onde $j$ depende do tamanho de $\tau_{F}, \tau_{H}, k_{H}$ e $k_{F}$. Como para o estado anterior temos a solução da forma

$$
\tilde{P}_{t}=G_{2, \tau_{F}}^{t} \tilde{P}_{t-1}
$$




$$
\tilde{Z}_{t}=D_{2, \tau_{F}}^{t} \tilde{P}_{t-1}
$$

que pode ser computada como antes, onde os valore de $G_{2, \tau_{F}}^{\tau_{\max }-1}$ e $D_{2, \tau_{F}}^{\tau_{\max }-1}$ vão depender de $\tau_{F}, \tau_{H}, k_{H}$ e $k_{F}$. O estado 4 possui uma solução simétrica.

\subsubsection{6}

Estado 1: $\tau_{F}>t \mathbf{e} t<\tau_{H}$

Ainda temos incerteza no estaod 1 por não sabermos os valores de $\tau_{H}$ e $\tau_{F}$. As alterações no modelo são:

$$
i_{H, t}=0, \phi_{H, t} \geq 0, i_{F, t}=0, \phi_{F, t} \geq 0, r_{H, t}^{n}=r_{l o w}^{n}, r_{F, t}^{n}=r_{l o w}^{n}
$$

e $E_{t} Z_{t+1}=(1-\gamma)^{2} \tilde{Z}_{t+1}+\gamma(1-\gamma) D_{1}^{j_{1}} \tilde{P}_{t}+\gamma(1-\gamma) D_{2}^{j_{2}} \tilde{P}_{t}+\gamma^{2} D_{3}^{j_{3}} \tilde{P}_{t}$. Os valores de $D_{1}^{j_{1}}, D_{2}^{j_{2}}$ e $D_{3}^{j_{3}}$, dependem dos valores de $k_{H}(t+1, t+1)$ e $k_{F}(t+1, t+1)$, assumindo que uma vez que $k_{H}(t+1, t+1)>0$ todos $k_{H}(j, t+1)>0$ para $j>t+1$ e uma vez que $k_{F}(t+1, t+1)>0$ todos $k_{F}(t+1, j)>0$ para $j>t+1^{4}$. Podemos então usar a mesma solução dos estados anteriores onde $D_{1}^{\tau_{\max }-1}$ e $G_{1}^{\tau_{\max }-1}$ vão depender se $k_{H}(t+1, t+1)$ e $k_{F}(t+1, t+1)$ são maiores ou iguais a zero.

\subsection{4}

Gráfico: política ótima cooperativa vs política ótima não cooperativa

${ }^{4}$ Depois de numericamente simular nossos modelos para todas as configurações possíveis de choques observamos que isso é veradde. 


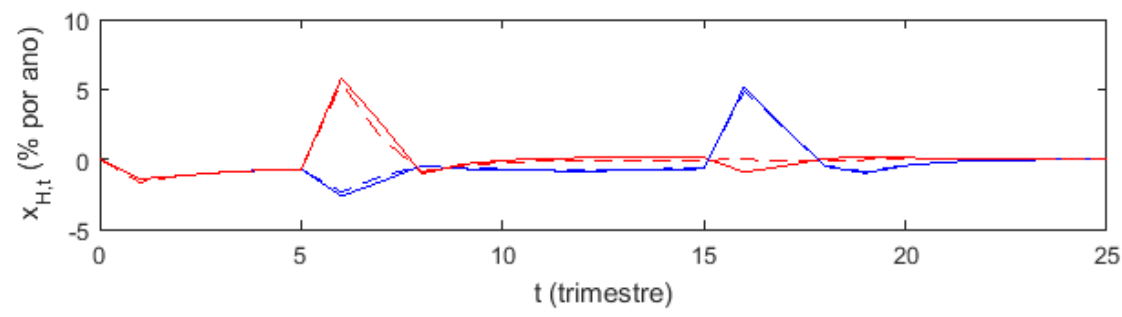

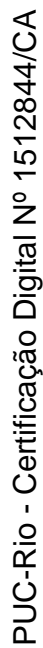
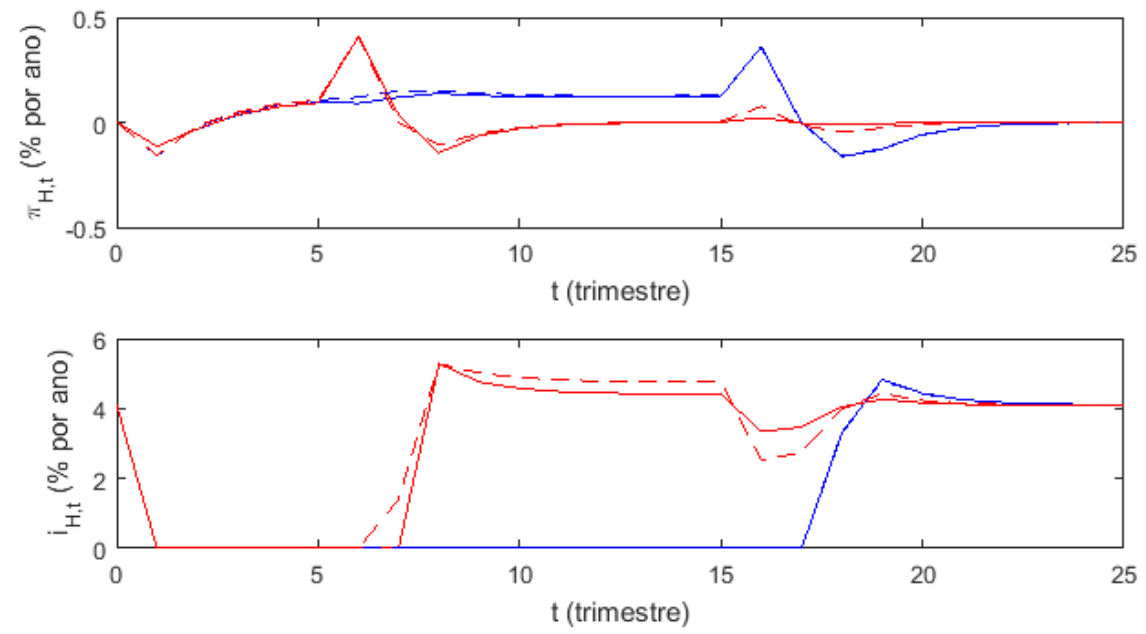

Figura 7.1: Política ótima cooperativa vs política ótima não cooperativa ( $j=H, F, \tau_{H}=16, \tau_{H}=16$, linha vermelha: país $F$, linha azul: país $H$, linha sólida: não cooperação, linha pontilhada: cooperação). 